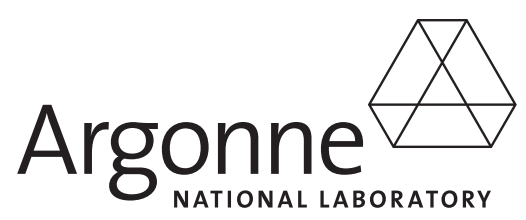

\title{
Transient Analyses for the Uzbekistan VVR-SM Reactor with IRT-3M HEU Fuel and IRT-4M LEU Fuel: Independent Verification Results
}

Nuclear Engineering Division 


\begin{abstract}
About Argonne National Laboratory
Argonne is a U.S. Department of Energy laboratory managed by UChicago Argonne, LLC under contract DE-AC02-06CH11357. The Laboratory's main facility is outside Chicago, at 9700 South Cass Avenue, Argonne, Illinois 60439. For information about Argonne, see www.anl.gov.
\end{abstract}

\title{
Availability of This Report
}

This report is available, at no cost, at http://www.osti.gov/bridge. It is also available on paper to the U.S. Department of Energy and its contractors, for a processing fee, from:

U.S. Department of Energy

Office of Scientific and Technical Information

P.O. Box 62

Oak Ridge, TN 37831-0062

phone (865) 576-8401

fax (865) 576-5728

reports@adonis.osti.gov

\section{Disclaimer}

This report was prepared as an account of work sponsored by an agency of the United States Government. Neither the United States Government nor any agency thereof, nor UChicago Argonne, LLC, nor any of their employees or officers, makes any warranty, express or implied, or assumes any legal liability or responsibility for the accuracy, completeness, or usefulness of any information, apparatus, product, or process disclosed, or represents that its use would not infringe privately owned rights. Reference herein to any specific commercial product, process, or service by trade name, trademark, manufacturer, or otherwise, does not necessarily constitute or imply its endorsement, recommendation, or favoring by the United States Government or any agency thereof. The views and opinions of document authors expressed herein do not necessarily state or reflect those of the United States Government or any agency thereof, Argonne National Laboratory, or UChicago Argonne, LLC. 
Transient Analyses for the Uzbekistan VVR-SM Reactor with IRT-3M HEU Fuel and IRT-4M LEU Fuel: Independent Verification Results

by

P.L. Garner and N.A. Hanan

Nuclear Engineering Division, Argonne National Laboratory

August 2007 


\title{
Transient Analyses for the Uzbekistan VVR-SM Reactor with IRT-3M HEU Fuel and IRT-4M LEU Fuel: ANL Independent Verification Results
}

\author{
P.L. Garner and N. A. Hanan
}

\section{Summary}

Calculations have been performed for postulated transients in the VVR-SM Reactor at the Institute of Nuclear Physics (INP) of the Academy of Sciences in the Republic of Uzbekistan. (The reactor designation in Cyrillic is BBP-CM; transliterating characters to English gives VVRSM but translating words gives WWR-SM.) These calculations have been performed at the request of staff of the INP who are performing similar calculations. The transients considered were established during working meetings between Argonne National Laboratory (ANL) and INP staff during summer 2006 [Ref. 1], subsequent email correspondence, and subsequent staff visits. Calculations were performed for the current high-enriched uranium (HEU) core, the proposed low-enriched uranium (LEU) core, and one mixed HEU-LEU core during the transition. These calculations have been performed independently from those being performed by INP and serve as one step in the verification process.

\section{General Reactor Information}

\subsection{General}

The VVR-SM reactor is a pool type reactor. An elevation schematic of the reactor is shown in Figure 2.1.1. The core is located in a cylindrical reactor vessel, having inner diameter of $0.652 \mathrm{~m}$ (labeled "682" in Figure 2.1.1) and height of approximately $2.8 \mathrm{~m}$. The reactor vessel is located off-center within a central tank, having diameter of $1.1 \mathrm{~m}$ and height of approximately $6.3 \mathrm{~m}$. The central tank is located within a shielding tank having the same height as central tank and diameter of $2.3 \mathrm{~m}$. The core is cooled by forced convection of water; the water enters the bottom of the central tank through a single $0.35 \mathrm{~m}$ diameter pipe, flows upward, turns toward the center and flows down through the core, exiting the center of the reactor vessel through a single $0.35 \mathrm{~m}$ diameter pipe. There are no other piping penetrations in the reactor vessel and central tank; beam tubes penetrate the wall of the shielding tank.

\subsection{HEU}

One version of the HEU core map is shown in left side of Figure 2.2.1. The fuel assembly (FA) type is IRT-3M, shown on left side of Figure 2.2.2. There are 18 fuel assemblies; all have 6 fuel tubes. The FAs are set on a pitch of $71.5 \mathrm{~mm}$. The fuel tubes have four flat sides joined by rounded corners. The fuel tubes are $1.4 \mathrm{~mm}$ thick, which consists of $0.5 \mathrm{~mm}$ of fuel between two $0.45 \mathrm{~mm}$ thicknesses of cladding. The thickness of the water gap between adjacent fuel tubes is $2.05 \mathrm{~mm}$. The outermost fuel tube has an outer flat-to-flat measurement of $69.4 \mathrm{~mm}$. The radius of the outer surface of the corners of the outermost fuel tube is $9.2 \mathrm{~mm}$; the radius for the outer surface of the corners of an interior fuel tube is $0.8 \mathrm{~mm}$ smaller than the next most outer fuel 
tube; the radius of the inner surface of a fuel tube corner is $1.4 \mathrm{~mm}$ (i.e., same as the tube thickness) less than the radius of the outer surface of the corner. Interior to the innermost fuel tube is a circular tube having $14.0 \mathrm{~mm}$ outer radius; material interior to this tube is ignored in the transient calculations since it does not heat up on this time scale.

The fuel meat is $\mathrm{UO}_{2}-\mathrm{Al}, 36 \%$ enriched in ${ }^{235} \mathrm{U}, 2.5 \mathrm{~g} \mathrm{U} / \mathrm{cm}^{3}, 309 \mathrm{~g}{ }^{235} \mathrm{U} / \mathrm{FA}$, and $0.6 \mathrm{~m}$ length.

The neutronics parameters calculated at ANL for this core are shown in the "HEU" column in the tables in Section 2.4.

\subsection{LEU}

The LEU core map is shown in right side of Figure 2.2.1. The FA type is IRT-4M, shown on right side of Figure 2.2.2. There are $20 \mathrm{FAs}$; all have 6 fuel tubes. The FAs have the same $71.5 \mathrm{~mm}$ pitch as in the HEU core and have a similar concentric fuel tube geometry. The fuel tubes are $1.6 \mathrm{~mm}$ thick, which consists of $0.7 \mathrm{~mm}$ of fuel between two $0.45 \mathrm{~mm}$ thicknesses of cladding. The thickness of the water gap between adjacent fuel tubes is $1.85 \mathrm{~mm}$. The outermost fuel tube has an outer flat-to-flat measurement of $69.6 \mathrm{~mm}$. The radius of the outer surface of the corners of the outermost fuel tube is $9.3 \mathrm{~mm}$; the radius for the outer surface of the corners of an interior fuel tube is $0.8 \mathrm{~mm}$ smaller than the next most outer fuel tube; the radius of the inner surface of a fuel tube corner is $1.6 \mathrm{~mm}$ (i.e., same as the plate thickness) less than the radius of the outer surface of the corner. Interior to the innermost fuel tube is a circular tube having $14.0 \mathrm{~mm}$ outer radius; material interior to this tube is ignored in the transient calculations since it does not heat up on this time scale.

The fuel meat is $\mathrm{UO}_{2}-\mathrm{Al}, 19.7 \%$ enriched in ${ }^{235} \mathrm{U}, 2.8 \mathrm{~g} \mathrm{U} / \mathrm{cm}^{3}, 266 \mathrm{~g}{ }^{235} \mathrm{U} / \mathrm{FA}$, and $0.6 \mathrm{~m}$ length.

The neutronics parameters calculated at ANL for this core are shown in the "LEU" column of the tables in Section 2.4

\subsection{HEU and LEU Comparison and Summary}

The VVR-SM reactor will undergo a gradual conversion from HEU to LEU. The current LEU core has $18 \mathrm{FAs}$ and operates at $10 \mathrm{MW}$ maximum power. The first step in the transition is to remove 2 HEU FAs, shuffle remaining FAs, and insert 4 LEU FAs for a total of 20 FAs (16 HEU and 4 LEU). During each subsequent refueling 2 HEU FAs will be replaced with 2 LEU FAs (plus FA shuffling). After the ninth-such refueling the core will be completely converted and have 20 LEU FAs. A maximum power of $11 \mathrm{MW}$ is planned for all mixed HEU-LEU cores and the final LEU core.

The MCNP code [Ref. 2] was used to calculate [Ref. 3] the shutdown margin, individual worth of control rods, detailed power distribution, and various other neutronics parameters for the HEU, 8 mixed HEU-LEU, and LEU cores. The MC-REBUS code [Ref. 4] was used for the burnup calculations. The results are shown in Tables 2.4.1, 2.4.2, and 2.4.3 for HEU, $1^{\text {st }}$ mixed, and LEU cores. Whenever needed, the rod worth curves in Table 2.4.2 and Figure 2.4.1 are assumed to be piecewise linear between the actual points for which worths were calculated. 
Control rod worths were computed for (A) all $\mathrm{KC}$ and $\mathrm{AR}$ rods inserted and (B) all $\mathrm{KC}$ and $\mathrm{AR}$ rods withdrawn; the values shown in Table 2.4.2 are the average of these two methods; values computed using method A are shown for the peak worth shim rods and for the AR rod and, since they are closer to the actual configuration and have larger value, are used for reactivity addition transients.

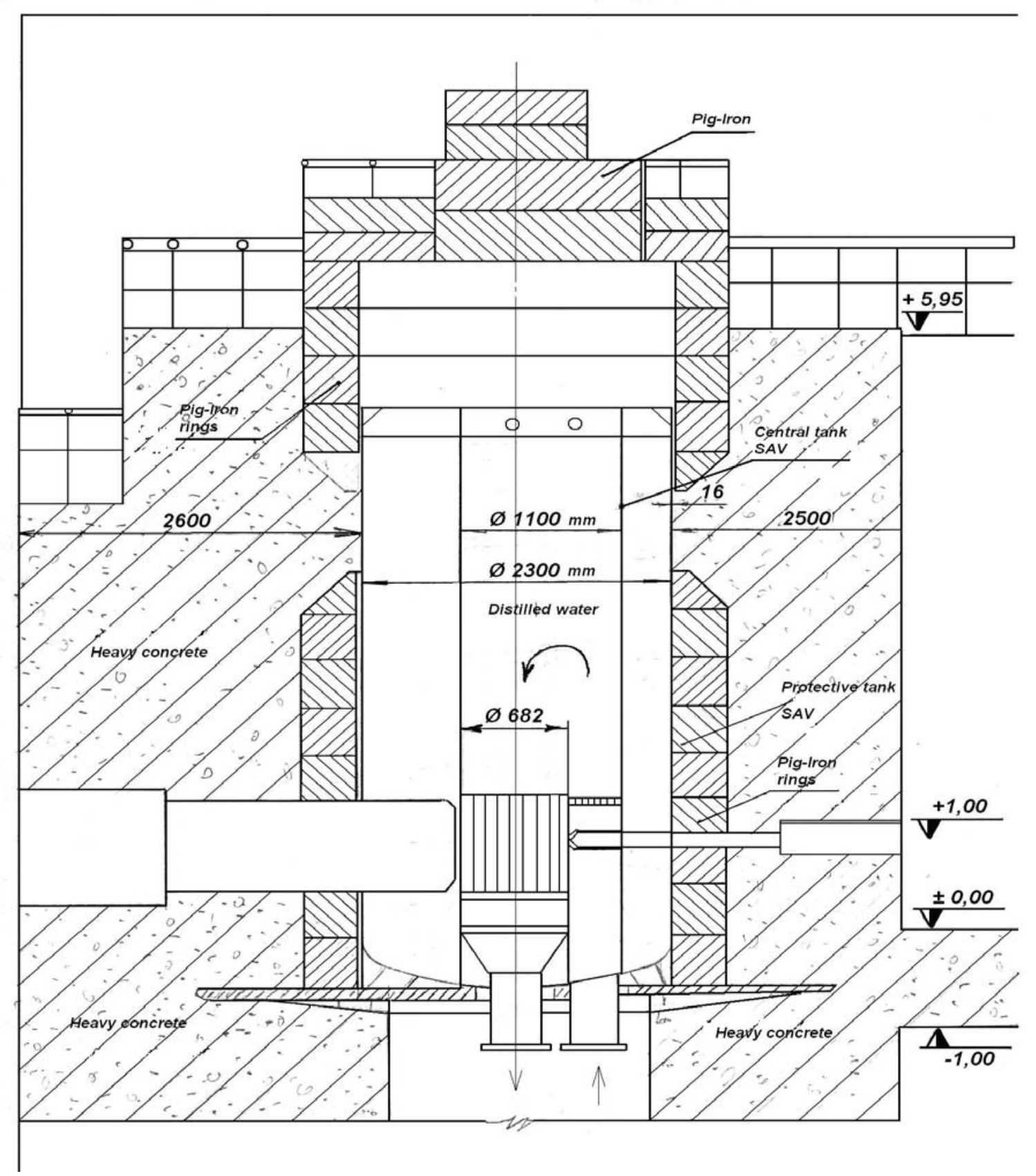

Figure 2.1.1 VVR-SM Elevation View 

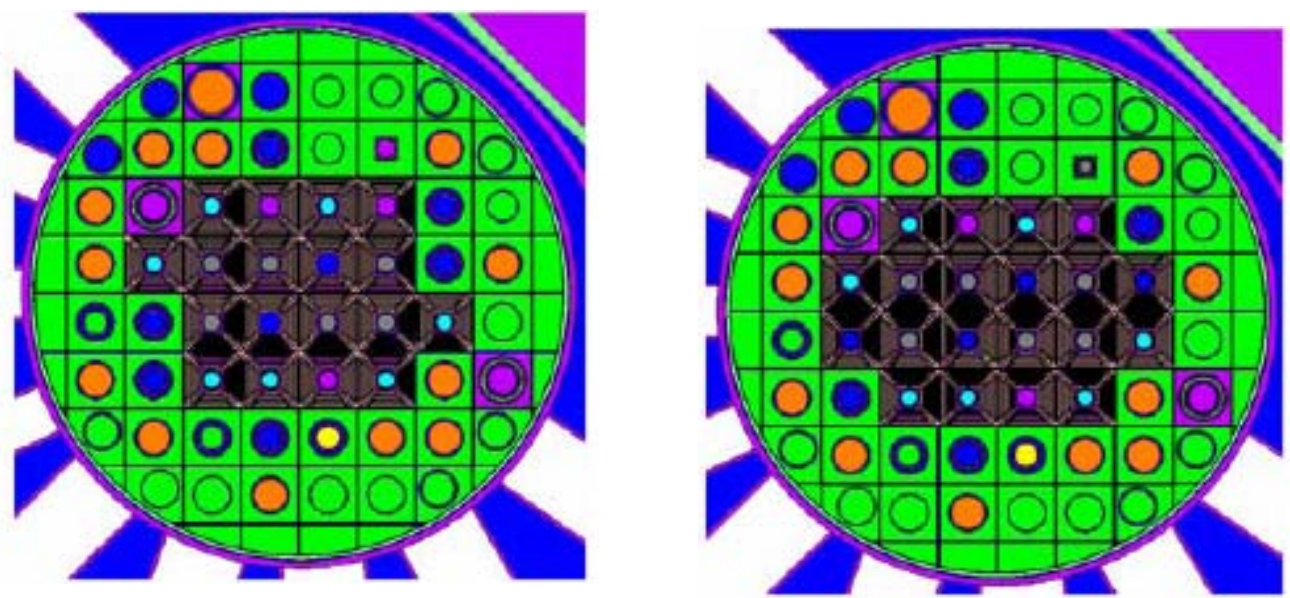

Figure 2.2.1 Horizontal Core Cross Sections: (a-left) 18 FA and (b-right) 20 FA
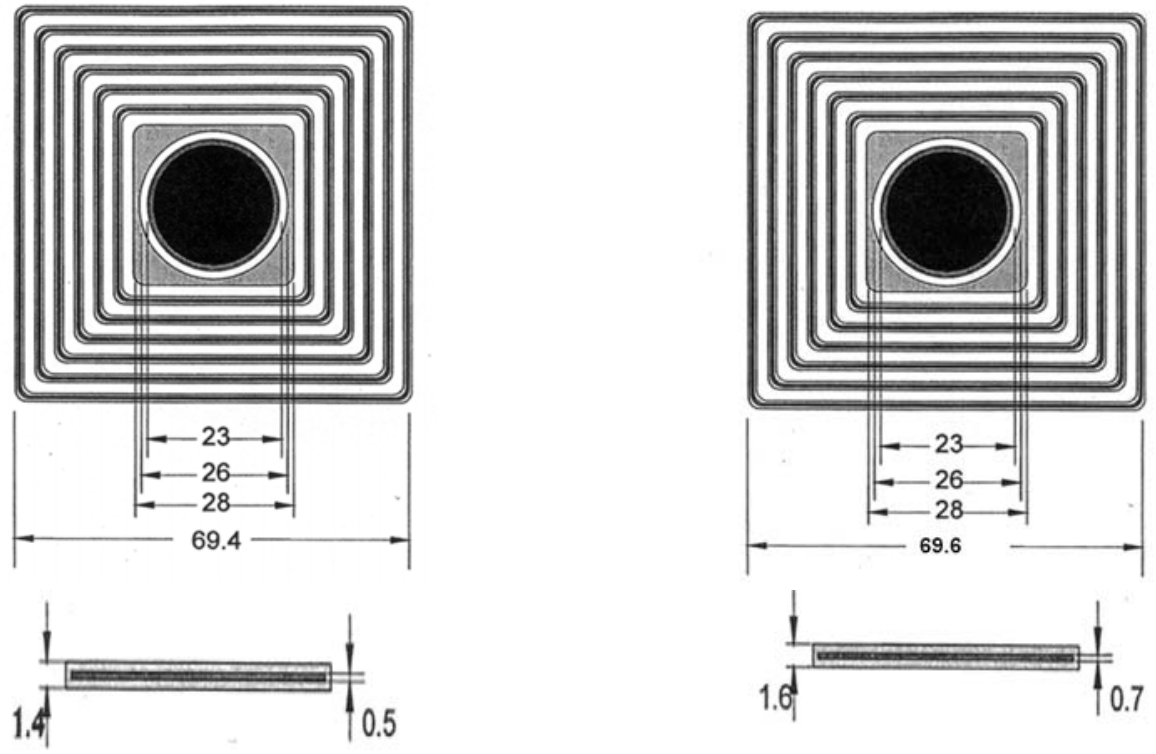

Figure 2.2.2 Horizontal Fuel Assembly Cross Sections: (a-left) IRT-3M and (b-right) IRT-4M 
Table 2.4.1 Neutronic Parameters

\begin{tabular}{|c|c|c|c|}
\hline & HEU Core & $1^{\text {st }}$ Mixed HEU-LEU & LEU Core \\
\hline Fuel Assemblies & $18 @$ IRT-3M & $16 @ 3 \mathrm{M}+4 @ 4 \mathrm{M}$ & $20 @$ IRT-4M \\
\hline $\begin{array}{l}\text { Effective Delayed Neutron } \\
\text { Fraction, } \beta_{\text {eff }}\end{array}$ & $7.6 \mathrm{e}-3$ & $7.6 \mathrm{e}-3$ & $7.6 \mathrm{e}-3$ \\
\hline $\begin{array}{l}\text { Neutron Generation Time, } \Lambda \\
{[\mu \mathrm{s}]}\end{array}$ & 47 & 50 & 53 \\
\hline $\begin{array}{l}\text { Moderator Temperature } \\
\text { Reactivity Coefficient, } \\
\Delta \rho / \Delta \mathrm{T}[\% / \mathrm{K}]:\end{array}$ & & & \\
\hline $294 \mathrm{~K}$ to $400 \mathrm{~K}$ & $-9.3 e-3$ & $-9.5 e-3$ & $-8.6 e-3$ \\
\hline $400 \mathrm{~K}$ to $600 \mathrm{~K}$ & $-7.5 \mathrm{e}-3$ & $-7.6 e-3$ & $-6.9 e-3$ \\
\hline $294 \mathrm{~K}$ to $600 \mathrm{~K}$ & $-8.1 \mathrm{e}-3$ & $-8.2 \mathrm{e}-3$ & $-7.5 \mathrm{e}-3$ \\
\hline $\begin{array}{l}\text { Fuel Temperature (Doppler) } \\
\text { Reactivity Coefficient, } \Delta \rho / \Delta \mathrm{T} \\
{[\% / \mathrm{K}] \text { : }}\end{array}$ & & & \\
\hline $294 \mathrm{~K}$ to $400 \mathrm{~K}$ & $-2.1 \mathrm{e}-3$ & $-2.0 \mathrm{e}-3$ & $-2.3 e-3$ \\
\hline $400 \mathrm{~K}$ to $600 \mathrm{~K}$ & $-1.4 \mathrm{e}-3$ & $-1.7 \mathrm{e}-3$ & $-2.2 \mathrm{e}-3$ \\
\hline $294 \mathrm{~K}$ to $600 \mathrm{~K}$ & $-1.7 \mathrm{e}-3$ & $-1.8 \mathrm{e}-3$ & $-2.2 \mathrm{e}-3$ \\
\hline $\begin{array}{l}\text { Moderator Density (Void) } \\
\text { Reactivity Coefficient, } \Delta \rho / \Delta \alpha \\
{[\% / \% \text { of void]: }}\end{array}$ & & & \\
\hline 0 to $5 \%$ & $-3.0 \mathrm{e}-1$ & $-2.8 \mathrm{e}-1$ & $-2.9 \mathrm{e}-1$ \\
\hline $5 \%$ to $10 \%$ & $-3.3 e-1$ & $-3.1 \mathrm{e}-1$ & $-3.2 \mathrm{e}-1$ \\
\hline 0 to $10 \%$ & $-3.2 \mathrm{e}-1$ & $-3.0 e-3$ & $-3.1 \mathrm{e}-1$ \\
\hline
\end{tabular}

Table 2.4.2 Control Rod Information

\begin{tabular}{|c|c|c|c|c|c|c|}
\hline & \multicolumn{2}{|c|}{ HEU Core } & \multicolumn{2}{|c|}{$1^{\text {st }}$ Mixed HEU-LEU } & \multicolumn{2}{|c|}{ LEU Core } \\
\hline $\begin{array}{l}\text { Shutdown Margin with all KC } \\
\text { and AR Rods Inserted [\%] }\end{array}$ & \multicolumn{2}{|c|}{-8.7} & \multicolumn{2}{|c|}{-5.5} & \multicolumn{2}{|c|}{-10.2} \\
\hline \multicolumn{7}{|l|}{ Control Rod Worths [\%]: } \\
\hline KC-1 & \multicolumn{2}{|l|}{3.7} & \multicolumn{2}{|l|}{3.4} & \multicolumn{2}{|l|}{3.7} \\
\hline $\mathrm{KC}-2$ & \multicolumn{2}{|l|}{4.3} & \multicolumn{2}{|l|}{4.2} & \multicolumn{2}{|l|}{4.7} \\
\hline $\mathrm{KC}-3$ & \multicolumn{2}{|l|}{3.1} & \multicolumn{2}{|l|}{2.6} & \multicolumn{2}{|l|}{2.9} \\
\hline $\mathrm{KC}-4$ & \multicolumn{2}{|l|}{3.3} & \multicolumn{2}{|l|}{2.9} & \multicolumn{2}{|l|}{3.2} \\
\hline AZ-1 & \multicolumn{2}{|l|}{1.9} & \multicolumn{2}{|l|}{1.7} & \multicolumn{2}{|l|}{1.7} \\
\hline AZ-2 & \multicolumn{2}{|l|}{1.9} & \multicolumn{2}{|l|}{2.1} & \multicolumn{2}{|l|}{2.1} \\
\hline AZ-2 & \multicolumn{2}{|l|}{1.5} & \multicolumn{2}{|l|}{1.4} & \multicolumn{2}{|l|}{1.5} \\
\hline All AZ & \multicolumn{2}{|l|}{5.7} & \multicolumn{2}{|l|}{5.7} & \multicolumn{2}{|l|}{5.8} \\
\hline AR & \multicolumn{2}{|l|}{0.6} & \multicolumn{2}{|l|}{0.6} & \multicolumn{2}{|l|}{0.6} \\
\hline Relative Control Rod Worth [-] & $\mathrm{KC}$ & $\mathrm{AR}$ & $\mathrm{KC}$ & $\mathrm{AR}$ & $\mathrm{KC}$ & AR \\
\hline$+350 \mathrm{~mm}$ & 0 & 0 & 0 & 0 & 0 & 0 \\
\hline$+300 \mathrm{~mm}$ & 0.0243 & 0.0028 & 0.0142 & 0.0055 & 0.0150 & 0.0029 \\
\hline$+200 \mathrm{~mm}$ & 0.0959 & 0.0804 & 0.0814 & 0.0990 & 0.0826 & 0.0542 \\
\hline$+100 \mathrm{~mm}$ (above nominal) & 0.250 & 0.259 & 0.233 & 0.275 & 0.236 & 0.233 \\
\hline $0 \mathrm{~mm}$ (nominal) & 0.477 & 0.485 & 0.466 & 0.532 & 0.462 & 0.459 \\
\hline$-100 \mathrm{~mm}$ (below nominal) & 0.762 & 0.750 & 0.732 & 0.797 & 0.728 & 0.735 \\
\hline$-200 \mathrm{~mm}$ & 0.945 & 0.949 & 0.940 & 0.948 & 0.942 & 0.939 \\
\hline$-250 \mathrm{~mm}$ & 1.0 & 1.0 & 1.0 & 1.0 & 1.0 & 1.0 \\
\hline
\end{tabular}




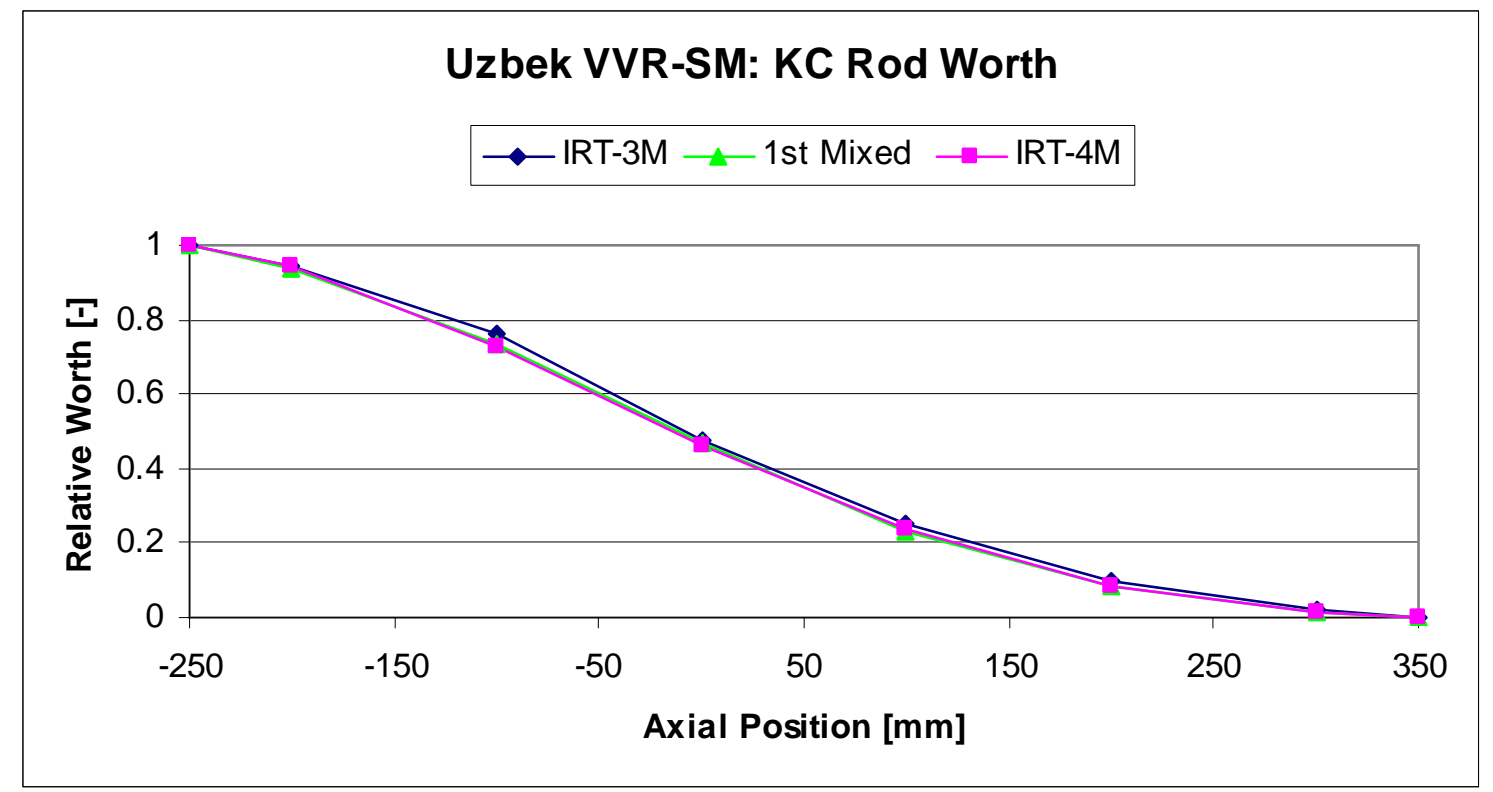

Figure 2.4.1 Relative KC Shim Rod Worth versus Axial Position

Table 2.4.3 Delayed Neutron Group Characteristics (Generic; not computed specifically for VVR-SM)

\begin{tabular}{|l|l|l|}
\hline Group & Fraction $[-]$ & Decay $[1 / \mathrm{s}]$ \\
\hline 1 & 0.0351 & $1.33 \mathrm{e}-2$ \\
\hline 2 & 0.1804 & $3.27 \mathrm{e}-2$ \\
\hline 3 & 0.1743 & $1.21 \mathrm{e}-1$ \\
\hline 4 & 0.3840 & $3.03 \mathrm{e}-1$ \\
\hline 5 & 0.1595 & $8.50 \mathrm{e}-1$ \\
\hline 6 & 0.0667 & $2.86 \mathrm{e}+0$ \\
\hline
\end{tabular}




\subsection{Steady State Analysis}

A steady state analysis using the PLTEMP code [Ref. 5] was performed for all cores. The model used for this analysis simulates all the fuel tubes as parallel plates separated by their respective coolant channels. For all cores the FA of each type with the highest power density, based on MCNP calculations, was used. The inlet temperature was $45^{\circ} \mathrm{C}$. The results for all cores operating at maximum power are presented in Table 2.5.1. These results show that using the Forster-Greif correlation for the onset of nucleate boiling (ONB), the criterion that the margin to ONB must be greater than 1.4 without including hot channel factors is met for both all cores operating at the maximum licensed power. The fuel catalog descriptions require cladding surface temperature to be less than $100^{\circ} \mathrm{C}$ for IRT-3M and $98^{\circ} \mathrm{C}$ for IRT-4M; these limits are satisfied for all cores. These results also show that the peak clad temperature is slightly higher in the LEU portion of most cores than in the HEU portion.

Table 2.5.1 Summary of Steady State Calculation for All Cores

\begin{tabular}{|c|c|c|c|c|c|c|c|c|}
\hline Core Configuration $^{\mathrm{a}}$ & \multicolumn{4}{|c|}{ IRT-3M Fuel Assemblies } & \multicolumn{4}{|c|}{ IRT-4M Fuel Assemblies } \\
\hline & $\begin{array}{l}\text { ONBR } \\
\text { F-G }\end{array}$ & $\begin{array}{l}\text { Clad } \\
\text { Max } \\
\text { Temp } \\
{\left[{ }^{\circ} \mathrm{C}\right]} \\
\end{array}$ & $\begin{array}{l}\text { Peak } \\
\text { Power } \\
\text { Density } \\
{[\mathrm{kW} / \mathrm{cc}]}\end{array}$ & $\begin{array}{l}\text { FA } \\
\text { Loc. }\end{array}$ & $\begin{array}{l}\text { ONBR }^{\mathrm{c}} \\
\mathrm{F}-\mathrm{G} \\
(\mathrm{B}-\mathrm{R})\end{array}$ & $\begin{array}{l}\text { Clad } \\
\text { Max } \\
\text { Temp } \\
{\left[\mathrm{C}^{\circ}\right]} \\
\end{array}$ & $\begin{array}{l}\text { Peak } \\
\text { Power } \\
\text { Density } \\
{[\mathrm{kW} / \mathrm{cc}]}\end{array}$ & $\begin{array}{l}\text { FA } \\
\text { Loc. }\end{array}$ \\
\hline $18 @ 3 \mathrm{M}$ & 1.56 & 93.7 & $3.05 / 3.42^{\mathrm{b}}$ & $4-5 / 5-5$ & & & & \\
\hline $16 @ 3 \mathrm{M}+4 @ 4 \mathrm{M}$ & 1.48 & 97.3 & 3.49 & $3-5$ & $\begin{array}{l}1.68 \\
(1.48) \\
\end{array}$ & 90.1 & $1.94 / 2.27$ & $5-5 / 5-5$ \\
\hline $14 @ 3 M+6 @ 4 M$ & 1.58 & 93.5 & 3.20 & $3-5$ & 1.54 & 94.4 & $2.19 / 2.26$ & $3-4 / 5-5$ \\
\hline $12 @ 3 \mathrm{M}+8 @ 4 \mathrm{M}$ & 1.64 & 91.6 & 3.06 & $3-5$ & 1.59 & 92.6 & $2.12 / 2.17$ & $3-4 / 5-5$ \\
\hline $10 @ 3 \mathrm{M}+10 @ 4 \mathrm{M}$ & 1.68 & 90.2 & 2.98 & $3-5$ & 1.60 & 92.4 & $2.02 / 2.32$ & $5-5 / 5-5$ \\
\hline $8 @ 3 \mathrm{M}+12 @ 4 \mathrm{M}$ & 1.67 & 89.8 & 2.96 & $3-5$ & 1.58 & 93.0 & $2.06 / 2.30$ & $4-5 / 4-4$ \\
\hline $6 @ 3 \mathrm{M}+14 @ 4 \mathrm{M}$ & 1.76 & 88.0 & 2.80 & $3-6$ & 1.56 & 94.1 & $2.21 / 2.40$ & $3-5 / 5-5$ \\
\hline $4 @ 3 \mathrm{M}+16 @ 4 \mathrm{M}$ & 1.83 & 85.7 & 2.64 & $3-6$ & 1.59 & 92.5 & $2.02 / 2.29$ & $4-5 / 5-5$ \\
\hline $2 @ 3 \mathrm{M}+18 @ 4 \mathrm{M}$ & 1.88 & 84.2 & 2.54 & $3-6$ & 1.55 & 94.4 & $2.27 / 2.38$ & $6-6 / 5-5$ \\
\hline $20 @ 4 \mathrm{M}$ & & & & & $\begin{array}{l}1.58 \\
(1.39)\end{array}$ & 92.9 & $2.06 / 2.32$ & $4-5 / 5-5$ \\
\hline
\end{tabular}

a. HEU core (18@3M) has power of $10 \mathrm{MW}$; all other cores have power $11 \mathrm{MW}$.

b. Style "A/B" denotes peak power in FA with minimum ONBR / peak power for FA type.

c. Analysis was done assuming Forster-Greif (F-G) as basis for ONB. IRT-4M fuel catalog as received later uses Bergles-Rohsenow (B-R) and limit of 1.3; the B-R values are shown in parentheses for the first mixed and full LEU cores only for comparison. 


\section{Specific Transients}

\subsection{Common Conditions}

The maximum normal operating power for the reactor is $10 \mathrm{MW}$ for the HEU core; this will increase to $11 \mathrm{MW}$ as conversion to LEU fuel begins. Forced convection cooling of the core is provided by three pumps operating in parallel; collectively these pumps provide $1250 \mathrm{~m}^{3} / \mathrm{h}$ coolant flow during normal operation. Only a portion of this coolant flow goes through the fuel assemblies. The prior Safety Analysis Report (SAR) [Ref. 6] shows a coolant flow rate of $31.3 \mathrm{~m}^{3} / \mathrm{h}$ for a 6 -tube IRT-3M assembly at $4 \mathrm{~m}$ water pressure drop and velocities from between FAs to interior of innermost fuel tube of 3.2, 3.0, 3.3, 3.4, 3.3, 3.8, and $3.7 \mathrm{~m} / \mathrm{s}$. The equivalent numbers for a 6-tube IRT-4M assembly are $28.2 \mathrm{~m}^{3} / \mathrm{h}$ and velocities of 3.0, 2.8, 3.1, 3.2, 3.1, 3.6, and $3.5 \mathrm{~m} / \mathrm{s}$ [Ref. 7]. The coolant flow input required by PARET is mass flux, which is the product of velocity and density.

A number of parameters are monitored by the VVR-SM operators and systems. Going above or below set point values generates an emergency protection action or scram to shut down the power production. Examples of these set points which are significant in the present analysis are as follows: power exceeding $12 \mathrm{MW}$ (i.e., 20\% overpower for HEU core and $9.1 \%$ for mixed and LEU cores); period less than $10 \mathrm{~s}$; total primary coolant flow less than $80 \%$ of nominal; and pool level dropping by $0.3 \mathrm{~m}$. There is assumed to be a delay time of $0.1 \mathrm{~s}$ between crossing any of these set points and start of control rod motion for scram. The AZ safety control rods are assumed to travel from fully withdrawn to fully inserted in $0.5 \mathrm{~s}$; the motion of the rods is assumed to insert the total available negative reactivity linearly in time. (For comparison, the free fall of an object would require approximately $0.35 \mathrm{~s}$ to cover the $0.6 \mathrm{~m}$ heights of these cores.) The $\mathrm{KC}$ shim rods are driven by motor into the core during scram; this insertion effect is ignored in the analyses to be shown and the $\mathrm{KC}$ rods are effectively treated as stuck rods. All (except one) transient calculations were started with the reactor critical at full power which means that the control rods are located as follows: shim rods $\mathrm{KC}-1$ and $\mathrm{KC}-2$ are greater than $50 \%$ inserted; shim rods $\mathrm{KC}-3$ and $\mathrm{KC}-4$ are mostly withdrawn; automatic rod AR is about $50 \%$ inserted; and safety rods AZ-1, AZ-2, and AZ-3 are fully withdrawn; the exact location of the shim rods is different for each core. Coolant pumps continue to operate following scram unless the transient initiator is loss of pumping.

All transient calculations were performed using Version 6.2 of PARET [Ref. 8]. The basic geometry in PARET is a "channel", which consists of a half-thickness fuel plate and the adjacent half-thickness water gap. Various channels may be modeled in parallel to represent the reactor core. The present work used two channels: one for the fuel plate having the highest cladding surface temperature (usually the same or near the plate having the highest power density) and a second channel to represent the rest of the reactor core. The original development of PARET was in the context of MTR-type fuel, characterized by flat plates of uniform width and spacing. This history imposes two restrictions on using the code for the VVR-SM core conversion.

First, PARET/v6.2 (and prior versions) allows only a single value of coolant mass flux [kg/ $\left./ \mathrm{m}^{2}-\mathrm{s}\right]$ to be specified for use in all channels, whereas the concentric tube FAs like IRT-3M and IRT- 
$4 \mathrm{M}$ would usually have different coolant mass fluxes for each gap between adjacent fuel tubes. Due to this restriction, the PARET analysis for VVR-SM has been performed using a coolant mass flux which is representative of the hot channel in order to characterize the temperatures in this channel as closely as possible; therefore, temperatures in the average channel will be an estimation; however, the reactivity feedbacks that come mostly from the average channel are correctly included. Note that if the peak occurs on the outside tube of the FA close to the beryllium blocks, the peak temperatures calculated with PARET will be conservative because the larger flow area between the beryllium blocks and the outer tube cannot be accounted for in PARET.

Second, PARET/v6.2 (and prior versions) allows only a single fuel type, both in terms of geometry and material. This provides no restriction for the full $3 \mathrm{M}$ or full $4 \mathrm{M}$ cores. The transition cores have been analyzed as two portions: $3 \mathrm{M}$ and $4 \mathrm{M}$. For example, the 1st mixed core has been analyzed having 16 IRT-3M FA generating 8.307 MW in one PARET run and 4 IRT-4M FA generating 2.693 MW in another PARET run; these power fractions were provided by the steady state neutronics analysis performed with MCNP; the powers from the two runs are added to get the total power. The net reactivity from the $3 \mathrm{M}$ and $4 \mathrm{M}$ portions are similar; the two values are averaged for plot purposes. This approach is not exact; however, the results appear to be an adequate approximation to those obtained using a more complicated code such as RELAP5/MOD3.2 [Ref. 9] which allows multiple FA types in a single calculation; the accuracy of this approach is being documented [Ref. 10] separately.

Of the 10 possible cores shown in Sec. 2.5, ANL has performed transient calculations for 3: Full HEU (18@ IRT-3M), first mixed HEU-LEU (16@ IRT-3M plus $4 @$ IRT-4M), and the full LEU (20@ IRT-4M). The conditions in these cores cover sufficiently those in the other transition cores.

Axial power distribution, as calculated with MCNP, has been represented by 15 equal distance mesh nodes. The fuel segments with the peak power densities in the fuel tubes are as follows:

1. Full HEU Core: Peak in the inner tube of FA 5-5, with an axial peak power equal to $3.424 \mathrm{E}+09 \mathrm{~W} / \mathrm{m}^{3}$. The axial power profile is provided in Table 3.1.1 below.

2. First Mixed HEU-LEU Core:

a. IRT-3M FA: Peak power density is in outer tube of FA 3-5, with an axial peak power equal to $3.523 \mathrm{E}+09 \mathrm{~W} / \mathrm{m}^{3}$. The hottest channel is on the interior side of this fuel tube. The axial power profile is provided in Table 3.1.1 below.

b. IRT-4M FA: Peak power density is in inner tube of FA 5-5, with an axial peak power density equal to $2.269 \mathrm{E}+09 \mathrm{~W} / \mathrm{m}^{3}$. The hottest channel is on the interior of the nextto-innermost fuel tube, with an axial peak power density of $2.030 \mathrm{E}+09 \mathrm{~W} / \mathrm{m}^{3}$. The axial power profile is provided in Table 3.1.1 below.

3. Full LEU Core: Peak power density is in inner tube of FA 5-5, with an axial peak power density equal to $2.319 \mathrm{E}+09 \mathrm{~W} / \mathrm{m}^{3}$. The hottest channel is on the interior of the next-toinnermost fuel tube, with an axial peak power density of $2.080 \mathrm{E}+09 \mathrm{~W} / \mathrm{m}^{3}$. The axial power profile is provided in Table 3.1.1 below.

The axial distribution in the hot plate is shown in Table 3.1.1 for the three cores analyzed. In MCNP and PARET, $6 \%$ of the power was assumed to be generated in non-fuel material. 
All (except one, which shall be noted later) transient calculations for the first mixed core and for the full LEU core were performed starting at a power of $11 \mathrm{MW}$, a coolant inlet temperature of $45^{\circ} \mathrm{C}$, and inlet pressure of $137.22 \mathrm{kPa}$ which corresponds to the static pressure of water column from the top of the core to a point of $4.0 \mathrm{~m}$ higher at the free surface. The steady-state coolant flow rate in the primary system has been determined to be $1250 \mathrm{~m}^{3} / \mathrm{h}$ total: $522.57 \mathrm{~m}^{3} / \mathrm{h}$ of this is through the fuel in HEU part of the core and $112.86 \mathrm{~m}^{3} / \mathrm{h}$ of this is through the fuel in LEU part of the core. The initial power for the full HEU IRT-3M core for all transients (except one, which shall be noted later) is $10 \mathrm{MW}$. The steady-state coolant flow rate in the primary system is also $1250 \mathrm{~m}^{3} / \mathrm{h}$.

All PARET transient calculations to be shown have constant boundary conditions for the first $1 \mathrm{~s}$; during this time there is a slight drift in power $(+0.8 \%)$ as the temperatures complete their adjustment to equilibrium conditions at steady state. The transient boundary conditions are imposed starting at $1 \mathrm{~s}$.

Calculations are presented below for the 15 cases for which Ref. 1 stated that analysis was required. Where possible, the corresponding section in the 2003 SAR will be noted.

Table 3.1.1 Power Density in Hottest Fuel Plate

\begin{tabular}{|l|l|l|l|l|}
\hline Core & Full HEU & \multicolumn{2}{|c|}{ First Mixed HEU-LEU } & Full LEU \\
\hline FA & IRT-3M & IRT-3M & IRT-4M & IRT-4M \\
\hline Axial $[\mathrm{m}]$ & $\mathrm{Q} / \mathrm{V}\left[\mathrm{GW} / \mathrm{m}^{3}\right]$ & $\mathrm{Q} / \mathrm{V}\left[\mathrm{GW} / \mathrm{m}^{3}\right]$ & $\mathrm{Q} / \mathrm{V}\left[\mathrm{GW} / \mathrm{m}^{3}\right]$ & $\mathrm{Q} / \mathrm{V}\left[\mathrm{GW} / \mathrm{m}^{3}\right]$ \\
\hline $0.58(\mathrm{top})$ & 1.258 & 1.609 & 0.768 & 0.682 \\
\hline 0.54 & 1.536 & 1.954 & 0.880 & 0.811 \\
\hline 0.50 & 1.966 & 2.437 & 1.135 & 1.053 \\
\hline 0.46 & 2.333 & 2.812 & 1.404 & 1.258 \\
\hline 0.42 & 2.659 & 3.136 & 1.640 & 1.454 \\
\hline 0.38 & 2.913 & 3.322 & 1.810 & 1.636 \\
\hline 0.34 & 3.125 & 3.410 & 1.935 & 1.777 \\
\hline 0.30 & 3.280 & 3.507 & 2.010 & 1.903 \\
\hline 0.26 & 3.367 & 3.523 & 2.030 & 2.023 \\
\hline 0.22 & 3.424 & 3.481 & 1.994 & 2.080 \\
\hline 0.18 & 3.373 & 3.336 & 1.906 & 2.054 \\
\hline 0.14 & 3.235 & 3.074 & 1.768 & 1.954 \\
\hline 0.10 & 2.961 & 2.795 & 1.562 & 1.771 \\
\hline 0.06 & 2.503 & 2.362 & 1.314 & 1.496 \\
\hline 0.02 & 2.378 & 2.045 & 1.275 & 1.466 \\
\hline
\end{tabular}




\subsection{Partial Blockage of Fuel Assembly}

\subsubsection{Boundary Conditions}

This case is not discussed in the 2003 SAR. The blockage of the coolant flow channel interior of the innermost fuel tube is postulated to occur without specifying a mechanism. All heat from the innermost fuel tube must be removed through its outer surface. Coolant flow rate through all other channels is assumed to be not affected by the inner blockage. Presence of the blockage would not be detected by facility instrumentation unless it leads to failure of the fuel tube and release of radioactive materials. A transient analysis is not required. A steady-state analysis is sufficient; this is performed using PLTEMP with no coolant flow in the channel interior to the innermost fuel tube. The temperature for the innermost fuel tube (and possibly others) will be higher due to the lack of cooling on one side; the temperature in other portions of the FA might also be higher due to the higher temperature for the coolant on outer side of the innermost fuel tube. The analysis is needed to see if the higher temperatures are high enough to cause other problems in the FA.

\subsubsection{Results}

Results are shown in Figures 3.2.1 through 3.2.3 for the full HEU core. Tube 6 (i.e., the innermost tube) has a peak temperature of $90^{\circ} \mathrm{C}$ for normal cooling. When the inner (or "right") coolant channel is blocked the peak temperature on tube 6 increases to $134^{\circ} \mathrm{C}$ on the right side and $126^{\circ} \mathrm{C}$ on the left side, as shown in Figure 3.2.1. The increased temperature in tube 6 and its coolant has an effect on tube 5, raising its peak temperature from $90^{\circ} \mathrm{C}$ to $94^{\circ} \mathrm{C}$, as shown in Figure 3.2.2. Tube 4 and those tubes further outward do not feel the effect of the blockage, as shown in Figure 3.2.3 for tube 4. The temperature increases from single channel blockage are not large enough to cause fuel damage, although some local coolant boiling might occur.

Results are shown in Figures 3.2.4 through 3.2.7 for the first mixed HEU-LEU core. Tube 6 (i.e., the innermost tube) has a peak temperature of $80^{\circ} \mathrm{C}$ in IRT-3M FA and $88^{\circ} \mathrm{C}$ in IRT-4M FA for normal cooling. When the inner (or "right") coolant channel is blocked the peak temperature on tube 6 increases to $114^{\circ} \mathrm{C}$ on the right side and $108^{\circ} \mathrm{C}$ on the left side in IRT-3M and $130^{\circ} \mathrm{C}$ on the right side and $122^{\circ} \mathrm{C}$ on the left side in IRT-4M, as shown in Figures 3.2.4 and 3.2.6, respectively. The increased temperature in tube 6 and its coolant has an effect on tube 5, raising its peak temperature from $83^{\circ} \mathrm{C}$ to $86^{\circ} \mathrm{C}$ in IRT-3M and from $88^{\circ} \mathrm{C}$ to $92^{\circ} \mathrm{C}$ in IRT-4M, as shown in Figure 3.2.5 and 3.2.7, respectively. Tube 4 and those tubes further outward do not feel the effect of the blockage, as was also the case for the full HEU core. The temperature increases from single channel blockage are not large enough to cause fuel damage, although some local coolant boiling might occur.

Results are shown in Figures 3.2.8 through 3.2.9 for the full LEU core. Tube 6 (i.e., the innermost tube) has a peak temperature of $89^{\circ} \mathrm{C}$ for normal cooling. When the inner (or "right") coolant channel is blocked the peak temperature on tube 6 increases to $133^{\circ} \mathrm{C}$ on the right side and $125^{\circ} \mathrm{C}$ on the left side, as shown in Figure 3.2.8. The increased temperature in tube 6 and its coolant has an effect on tube 5, raising its peak temperature from $90^{\circ} \mathrm{C}$ to $94^{\circ} \mathrm{C}$, as shown in 
Figure 3.2.9. Tube 4 and those tubes further outward do not feel the effect of the blockage, as was also true for the full HEU and first mixed HEU-LEU core. The temperature increases from single channel blockage are not large enough to cause fuel damage, although some local coolant boiling might occur.

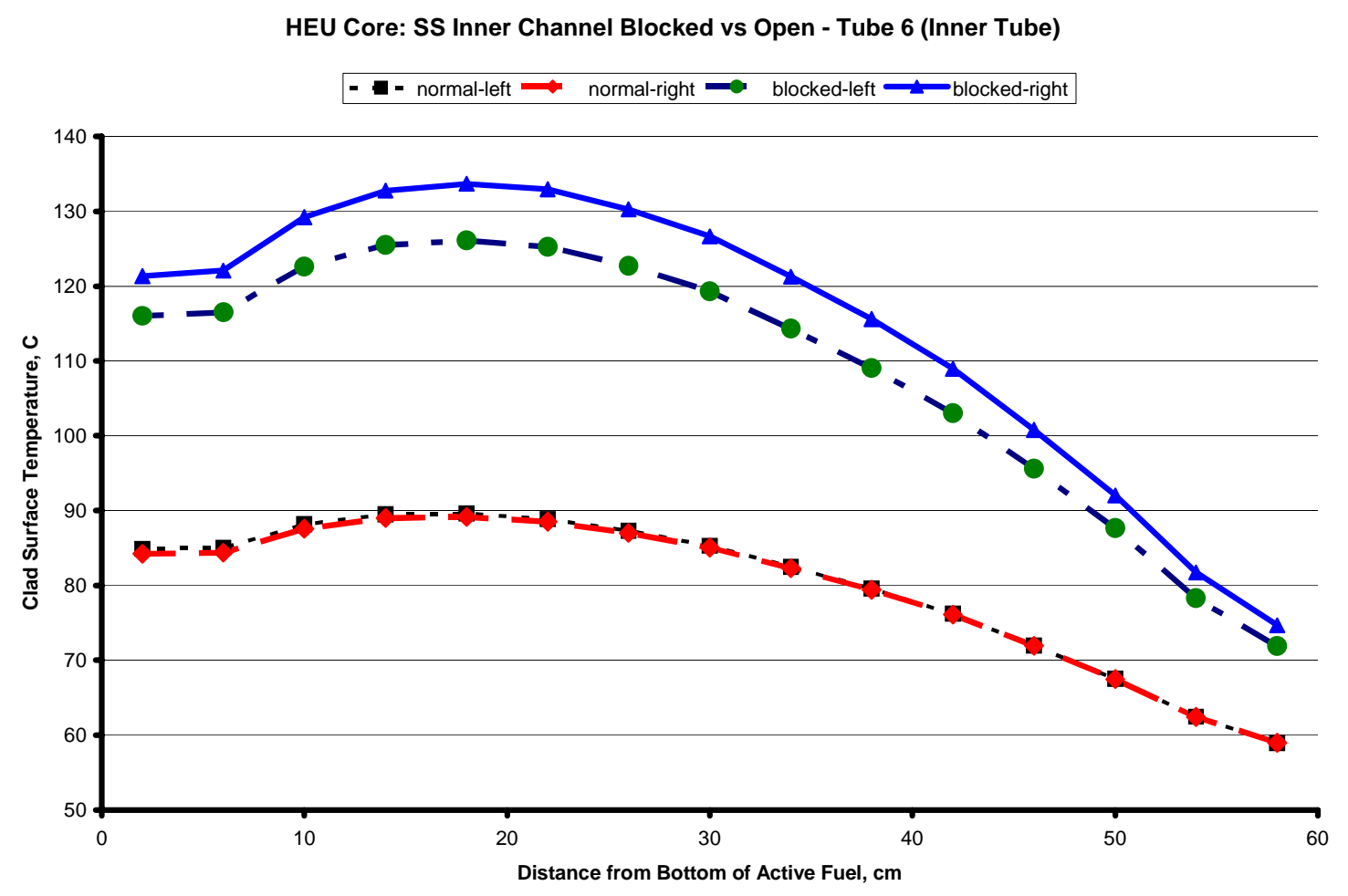

Figure 3.2.1 Effect of Inner Channel Blockage on Tube 6 in Full HEU Core 


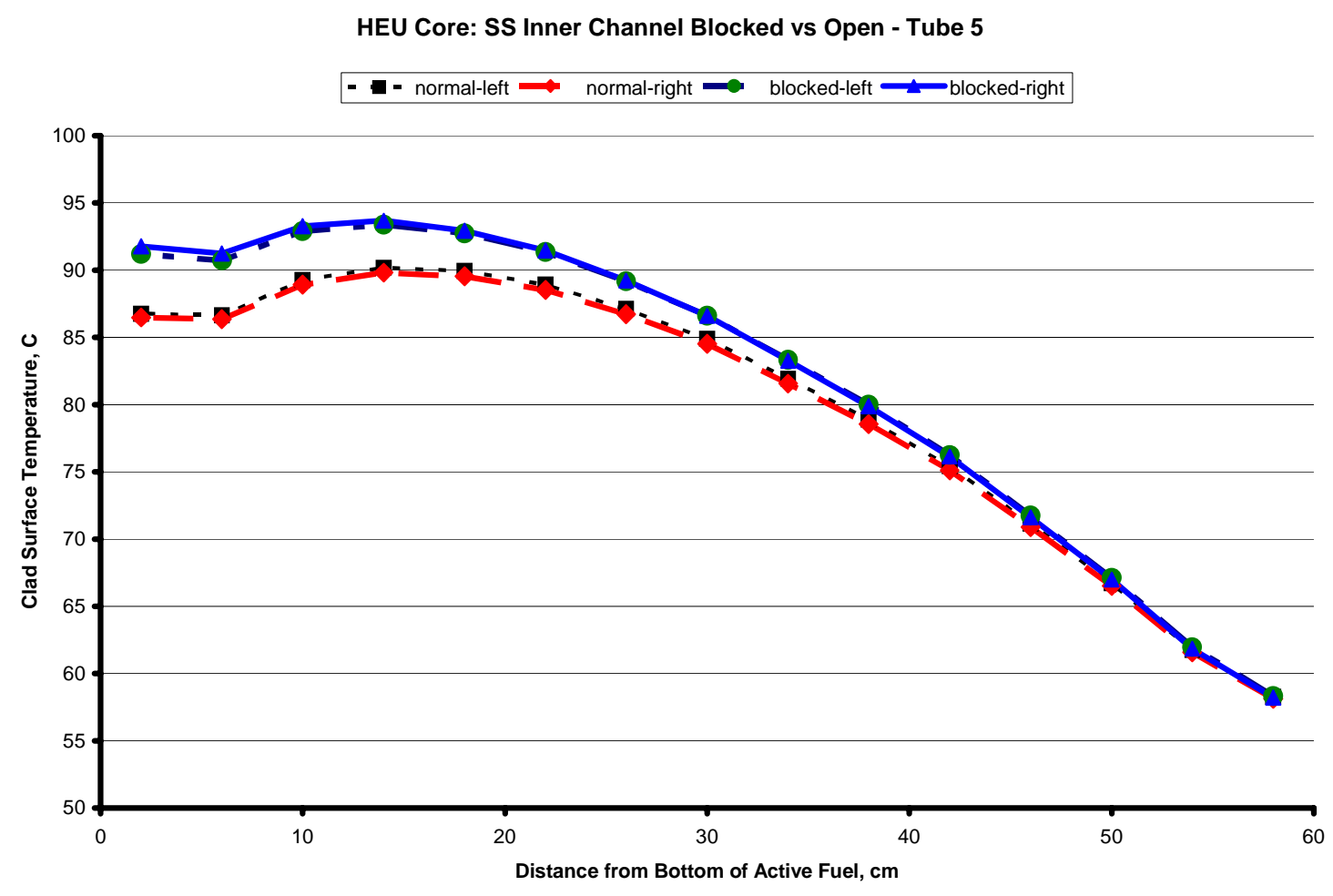

Figure 3.2.2 Effect of Inner Channel Blockage on Tube 5 in Full HEU Core

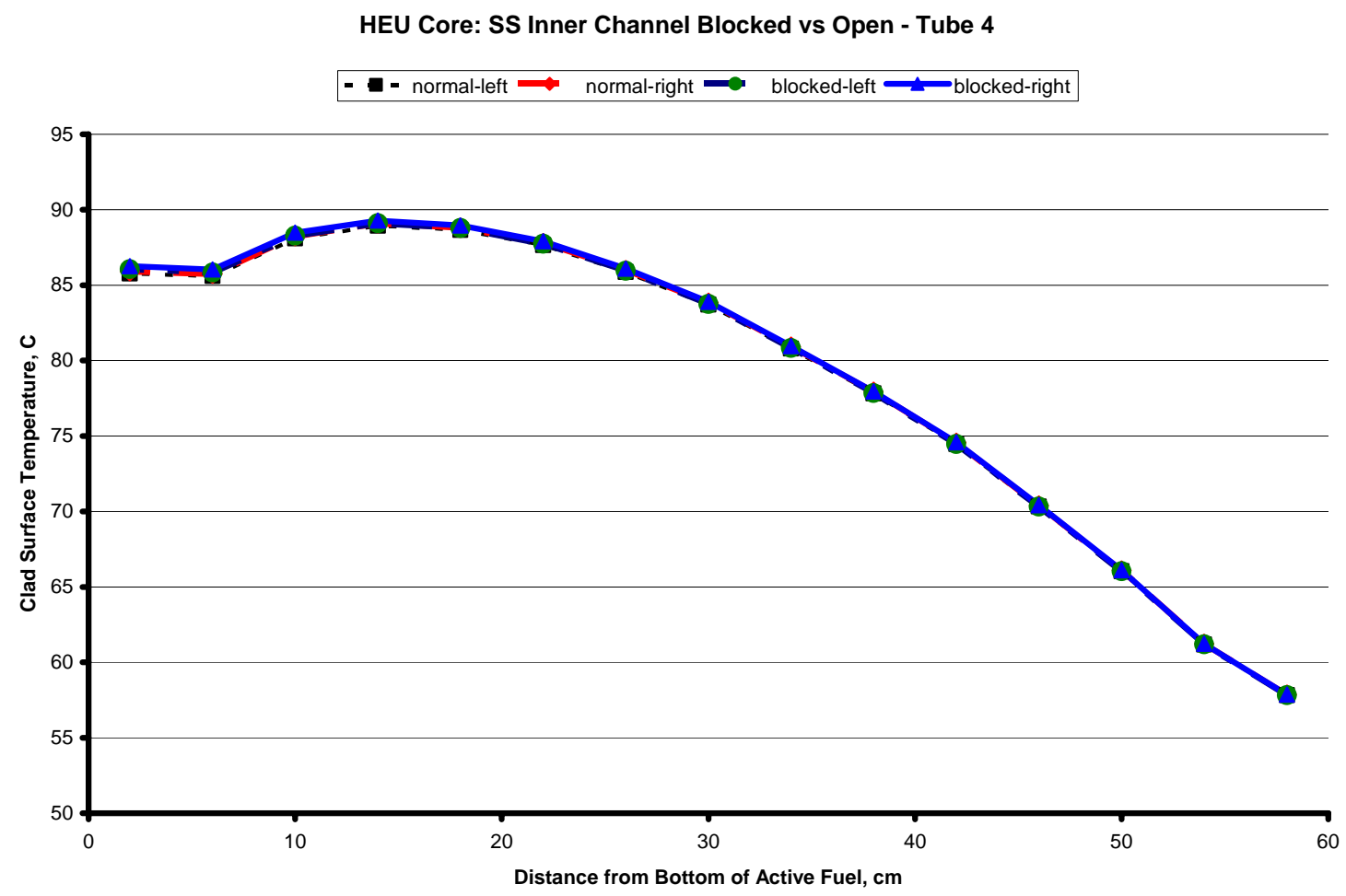

Figure 3.2.3 Effect of Inner Channel Blockage on Tube 4 in Full HEU Core 
1st Mixed Core: SS Inner Channel Blocked vs Open - IRT-3M Tube 6 (Inner Tube)

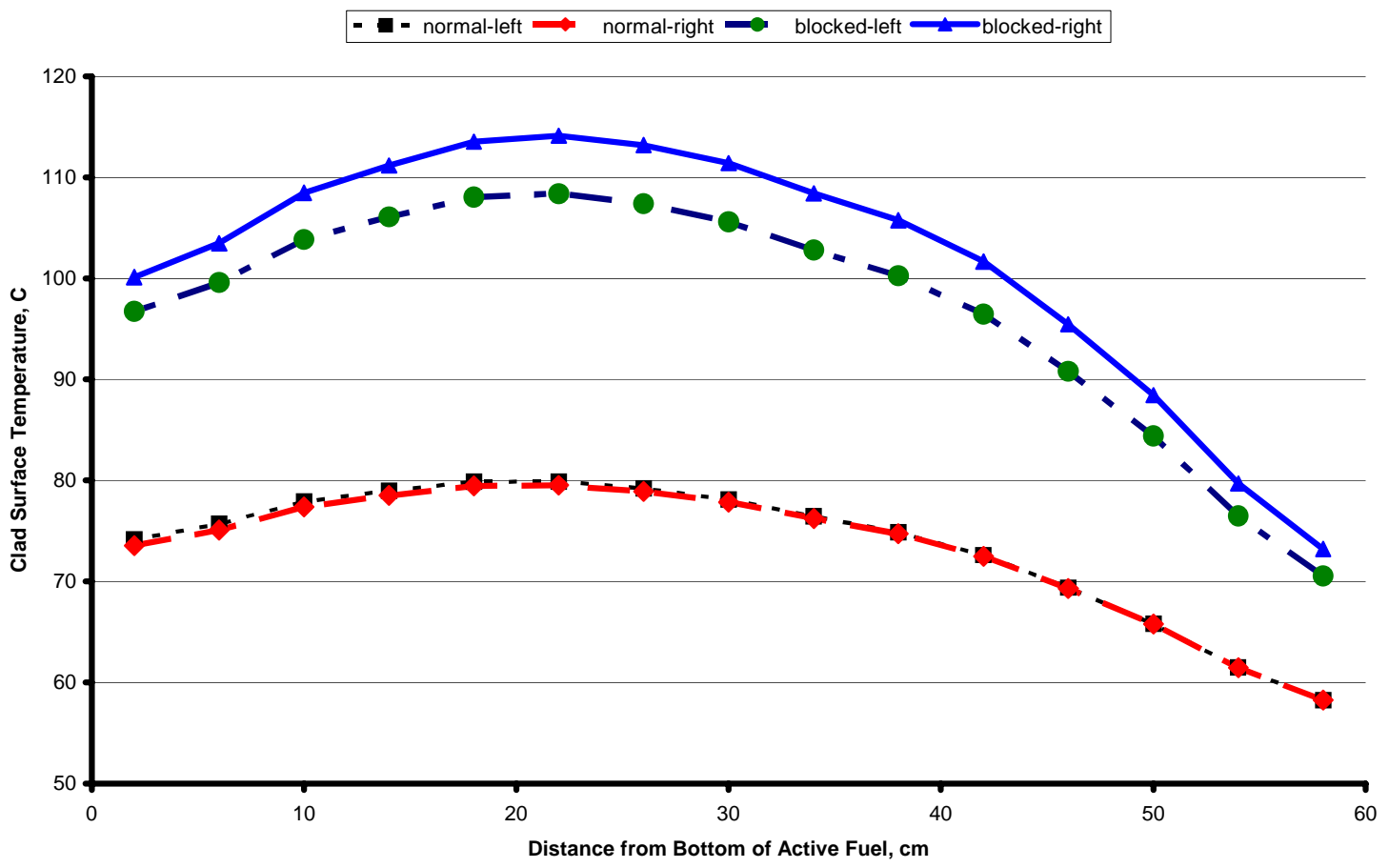

Figure 3.2.4 Effect of Inner Channel Blockage on Tube 6 in HEU Part of First Mixed Core

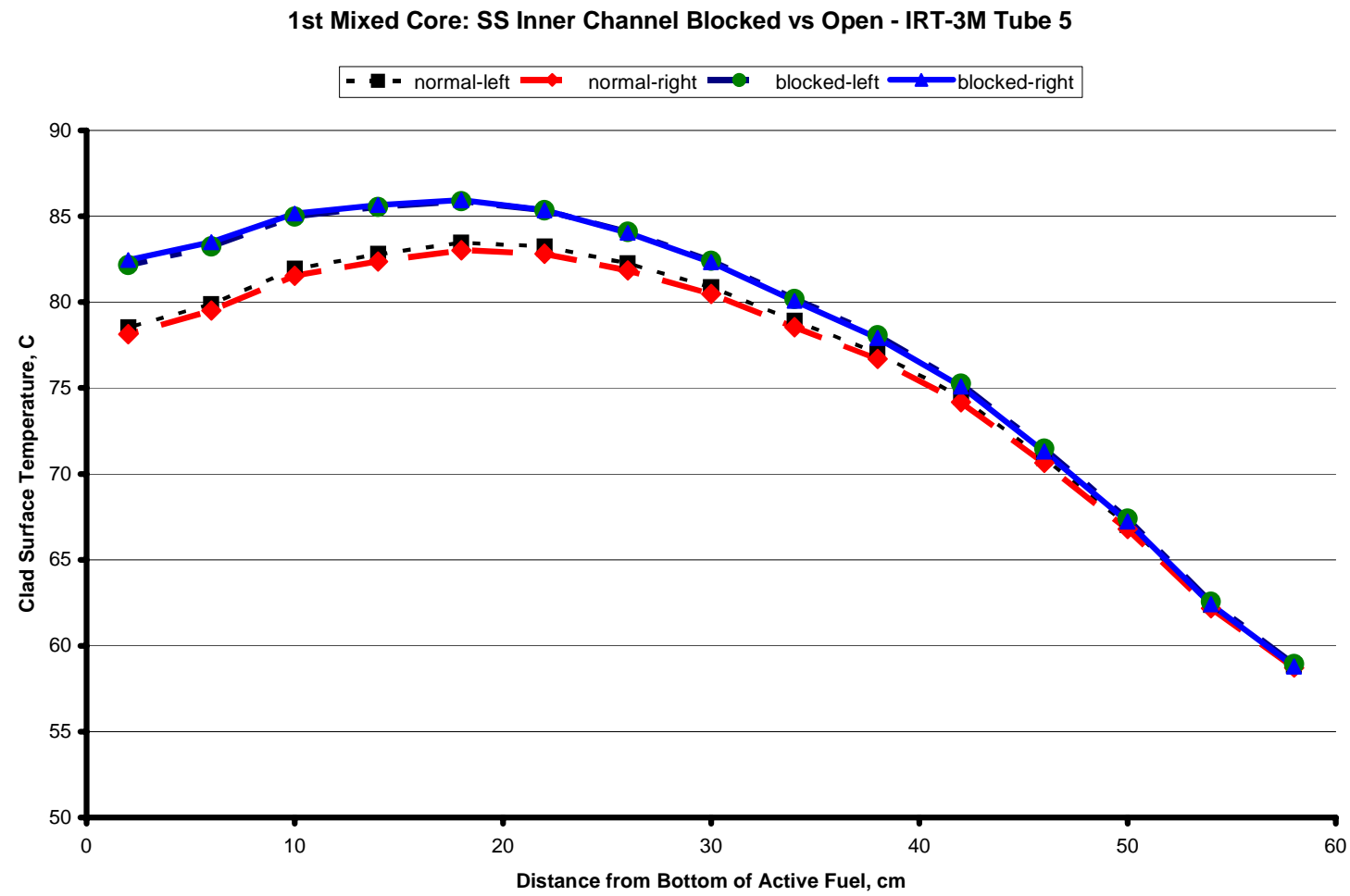

Figure 3.2.5 Effect of Inner Channel Blockage on Tube 5 in HEU Part of First Mixed Core 
1st Mixed Core: SS Inner Channel Blocked vs Open - IRT-4M Tube 6 (Inner Tube)

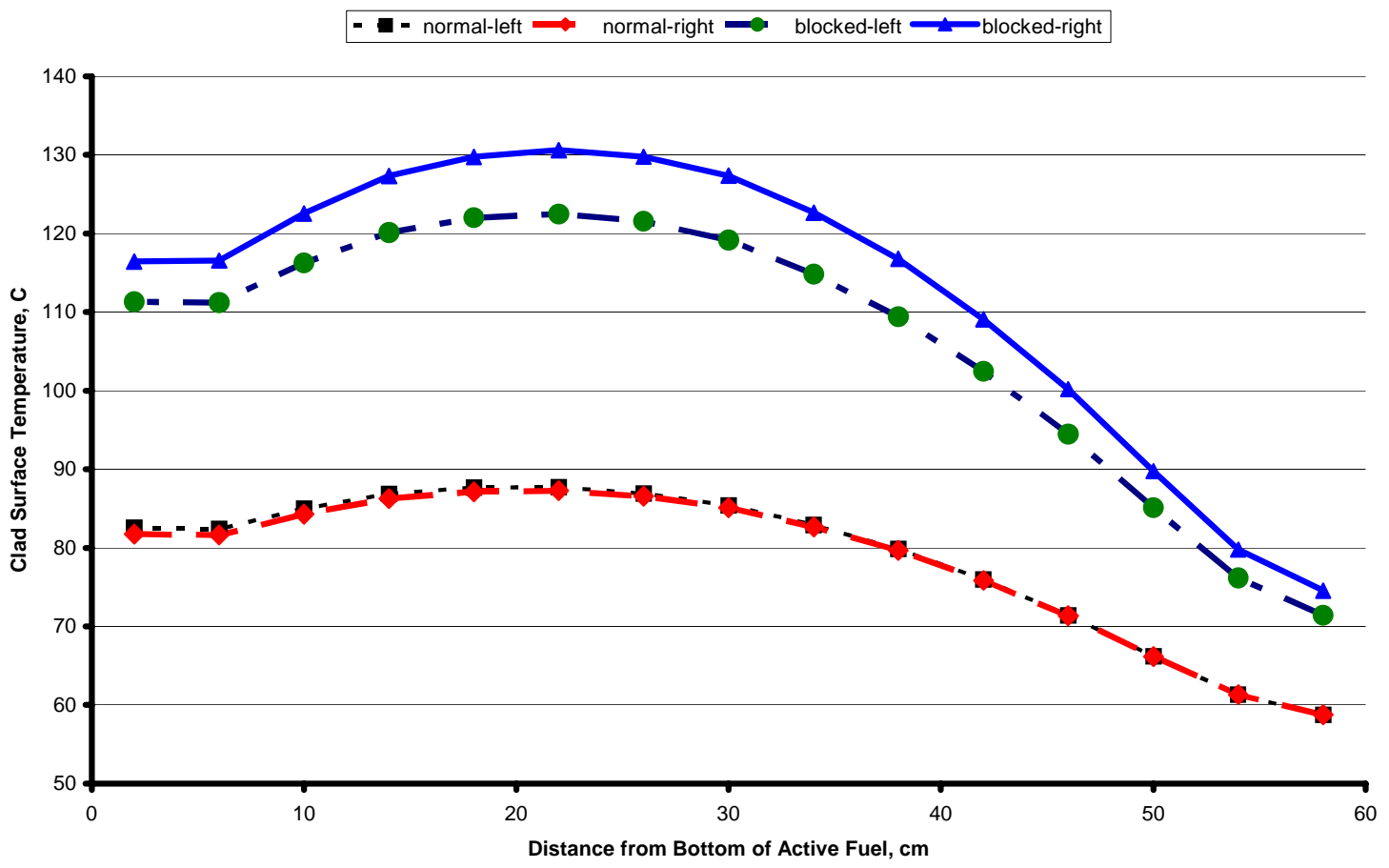

Figure 3.2.6 Effect of Inner Channel Blockage on Tube 6 in LEU Part of First Mixed Core

1st Mixed Core: SS Inner Channel Blocked vs Open - IRT-4M Tube 5

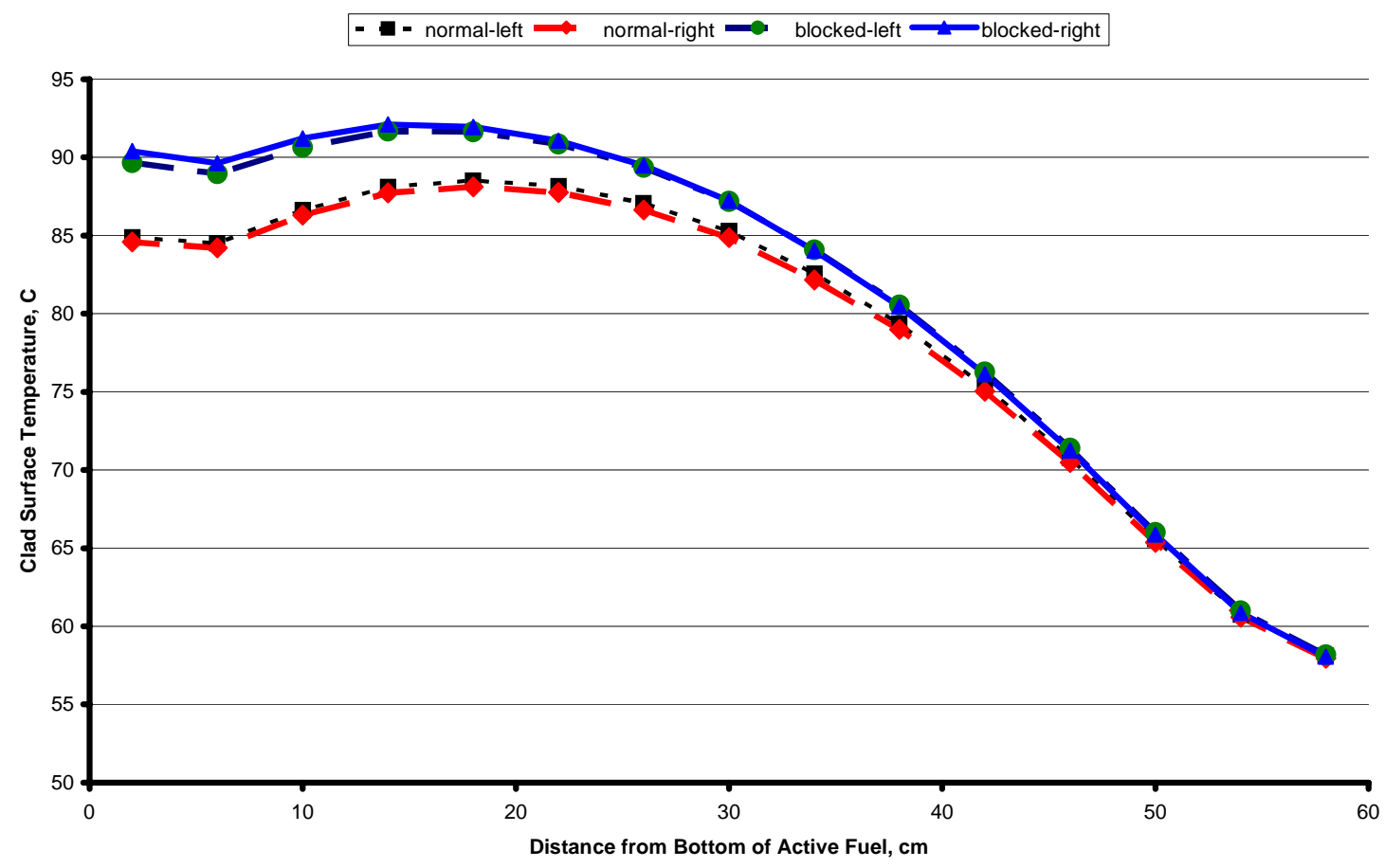

Figure 3.2.7 Effect of Inner Channel Blockage on Tube 5 in LEU Part of First Mixed Core 
LEU Core: SS Inner Channel Blocked vs Open - Tube 6 (Inner Tube)

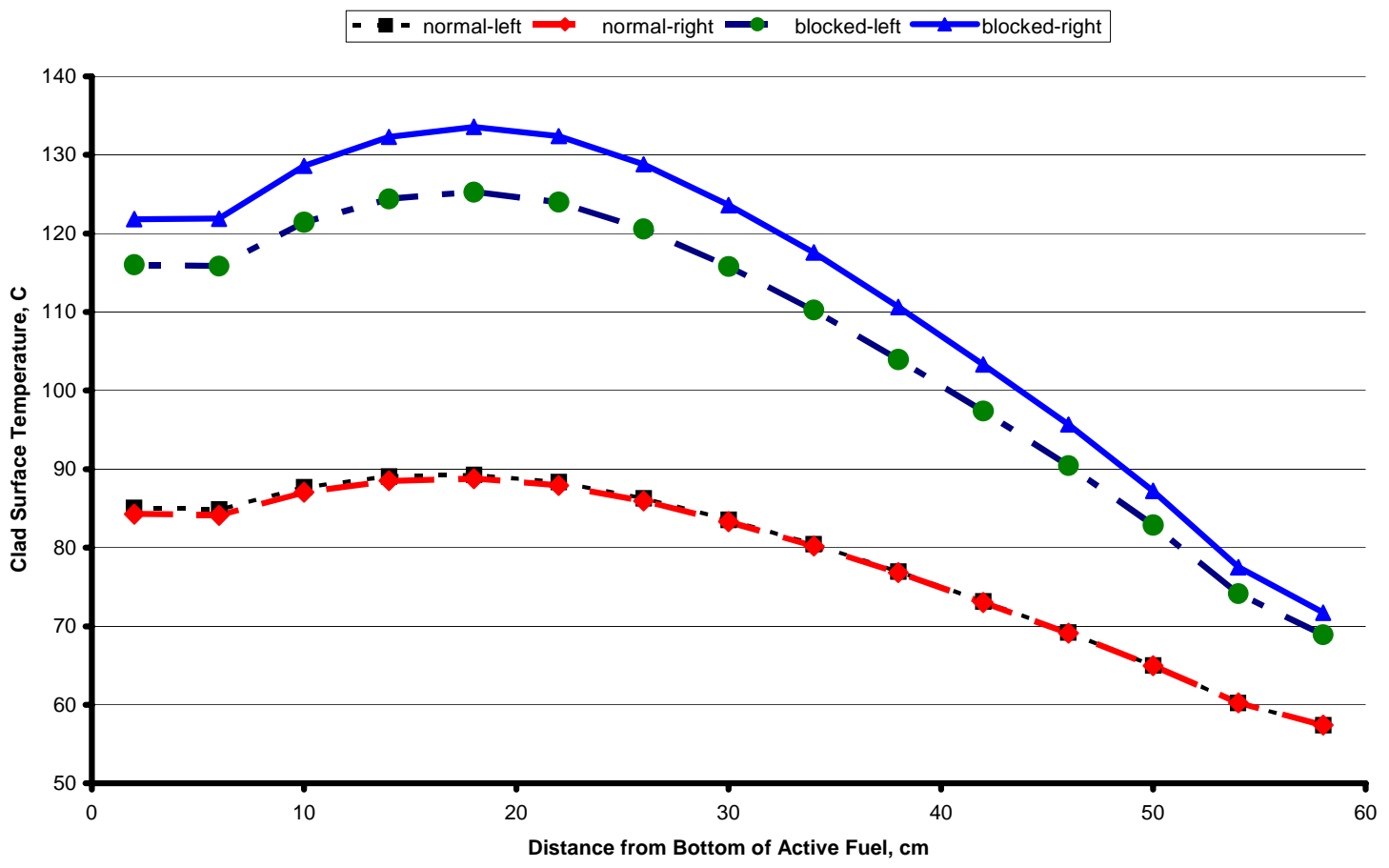

Figure 3.2.8 Effect of Inner Channel Blockage on Tube 6 in Full LEU Core

LEU Core: SS Inner Channel Blocked vs Open - Tube 5

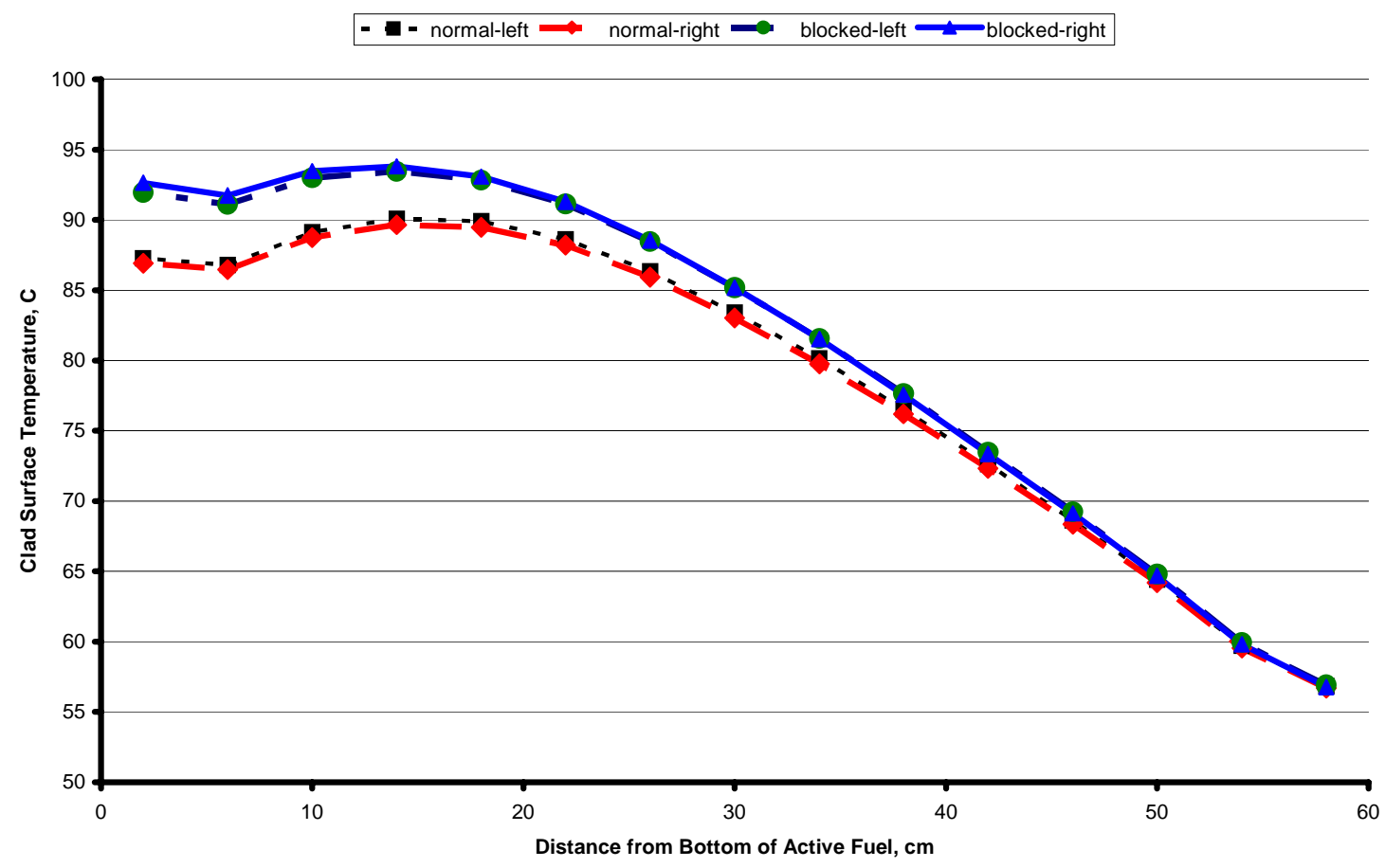

Figure 3.2.9 Effect of Inner Channel Blockage on Tube 5 in Full LEU Core 
3.3. Fuel Assembly Integrity Loss Due to Totally Blocked Flow of Coolant

\subsubsection{Boundary Conditions}

This case is discussed in Sec. 4.2.1.2 of the 2003 SAR. The postulate is total blockage of coolant flow to one FA. Origin of blockage is not specified. No transient analysis is performed; instead, the blockage is assume to cause melting of one FA.

\subsubsection{Results}

Analyses were performed only for the full HEU core and for the full LEU core; the mixed cores during the transition were not analyzed. The ORIGEN2 computer code [Ref. 11] was used to calculate the inventory of fission products and actinides in the reactor fuel. The nuclear data library for a thermal reactor in ORIGEN2 was used for all isotopes with exception to the actinides. The one-group cross sections for the actinides in ORIGEN2 were replaced by those calculated using the MCNP-4C code. The following assumptions were used to calculate the source term for both the HEU and the LEU cores:

a. The reactor was assumed to be operated continuously at the power of $10 \mathrm{MW}$ for the HEU core (18 IRT-3M FA) and at 11 MW for the LEU core (20 IRT-4M FA).

b. The selected fuel assemblies were burned for a total of megawatt-days required to obtain an average burnup of about 60 a/o for the IRT-3M FA (based on operating experience), and about $40 \%$ for the IRT-4M FA (expected maximum average burnup).

The calculated inventories for selected fission products are provided in Table 3.3.1, where it can be seen that the radioactive inventory for both fuel assemblies are very similar.

The next step for the determination of the consequences of this accident would be a calculation for the doses at different locations, i.e. the transport of the radioactivity release from the reactor core to the environment. Since the information for the VVR-SM site was not available, a comparison for the doses at a distance of $1000 \mathrm{~m}$ (i.e., site boundary) for both the HEU and LEU cores was made using the following assumptions:

a. Release from fuel to water:

i. Iodines: $25 \%$

ii. Halogens: $100 \%$

iii. Solids: $1 \%$

b. Release from buildings/containment: $1 \%$ per day.

c. Release is at ground level.

d. Breathing rate $\left[\mathrm{m}^{3} / \mathrm{s}\right]$ :

i. 0 to 8 hour: $3.47 \mathrm{e}-4$,

ii. 8 to 24 hour: $1.75 \mathrm{e}-4$, and

iii. 1 to 30 day: $2.32 \mathrm{e}-4$.

e. Atmospheric diffusion factor, $\chi / \mathrm{Q}\left[\mathrm{s} / \mathrm{m}^{3}\right]$

i. 0 to 8 hour: $6.5 \mathrm{e}-4$,

ii. 8 to 24 hour: $1.5 \mathrm{e}-4$,

iii. 1 to 4 day: $5.3 \mathrm{e}-5$, and 
iv. 4 to 30 day: 1.2e-5 (all from Ref. 12 for ground release).

f. No credit taken for filtering, wash down, or other engineered safety features.

The resulting doses (bone, lung, thyroid, and whole body-internal and -external were calculated using the DOSER3 computer code [Ref. 13], and the results are presented in Table 3.3.2. The major contributors to the bone, lung, thyroid, and whole body doses for both the HEU and LEU cases are presented in Table 3.3.3. As expected, because the radioactive inventories are very close, the doses and major contributors for the HEU and LEU FA are also similar.

Table 3.3.1 Inventory [Ci] for Selected Fission Products

\begin{tabular}{|l|c|c|}
\hline $\begin{array}{c}\text { Fission } \\
\text { Product }\end{array}$ & $\begin{array}{c}\text { HEU } \\
\text { IRT-3M FA } \\
\text { 60 BU }\end{array}$ & $\begin{array}{c}\text { LEU } \\
\text { IRT-4M FA } \\
\text { 40\% BU }\end{array}$ \\
\hline $\mathrm{Kr}-85 \mathrm{~m}$ & $6.86 \mathrm{E}+03$ & $6.73 \mathrm{E}+03$ \\
\hline $\mathrm{Kr}-87$ & $1.38 \mathrm{E}+04$ & $1.35 \mathrm{E}+04$ \\
\hline $\mathrm{Kr}-88$ & $1.94 \mathrm{E}+04$ & $1.91 \mathrm{E}+04$ \\
\hline $\mathrm{Kr}-90$ & $2.44 \mathrm{E}+04$ & $2.39 \mathrm{E}+04$ \\
\hline $\mathrm{Kr}-91$ & $1.79 \mathrm{E}+04$ & $1.76 \mathrm{E}+04$ \\
\hline $\mathrm{Xe}-133$ & $3.82 \mathrm{E}+04$ & $3.60 \mathrm{E}+04$ \\
\hline $\mathrm{Xe}-133 \mathrm{~m}$ & $1.15 \mathrm{e}+03$ & $1.02 \mathrm{E}+03$ \\
\hline $\mathrm{Xe}-135$ & $3.65 \mathrm{E}+03$ & $4.59 \mathrm{E}+03$ \\
\hline $\mathrm{Xe}-135 \mathrm{~m}$ & $6.79 \mathrm{E}+03$ & $6.58 \mathrm{E}+03$ \\
\hline $\mathrm{Xe}-137$ & $3.44 \mathrm{e}+04$ & $3.34 \mathrm{E}+04$ \\
\hline $\mathrm{I}-131$ & $1.78 \mathrm{E}+04$ & $1.68 \mathrm{E}+04$ \\
\hline $\mathrm{I}-132$ & $2.59 \mathrm{E}+04$ & $2.49 \mathrm{E}+04$ \\
\hline $\mathrm{I}-133$ & $3.88 \mathrm{E}+04$ & $3.77 \mathrm{E}+04$ \\
\hline $\mathrm{I}-134$ & $4.36 \mathrm{E}+04$ & $4.24 \mathrm{E}+04$ \\
\hline $\mathrm{I}-135$ & $3.62 \mathrm{E}+04$ & $3.51 \mathrm{E}+04$ \\
\hline $\mathrm{Sr}-89$ & $2.65 \mathrm{E}+04$ & $2.18 \mathrm{E}+04$ \\
\hline $\mathrm{Zr}-95$ & $3.47 \mathrm{E}+04$ & $2.72 \mathrm{E}+04$ \\
\hline $\mathrm{Te}-131 \mathrm{~m}$ & $2.25 \mathrm{E}+03$ & $2.18 \mathrm{E}+03$ \\
\hline Te-131 & $1.53 \mathrm{E}+04$ & $1.49 \mathrm{E}+04$ \\
\hline Te-133m & $1.64 \mathrm{E}+04$ & $1.60 \mathrm{E}+04$ \\
\hline $\mathrm{Ba}-140$ & $3.78 \mathrm{E}+04$ & $3.49 \mathrm{E}+04$ \\
\hline $\mathrm{La}-140$ & $3.95 \mathrm{E}+04$ & $3.52 \mathrm{E}+04$ \\
\hline $\mathrm{Ce}-141$ & $3.52 \mathrm{E}+04$ & $3.10 \mathrm{E}+04$ \\
\hline $\mathrm{Ce}-143$ & $3.31 \mathrm{E}+04$ & $3.25 \mathrm{E}+04$ \\
\hline $\mathrm{Ce}-144$ & $1.30 \mathrm{E}+04$ & $8.27 \mathrm{E}+03$ \\
\hline & & \\
\hline & & \\
\hline & & \\
\hline
\end{tabular}


Table 3.3.2 Doses [rem] at $1000 \mathrm{~m}$

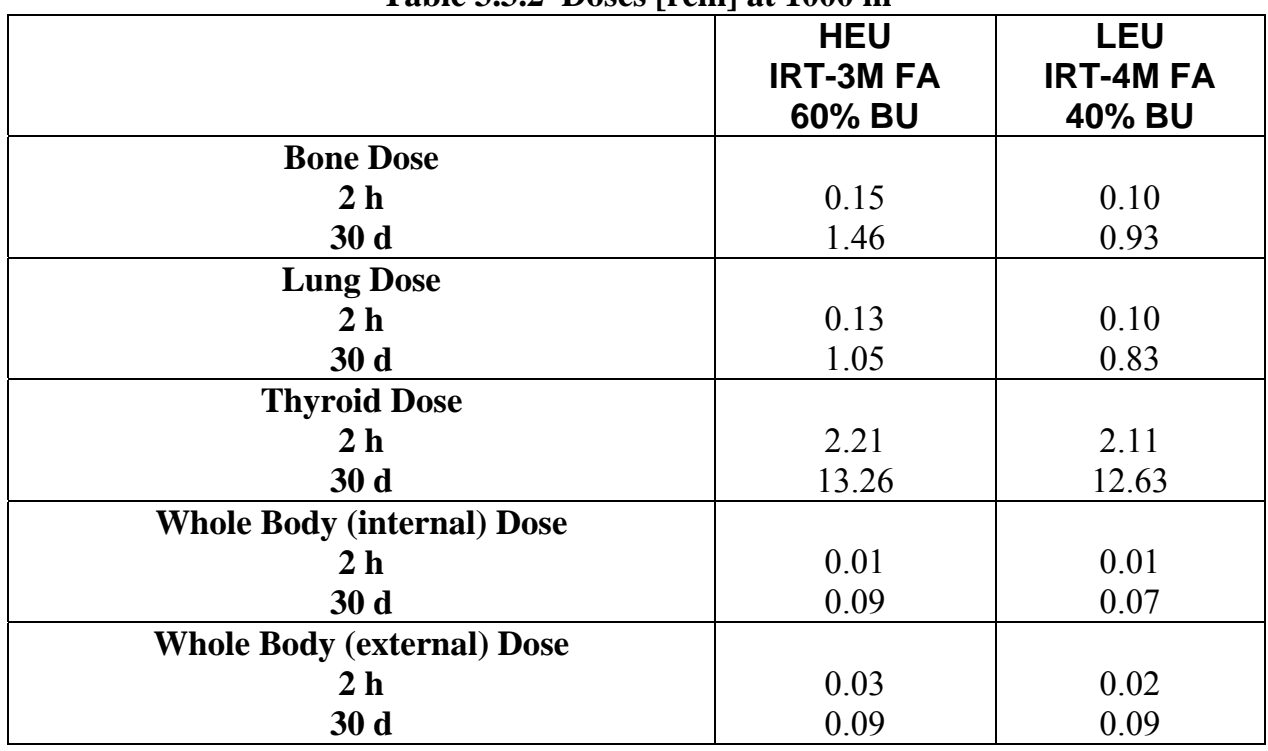

Table 3.3.3 Major Contributors [\%] to Doses

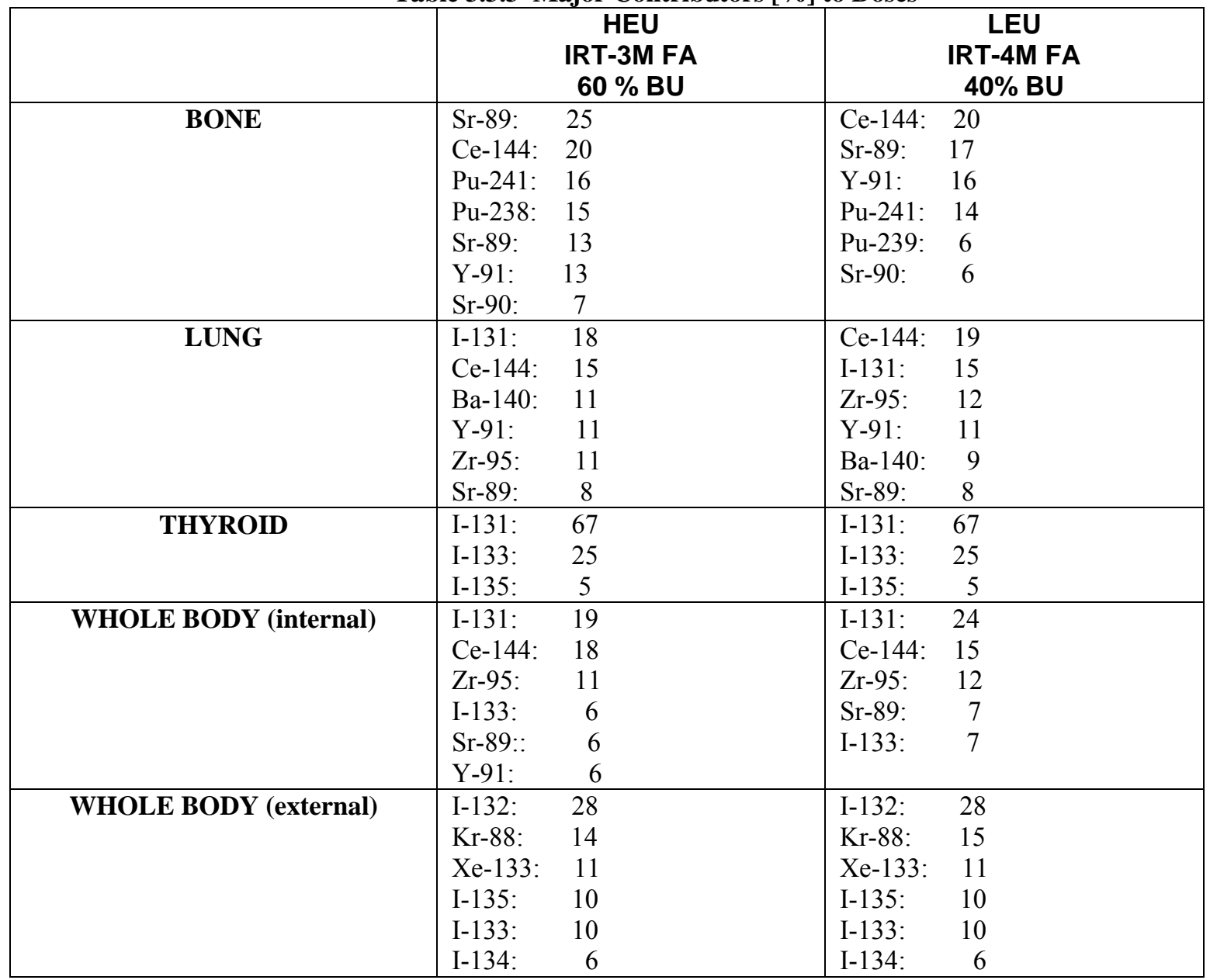




\subsection{Accidental Reactivity Increase by In-Pile Experimental Devices}

\subsubsection{Boundary Conditions}

This case is discussed in Sec. 4.2.1.5 of the 2003 SAR. The initiator is sudden entry of water into a horizontal beam tube. In PARET, "sudden" is taken to be a time period of $0.05 \mathrm{~s}$. The reactivity introduced is $0.053 \$$ for the full HEU core, $0.053 \$$ for the first mixed HEU-LEU core, and $0.040 \$$ for the full LEU core.

\subsubsection{Results}

The calculated results for the full HEU core are shown in Figures 3.4.1 and 3.4.2. The step reactivity insertion results in a sudden increase in power from 10 to $11.59 \mathrm{MW}$ over $0.07 \mathrm{~s}$. During this time the reactor period is as low as $1 \mathrm{~s}$; even though this is less than the $10 \mathrm{~s}$ limit reactor scram due to crossing this limit is ignored in the calculation. After the prompt jump, the power continues to increase but at a more gradual rate. After $69.8 \mathrm{~s}$, the power crosses the scram limit of $12 \mathrm{MW}$; the safety rods start moving into the core $0.1 \mathrm{~s}$ later. The peak power is 12.00 MW. The peak cladding surface temperature is $109.4^{\circ} \mathrm{C}$; this value is less than $8^{\circ} \mathrm{C}$ higher than its steady-state value; this peak value is well below the limit at which fuel damage might occur.

The calculated results for the first mixed HEU-LEU core are shown in Figures 3.4.3 and 3.4.4. The HEU and LEU components of power are shown in Figure 3.4.3; the peak cladding temperatures in the average HEU and LEU core channels are shown in Figure 3.4.4; normally these components will not be shown. The step reactivity insertion results in a sudden increase in power from 11 to $11.66 \mathrm{MW}$ over $0.07 \mathrm{~s}$. During this time the reactor period is as low as $1 \mathrm{~s}$; even though this is less than the $10 \mathrm{~s}$ limit reactor scram due to crossing this limit is ignored in the calculation. After the prompt jump, the power continues to increase but at a more gradual rate. After $5.6 \mathrm{~s}$, the power crosses the scram limit of $12 \mathrm{MW}$; the safety rods start moving into the core $0.1 \mathrm{~s}$ later. The peak power is $12.005 \mathrm{MW}$. The peak cladding surface temperature is $109.9^{\circ} \mathrm{C}$ in IRT-3M fuel and $96.7^{\circ} \mathrm{C}$ in IRT-4M fuel; these values are less than $4^{\circ} \mathrm{C}$ higher than their steady-state values; these peak values are well below the limit at which fuel damage might occur.

The calculated results for the full LEU core are shown in Figures 3.4.5 and 3.4.6. The step reactivity insertion results in a sudden increase in power from 10 to $11.51 \mathrm{MW}$ over $0.07 \mathrm{~s}$. During this time the reactor period is as low as $1 \mathrm{~s}$; even though this is less than the $10 \mathrm{~s}$ limit reactor scram due to crossing this limit is ignored in the calculation. After the prompt jump, the power continues to increase but at a more gradual rate. After $13.4 \mathrm{~s}$, the power crosses the scram limit of $12 \mathrm{MW}$; the safety rods start moving into the core $0.1 \mathrm{~s}$ later. The peak power is 12.00 MW. The peak cladding surface temperature is $98.6^{\circ} \mathrm{C}$; this value is less than $5^{\circ} \mathrm{C}$ higher than its steady-state value; this peak value is well below the limit at which fuel damage might occur. 
The large difference in timing between the full LEU case and the other two is that the full HEU core starts at an initial power of $10 \mathrm{MW}$; a $20 \%$ increase is required to cross the overpower trip setpoint of $12 \mathrm{MW}$. The mixed HEU-LEU and full LEU cores have the same $12 \mathrm{MW}$ overpower trip setpoint but this is only $9.1 \%$ larger than the $11 \mathrm{MW}$ initial power. This will be a factor in the timing for some of the other transients.
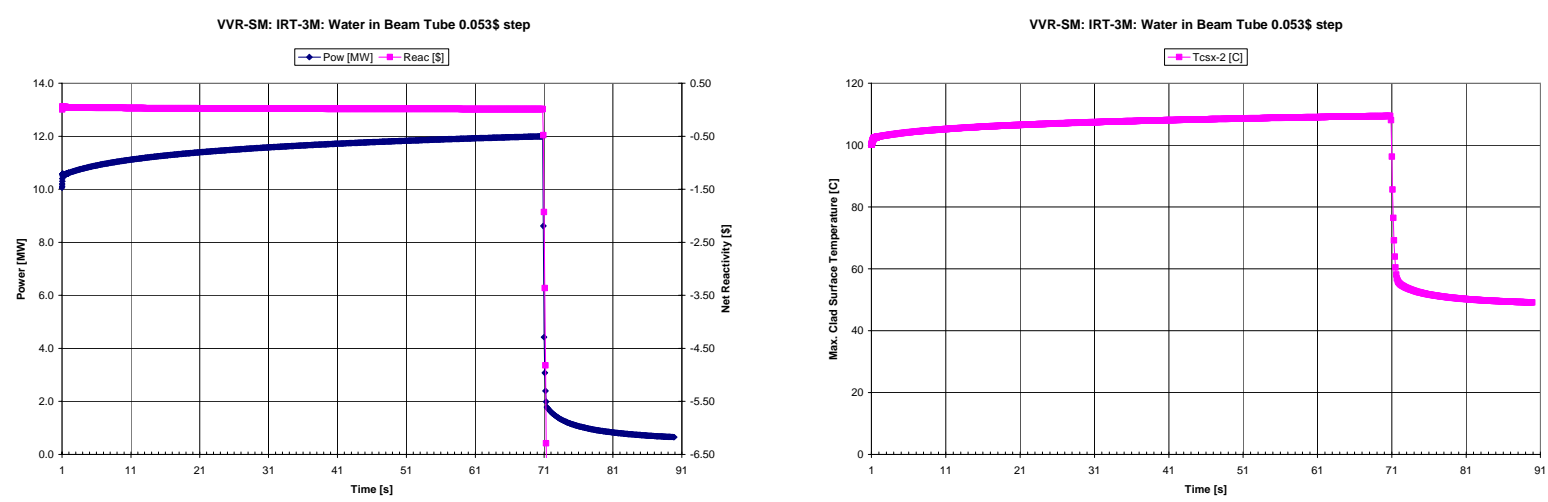

Figure 3.4.1 (left) and 3.4.2 (right) HEU Core PARET Results for Water Entry into Beam Tube
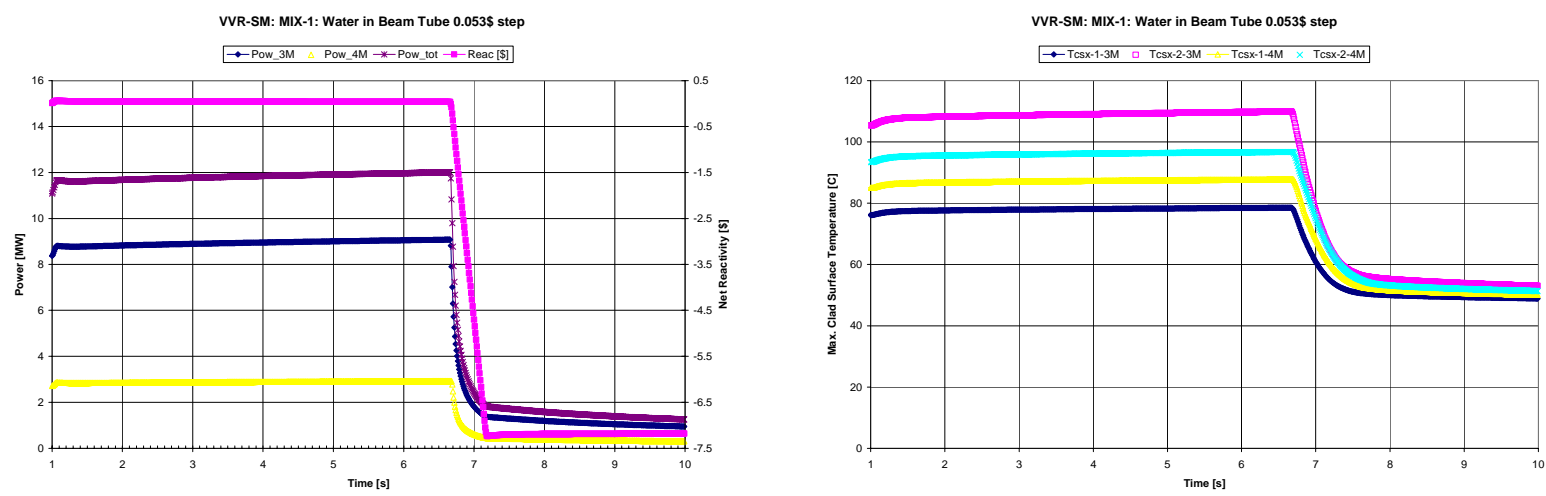

Figure 3.4.3 and 3.4.4 Mix1 Core PARET Results for Water Entry into Beam Tube
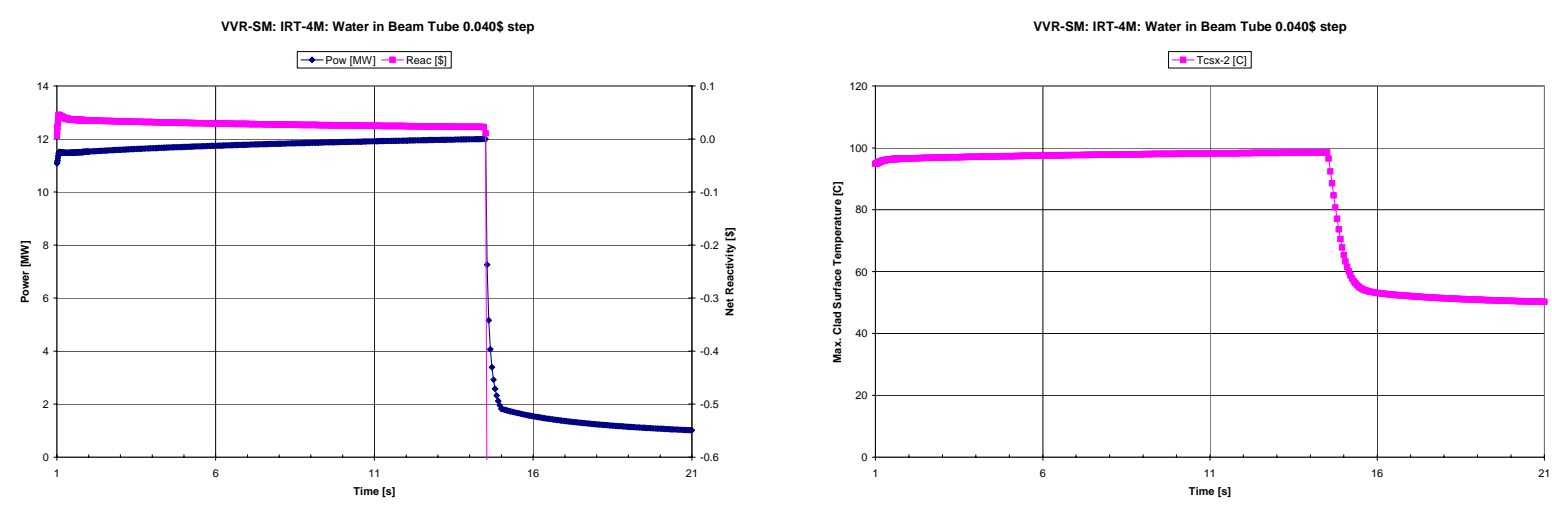

Figure 3.4.5 and 3.4.6 LEU Core PARET Results for Water Entry into Beam Tube 


\subsection{Accidental Upward Movement of Safety Rods}

\subsubsection{Boundary Conditions}

This case is discussed in Sec. 4.2.2.5 of the 2003 SAR. The initiator is sudden upward movement by $50 \mathrm{~mm}$ of the safety control rods, which are fully withdrawn during normal operation. In PARET, "sudden" is taken to be a time period of $0.05 \mathrm{~s}$. The reactivity introduced is $0.116 \$$ for the full HEU core, $0.105 \$$ for the first mixed HEU-LEU core, and $0.105 \$$ for the full LEU core.

\subsubsection{Results}

The calculated results for the full HEU core are shown in Figures 3.5.1 and 3.5.2. The step reactivity insertion results in a sudden increase in power from 10 to $11.29 \mathrm{MW}$ over $0.07 \mathrm{~s}$. During this time the reactor period is as low as $0.4 \mathrm{~s}$; even though this is less than the $10 \mathrm{~s}$ limit reactor scram due to crossing this limit is ignored in the calculation. After the prompt jump, the power continues to increase but at a more gradual rate. After $5.36 \mathrm{~s}$ the power crosses the scram limit of $12 \mathrm{MW}$; the safety rods start moving into the core $0.1 \mathrm{~s}$ later. The peak power is 12.01 MW. The peak cladding surface temperature is $109.4^{\circ} \mathrm{C}$; this value is less than $9{ }^{\circ} \mathrm{C}$ higher than its steady-state value; this peak value is well below the limit at which fuel damage might occur.

The calculated results for the first mixed HEU-LEU core are shown in Figures 3.5.3 and 3.5.4. The step reactivity insertion results in a sudden increase in power from 11 to $12.30 \mathrm{MW}$ over $0.07 \mathrm{~s}$. During this time the reactor period is as low as $0.5 \mathrm{~s}$; even though this is less than the $10 \mathrm{~s}$ limit reactor scram due to crossing this limit is ignored in the calculation. After the prompt jump, the power continues to increase but at a more gradual rate. After $0.05 \mathrm{~s}$ (i.e., during the prompt jump), the power crosses the scram limit of $12 \mathrm{MW}$; the safety rods start moving into the core $0.1 \mathrm{~s}$ later. The peak power is $12.30 \mathrm{MW}$. The peak cladding surface temperature is $108.1^{\circ} \mathrm{C}$ in IRT-3M fuel and $95.4^{\circ} \mathrm{C}$ in IRT-4M fuel; these values are less than $3^{\circ} \mathrm{C}$ higher than their steady-state values; these peak values are well below the limit at which fuel damage might occur.

The calculated results for the full LEU core are shown in Figures 3.5.5 and 3.5.6. The step reactivity insertion results in a sudden increase in power from 11 to $12.28 \mathrm{MW}$ over $0.07 \mathrm{~s}$. During this time the reactor period is as low as $0.5 \mathrm{~s}$; even though this is less than the $10 \mathrm{~s}$ limit reactor scram due to crossing this limit is ignored in the calculation. After the prompt jump, the power continues to increase but at a more gradual rate. After $0.05 \mathrm{~s}$ (i.e., during the prompt jump), the power crosses the scram limit of $12 \mathrm{MW}$; the safety rods start moving into the core $0.1 \mathrm{~s}$ later. The peak power is $12.28 \mathrm{MW}$. The peak cladding surface temperature is $96.7^{\circ} \mathrm{C}$; this value is less than $2{ }^{\circ} \mathrm{C}$ higher than its steady-state value; this peak value is well below the limit at which fuel damage might occur. 

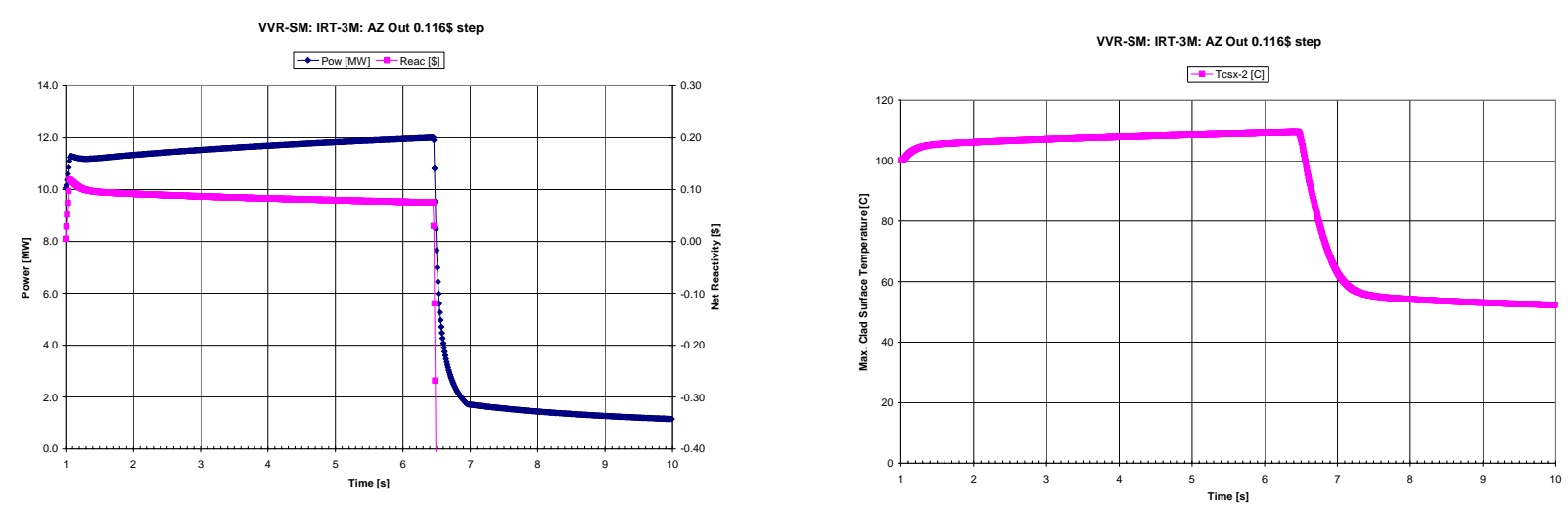

Figure 3.5.1 and 3.5.2 HEU Core PARET Results for Safety Rod Withdrawal
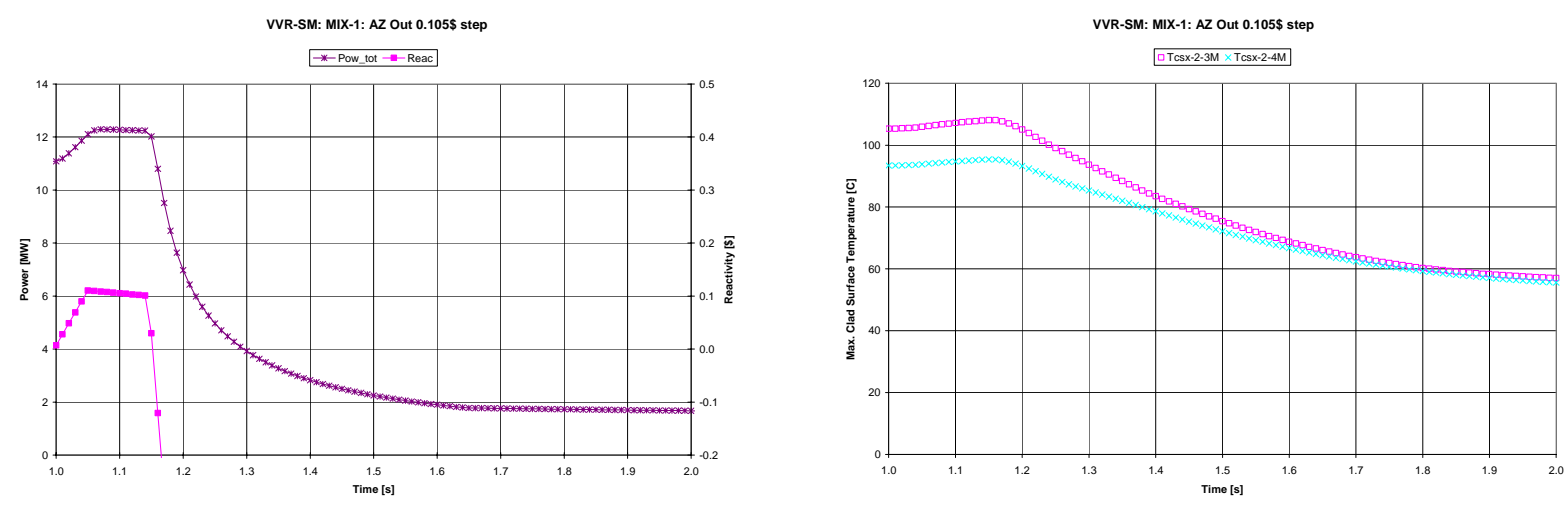

Figure 3.5.3 and 3.5.4 Mix1 Core PARET Results for Safety Rod Withdrawal
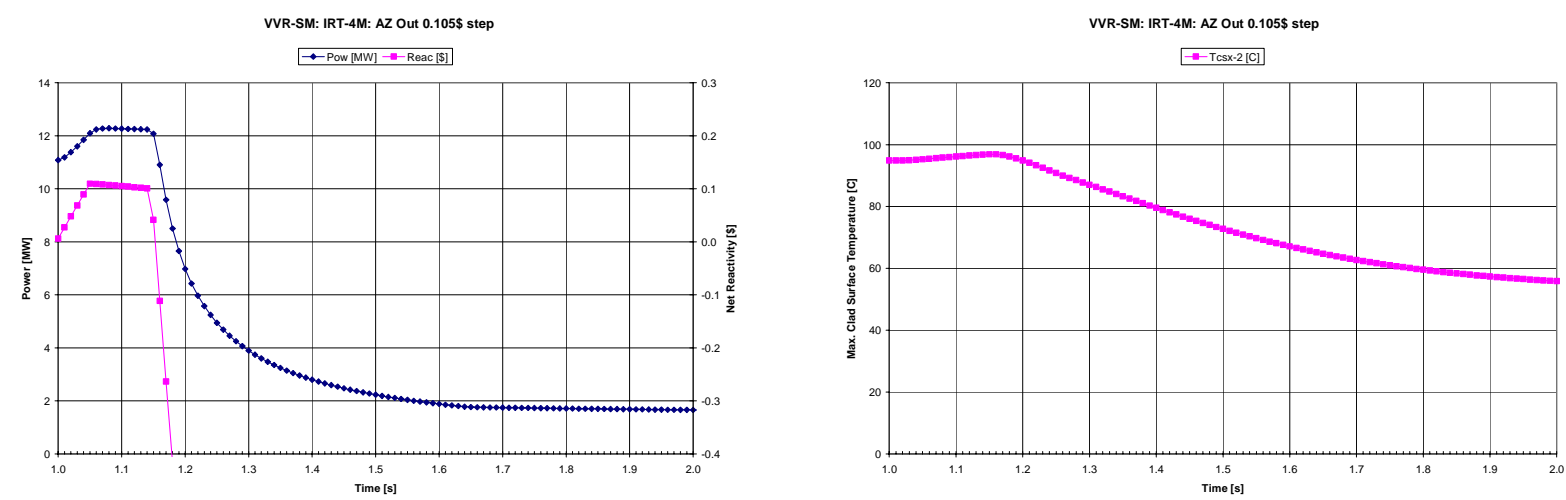

Figure 3.5.5.and 3.5.6 LEU Core PARET Results for Safety Rod Withdrawal 


\subsection{Accidental Upward Movement of Shim Rod}

\subsubsection{Boundary Conditions}

This case is discussed in Sec. 4.2.2.6 of the 2003 SAR. The initiator is upward movement by $25 \mathrm{~mm}$ (which is 1 step) of a shim control rod, which are partly withdrawn during normal operation, over $10 \mathrm{~s}$ (at normal rod movement speed). The reactivity introduced is $0.403 \$$ for the full HEU core, $0.368 \$$ for the first mixed HEU-LEU core, and $0.411 \$$ for the full LEU core.

\subsubsection{Results}

The calculated results for the full HEU core are shown in Figures 3.6.1 and 3.6.2. The gradual reactivity insertion results in a gradual increase in power from 10 to $12.0 \mathrm{MW}$, which is the scram limit, over $3.78 \mathrm{~s}$. During this time the reactor period is no lower than $17 \mathrm{~s}$, which is not low enough to cause a scram. Note that scram occurs before the entire reactivity can be inserted. The peak power is $12.07 \mathrm{MW}$. The peak cladding surface temperature is $109.2^{\circ} \mathrm{C}$; this value is less than $9^{\circ} \mathrm{C}$ higher than its steady-state value; this peak value is well below the limit at which fuel damage might occur.

The calculated results for the first mixed HEU-LEU core are shown in Figures 3.6.3 and 3.6.4. The gradual reactivity insertion results in a gradual increase in power from 11 to $12.0 \mathrm{MW}$, which is the scram limit, over $2.12 \mathrm{~s}$. During this time the reactor period is no lower than $23 \mathrm{~s}$, which is not low enough to cause a scram. Note that scram occurs before the entire reactivity can be inserted. The peak power is $12.05 \mathrm{MW}$. The peak cladding surface temperature is $109.7^{\circ} \mathrm{C}$ in IRT-3M fuel and $96.6^{\circ} \mathrm{C}$ in IRT-4M fuel; these values are less than $5^{\circ} \mathrm{C}$ higher than their steady-state values; these peak values are well below the limit at which fuel damage might occur.

The calculated results for the full LEU core are shown in Figures 3.6.5 and 3.6.6. The gradual reactivity insertion results in a gradual increase in power from 11 to $12.0 \mathrm{MW}$, which is the scram limit, over $1.94 \mathrm{~s}$. During this time the reactor period is no lower than $21 \mathrm{~s}$, which is not low enough to cause a scram. Note that scram occurs before the entire reactivity can be inserted. The peak power is $12.05 \mathrm{MW}$. The peak cladding surface temperature is $98.3^{\circ} \mathrm{C}$; this value is less than $4^{\circ} \mathrm{C}$ higher than its steady-state value; this peak value is well below the limit at which fuel damage might occur. 

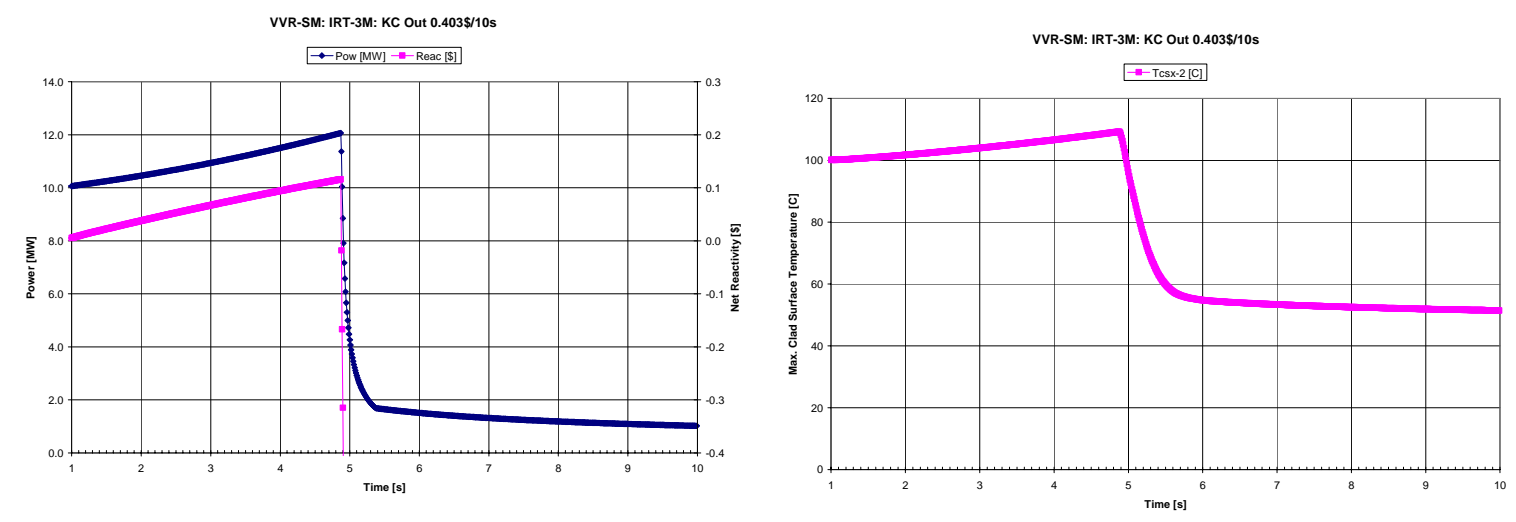

Figure 3.6.1 and 3.6.2 HEU Core PARET Results for Shim Rod Withdrawal
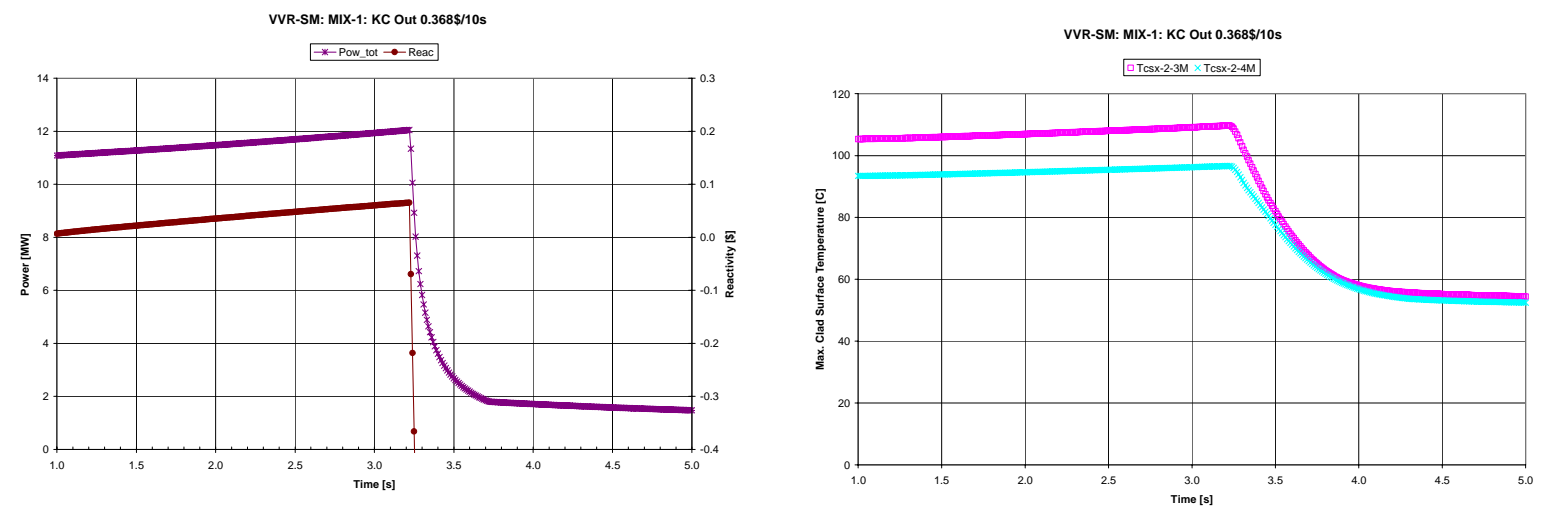

Figure 3.6.3 and 3.6.4 Mix1 Core PARET Results for Shim Rod Withdrawal
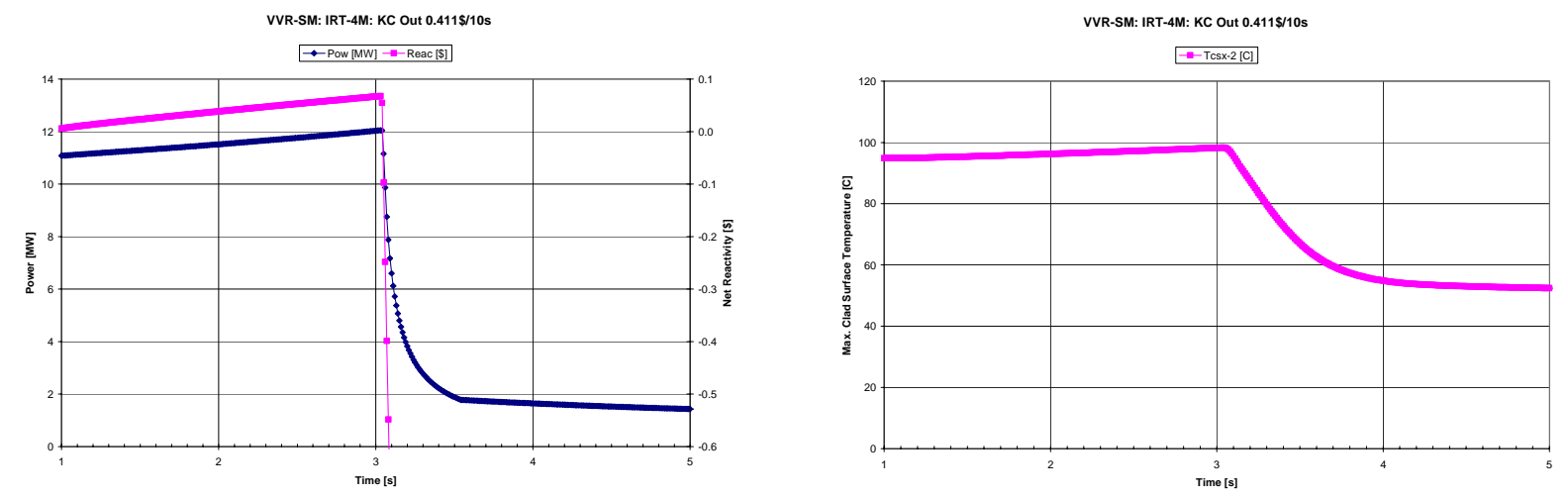

Figure 3.6.5 and 3.6.6 LEU Core PARET Results for Shim Rod Withdrawal 


\subsection{Ejection of Shim Rod}

\subsubsection{Boundary Conditions}

This case is discussed in Sec. 4.2.2.7 of the 2003 SAR, where the event is declared "unlikely" and no transient analysis is performed. The initiator is rapid upward movement of a shim control rod completely out of the core. The reactivity is taken to be half the worth of the rod pair KC-1 (or KC-2, whichever is bigger), which is partially withdrawn during normal operation. The reactivity introduced is 2.829 \$ for the full HEU core, $2.763 \$$ for the first mixed HEU-LEU core, and $3.092 \$$ for the full LEU core. The reactivity insertion is assumed to occur over $0.5 \mathrm{~s}$, which is the time required for full insertion of the safety rods during scram.

\subsubsection{Results}

The calculated results for the full HEU core are shown in Figures 3.7.1 and 3.7.2. The ramp reactivity insertion results in a ramp increase in power, rising above the $12 \mathrm{MW}$ trip limit in about $0.037 \mathrm{~s}$. During this time the reactor period is less than $0.2 \mathrm{~s}$; even though this is less than the $10 \mathrm{~s}$ limit reactor scram due to crossing this limit would have little effect on the calculation since the power limit is also reached very quickly. After crossing the trip limit, the power continues to increase. After a delay of $0.1 \mathrm{~s}$; the safety rods start moving into the core. The peak power is $28.6 \mathrm{MW}$. The peak cladding surface temperature is $126.1^{\circ} \mathrm{C}$; this value is less than $26^{\circ} \mathrm{C}$ higher than its steady-state value; this peak value is well below the limit at which fuel damage might occur.

The calculated results for the first mixed HEU-LEU core are shown in Figures 3.7.3 and 3.7.4. The ramp reactivity insertion results in a ramp increase in power, rising above the $12 \mathrm{MW}$ trip limit in about $0.022 \mathrm{~s}$. During this time the reactor period is less than $0.2 \mathrm{~s}$; even though this is less than the $10 \mathrm{~s}$ limit reactor scram due to crossing this limit would have little effect on the calculation since the power limit is also reached very quickly. After crossing the trip limit, the power continues to increase. After a delay of $0.1 \mathrm{~s}$; the safety rods start moving into the core. The peak power is $25.5 \mathrm{MW}$. The peak cladding surface temperature is $124.7^{\circ} \mathrm{C}$ in IRT-3M fuel and $108.6^{\circ} \mathrm{C}$ in IRT-4M fuel; these values are less than $20^{\circ} \mathrm{C}$ higher than their steady-state values; these peak values are well below the limit at which fuel damage might occur.

The calculated results for the full LEU core are shown in Figures 3.7.5 and 3.7.6. The ramp reactivity insertion results in a ramp increase in power, rising above the $12 \mathrm{MW}$ trip limit in about $0.020 \mathrm{~s}$. During this time the reactor period is less than $0.2 \mathrm{~s}$; even though this is less than the $10 \mathrm{~s}$ limit reactor scram due to crossing this limit would have little effect on the calculation since the power limit is also reached very quickly. After crossing the trip limit, the power continues to increase. After a delay of $0.1 \mathrm{~s}$; the safety rods start moving into the core. The peak power is $29.0 \mathrm{MW}$. The peak cladding surface temperature is $115.3^{\circ} \mathrm{C}$; this value is less than $21^{\circ} \mathrm{C}$ higher than its steady-state value; this peak value is well below the limit at which fuel damage might occur. 
VVR-SM: IRT-3M: KC Eject 2.829\$10.55

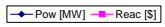

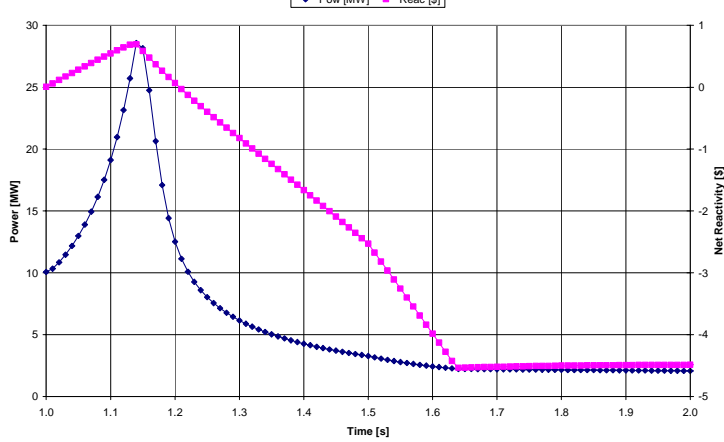

VVR-SM: IRT-3M: KC Eject 2.829\$10.55

- Tcsx:2[C]

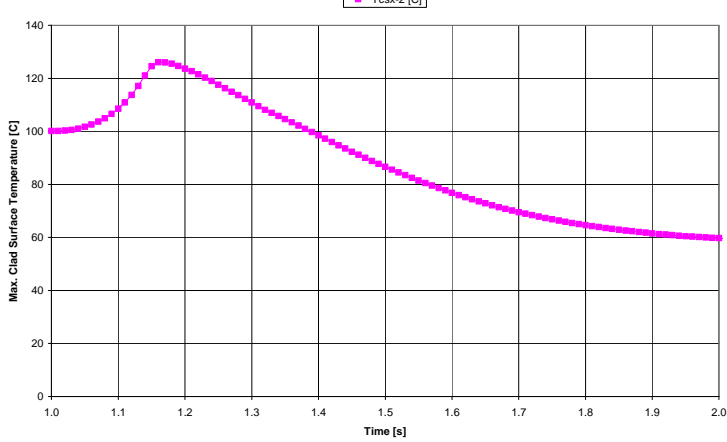

Figure 3.7.1 and 3.7.2 HEU Core PARET Results for Shim Rod Ejection
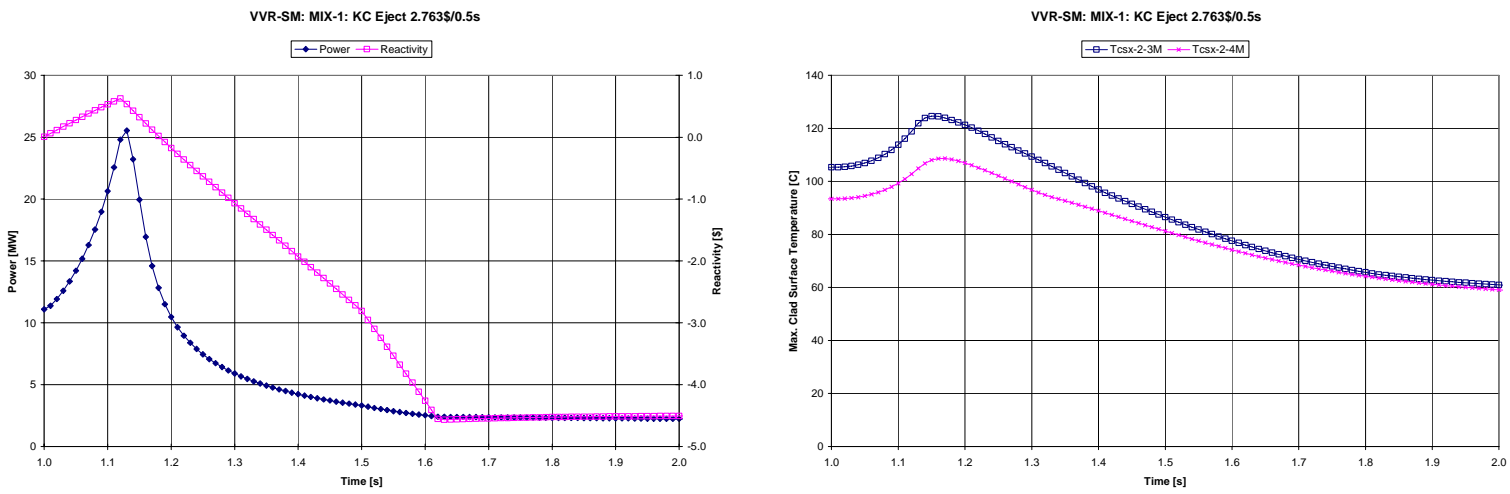

Figure 3.7.3 and 3.7.4 Mix1 Core PARET Results for Shim Rod Ejection
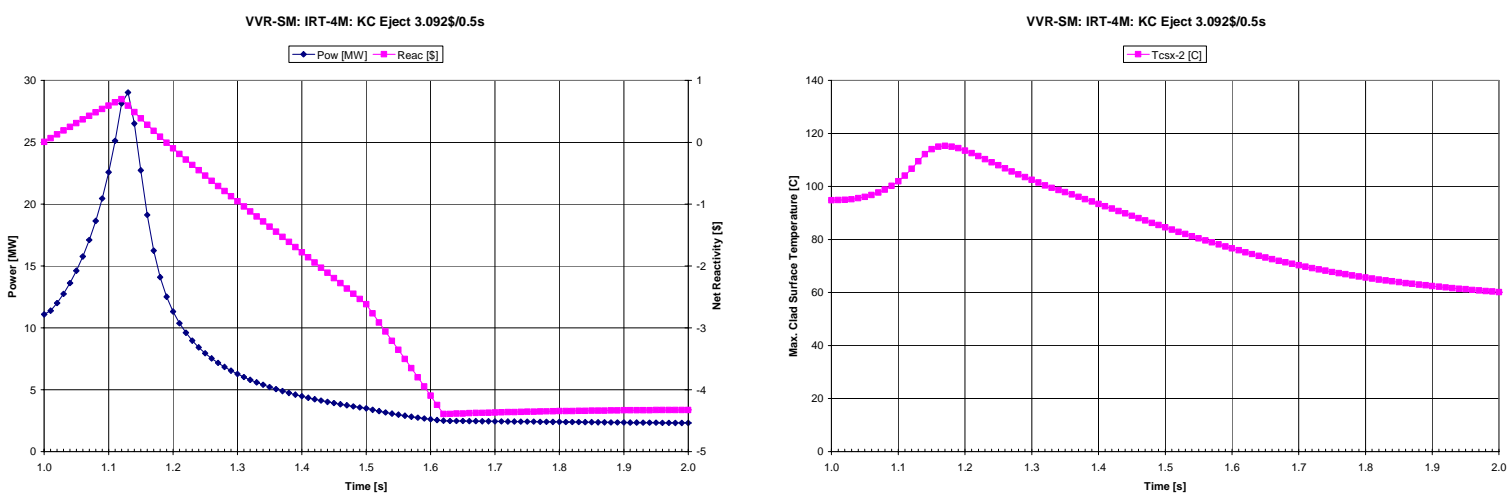

Figure 3.7.5 and 3.7.6 LEU Core PARET Results for Shim Rod Ejection 


\subsection{Loss of Control Rod Follower}

\subsubsection{Boundary Conditions}

This case is not discussed in the 2003 SAR. The shim and safety control rods in VVR-SM have a "follower" portion made of aluminum which is below the boron-containing portion. The initiator is separation of the follower from the rod and its subsequent downward movement, which allows additional water to enter the core space where the follower used to be. The reactivity is taken to be for the highest worth follower and is $0.553 \$$ for the full HEU core, $0.421 \$$ for the first mixed HEU-LEU core, and $0.640 \$$ for the full LEU core. The reactivity insertion is assumed to occur linearly over $0.5 \mathrm{~s}$, which assumes that the follower drops at the same speed as the safety rods during scram.

\subsubsection{Results}

The calculated results for the full HEU core are shown in Figures 3.8.1 and 3.8.2. The ramp reactivity insertion results in a ramp increase in power, rising above the $12 \mathrm{MW}$ trip limit in about $0.17 \mathrm{~s}$. During this time the reactor period is less than $0.9 \mathrm{~s}$; even though this is less than the $10 \mathrm{~s}$ limit reactor scram due to crossing this limit would have little effect on the calculation since the power limit is also reached very quickly. After crossing the trip limit, the power continues to increase. After a delay of $0.1 \mathrm{~s}$; the safety rods start moving into the core. The peak power is $13.4 \mathrm{MW}$. The peak cladding surface temperature is $108.4^{\circ} \mathrm{C}$; this value is less than $9^{\circ} \mathrm{C}$ higher than its steady-state value; this peak value is well below the limit at which fuel damage might occur.

The calculated results for the first mixed HEU-LEU core are shown in Figures 3.8.3 and 3.8.4. The ramp reactivity insertion results in a ramp increase in power, rising above the $12 \mathrm{MW}$ trip limit in about $0.11 \mathrm{~s}$. During this time the reactor period is less than $1.2 \mathrm{~s}$; even though this is less than the $10 \mathrm{~s}$ limit reactor scram due to crossing this limit would have little effect on the calculation since the power limit is also reached very quickly. After crossing the trip limit, the power continues to increase. After a delay of $0.1 \mathrm{~s}$; the safety rods start moving into the core. The peak power is $13.0 \mathrm{MW}$. The peak cladding surface temperature is $109.3^{\circ} \mathrm{C}$ in IRT-3M fuel and $96.2^{\circ} \mathrm{C}$ in IRT-4M fuel; these values are less than $4^{\circ} \mathrm{C}$ higher than their steady-state values; these peak values are well below the limit at which fuel damage might occur.

The calculated results for the full LEU core are shown in Figures 3.8.5 and 3.8.6. The ramp reactivity insertion results in a ramp increase in power, rising above the $12 \mathrm{MW}$ trip limit in about $0.07 \mathrm{~s}$. During this time the reactor period is less than $0.8 \mathrm{~s}$; even though this is less than the $10 \mathrm{~s}$ limit reactor scram due to crossing this limit would have little effect on the calculation since the power limit is also reached very quickly. After crossing the trip limit, the power continues to increase. After a delay of $0.1 \mathrm{~s}$; the safety rods start moving into the core. The peak power is $13.7 \mathrm{MW}$. The peak cladding surface temperature is $98.3^{\circ} \mathrm{C}$; this value is less than $4^{\circ} \mathrm{C}$ higher than its steady-state value; this peak value is well below the limit at which fuel damage might occur. 

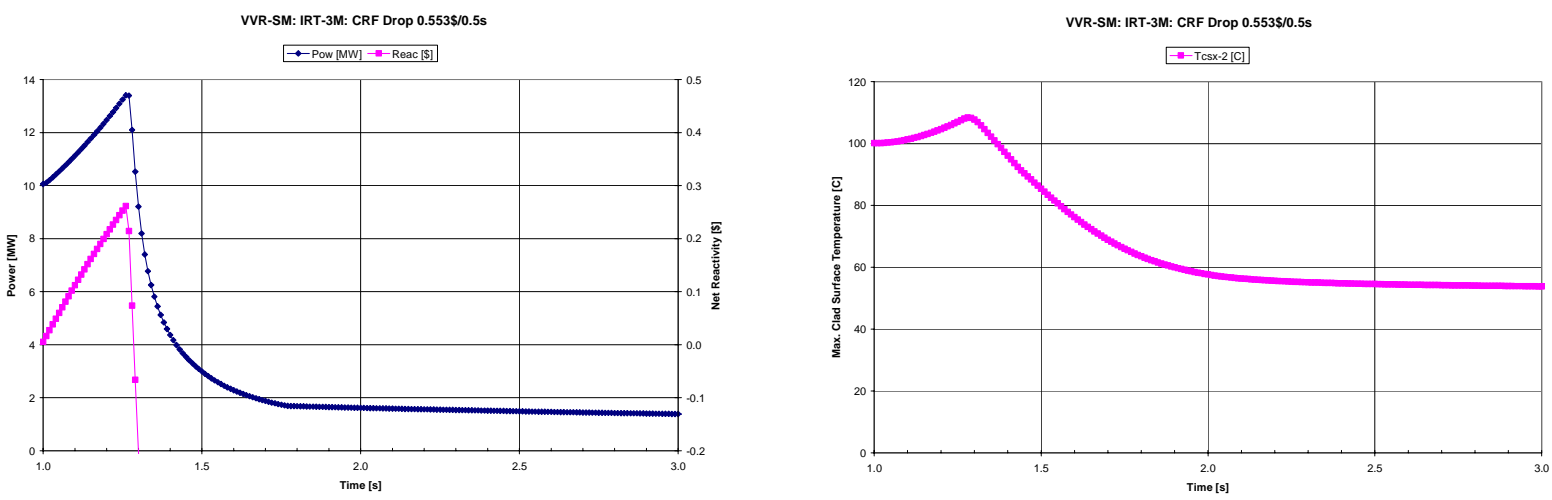

Figure 3.8.1 and 3.8.2 HEU Core PARET Results for Shim Rod Follower Loss
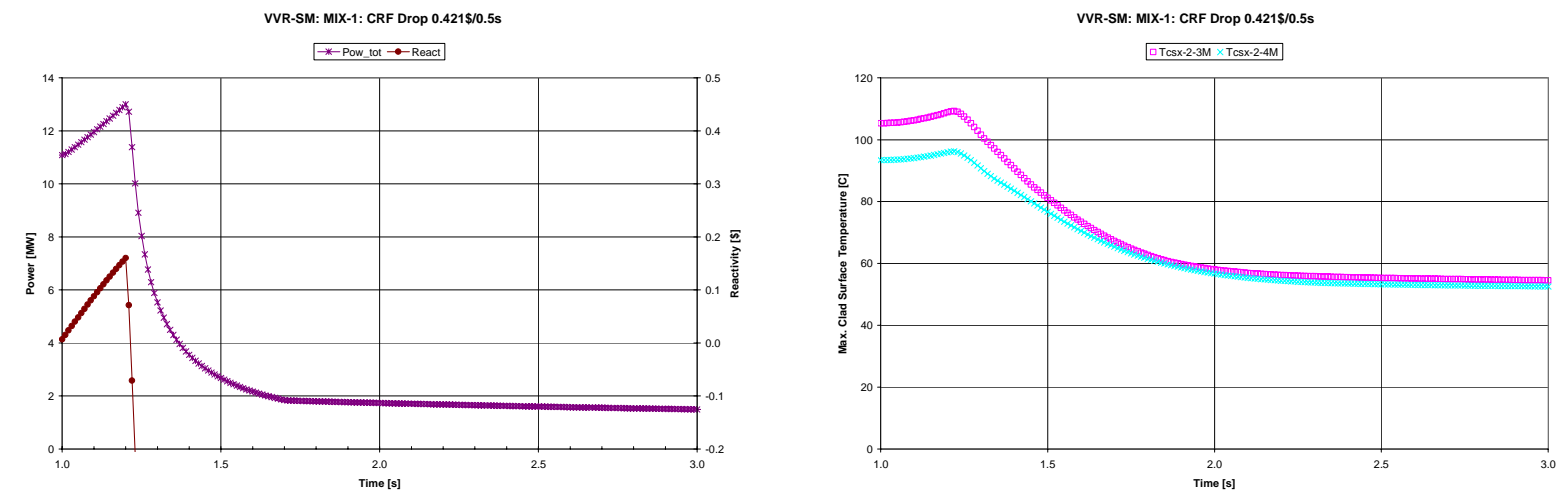

Figure 3.8.3 and 3.8.4 Mix1 Core PARET Results for Shim Rod Follower Loss
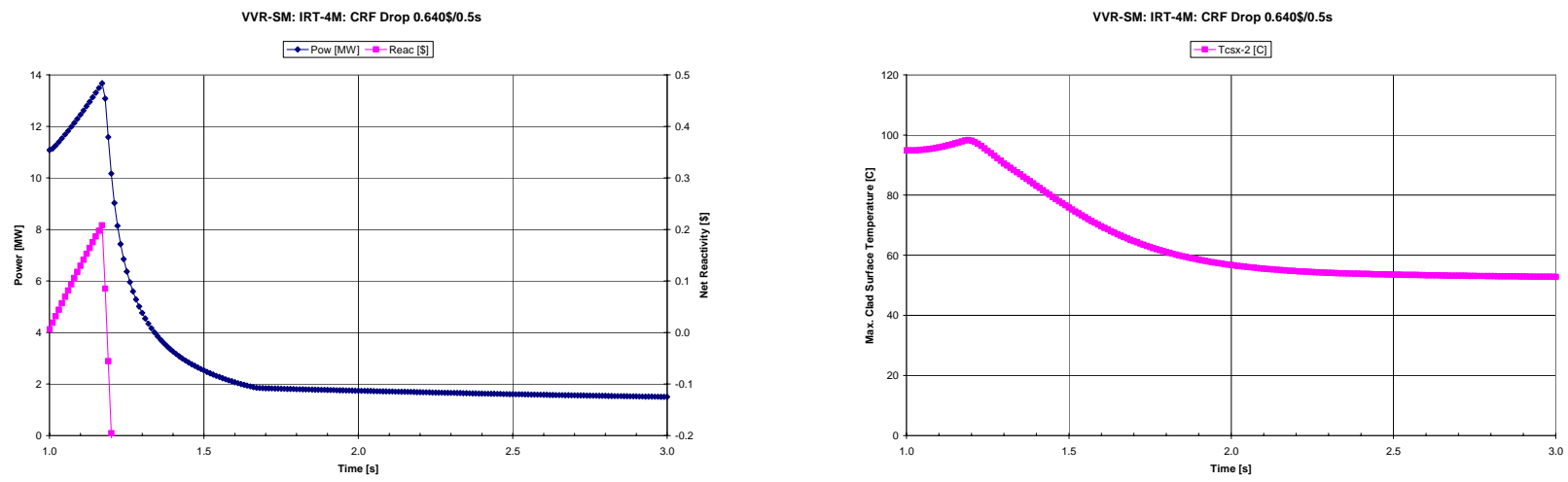

Figure 3.8.5 and 3.8.6 LEU Core PARET Results for Shim Rod Follower Loss 


\subsection{Lockup of Shim Rod}

This case is discussed in Section 4.2.2.8 of the 2003 SAR. Sticking of a shim rod was stated to be unlikely due to the control rod diameter of $23 \mathrm{~mm}$ being sufficiently less than the $26 \mathrm{~mm}$ diameter of guide opening. The operator would recognize the lack of motion during operation and make a decision.

The possibility of shim rod sticking is included in the analyses presented here since the motion of all shim rods during scram has been ignored. No additional analysis is required. 


\subsection{Continuous Withdrawal of Automatic Power Control Rod}

\subsubsection{Boundary Conditions}

This case is discussed in Section 4.2.2.12 of the 2003 SAR. The initiator is degradation of electrical insulation which causes a false reading of "power decreasing". The automatic power control (APC) system will withdraw the AR control rod to counteract the apparent power decrease. Actual reactor power will increase. If not discovered and acted upon by the operators, the reactor will trip on high power, which uses different power sensing than the APC. Nominally, $350 \mathrm{~mm}$ of AR is inserted in the core; this gives a maximum withdrawable reactivity of $0.383 \$$ for the full HEU core, $0.420 \$$ for the first mixed HEU-LEU core, and $0.362 \$$ for the full LEU core. The AR is assumed to move upward from its location at its normal speed of $10 \mathrm{~mm} / \mathrm{s}$; complete withdrawal would require $35 \mathrm{~s}$. Reactivity is added as function of time using the position-dependent relative worths shown in Table 2.4.2.

\subsubsection{Results}

The calculated results for the full HEU core are shown in Figures 3.10.1 and 3.10.2. The ramp reactivity insertion results in a ramp increase in power, rising above the $12 \mathrm{MW}$ trip limit in about $7.36 \mathrm{~s}$. During this time the reactor period is greater than $33 \mathrm{~s}$; therefore, scram would not occur earlier due to being below the $10 \mathrm{~s}$ limit. After crossing the trip limit, the power continues to increase. After a delay of $0.1 \mathrm{~s}$; the safety rods start moving into the core. The peak power is 12.03 MW. The peak cladding surface temperature is $109.3^{\circ} \mathrm{C}$; this value is less than $10^{\circ} \mathrm{C}$ higher than its steady-state value; this peak value is well below the limit at which fuel damage might occur.

The calculated results for the first mixed HEU-LEU core are shown in Figures 3.10.3 and 3.10.4. The ramp reactivity insertion results in a ramp increase in power, rising above the $12 \mathrm{MW}$ trip limit in about $3.53 \mathrm{~s}$. During this time the reactor period is greater than $37 \mathrm{~s}$; therefore, scram would not occur earlier due to being below the $10 \mathrm{~s}$ limit. After crossing the trip limit, the power continues to increase. After a delay of $0.1 \mathrm{~s}$; the safety rods start moving into the core. The peak power is $12.03 \mathrm{MW}$. The peak cladding surface temperature is $109.8^{\circ} \mathrm{C}$ in IRT-3M fuel and $96.7^{\circ} \mathrm{C}$ in IRT-4M fuel; these values are less than $5^{\circ} \mathrm{C}$ higher than their steady-state values; these peak values are well below the limit at which fuel damage might occur.

The calculated results for the full LEU core are shown in Figures 3.10.5 and 3.10.6. The ramp reactivity insertion results in a ramp increase in power, rising above the $12 \mathrm{MW}$ trip limit in about $3.96 \mathrm{~s}$. During this time the reactor period is greater than $41 \mathrm{~s}$; therefore, scram would not occur earlier due to being below the $10 \mathrm{~s}$ limit. After crossing the trip limit, the power continues to increase. After a delay of $0.1 \mathrm{~s}$; the safety rods start moving into the core. The peak power is 12.03 MW. The peak cladding surface temperature is $98.4^{\circ} \mathrm{C}$; this value is less than $4{ }^{\circ} \mathrm{C}$ higher than its steady-state value; this peak value is well below the limit at which fuel damage might occur. 
VVR-SM: IRT-3M: AR Rod 0.383s/35s

$\rightarrow-$ Pow [MW] - Reac [S]

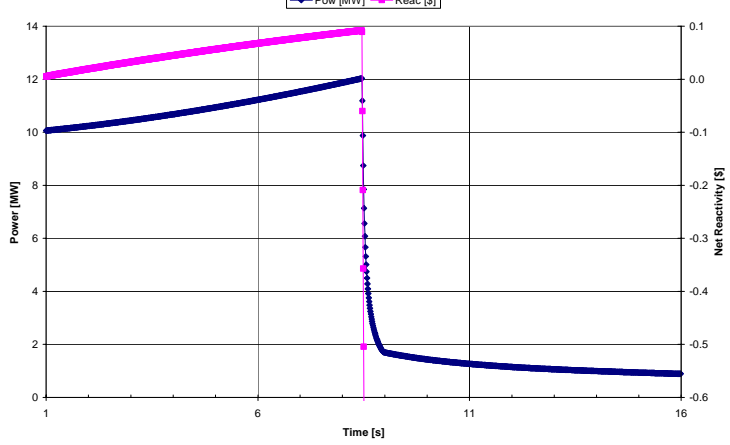

VVR-SM: IRT-3M: AR Rod 0.383\$/35

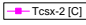

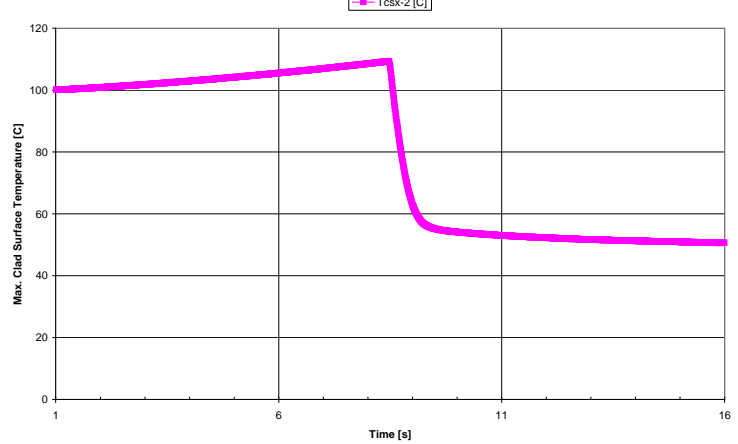

Figure 3.10.1 and 3.10.2 HEU Core PARET Results for Automatic Power Rod Withdrawal
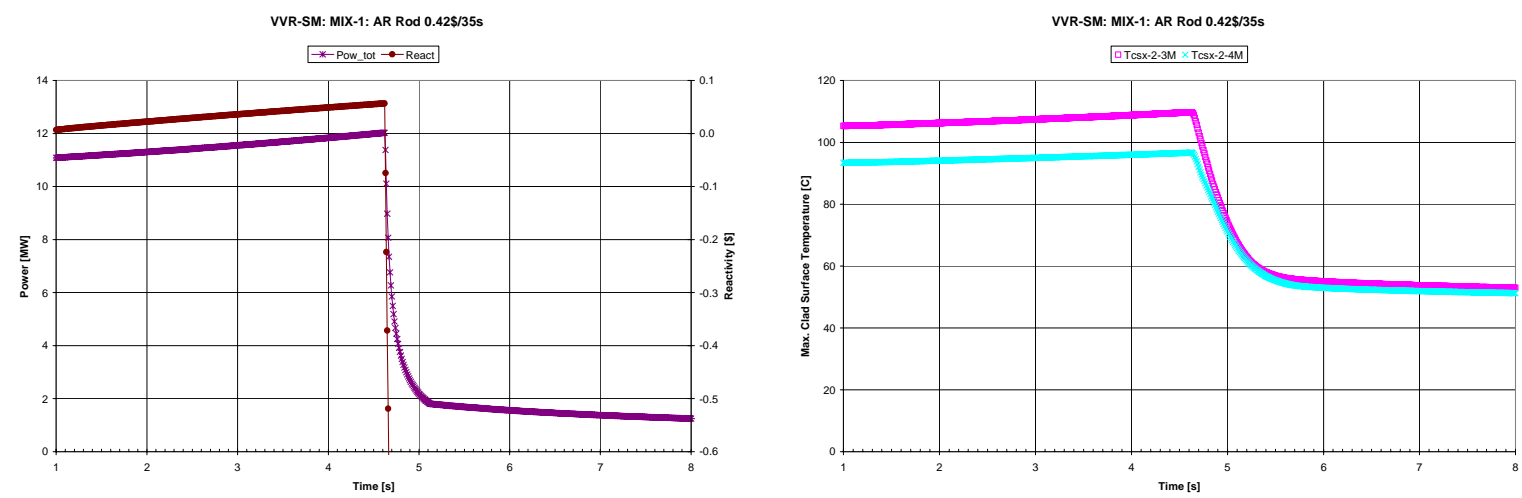

Figure 3.10.3 and 3.10.4 Mix1 Core PARET Results for Automatic Power Rod Withdrawal
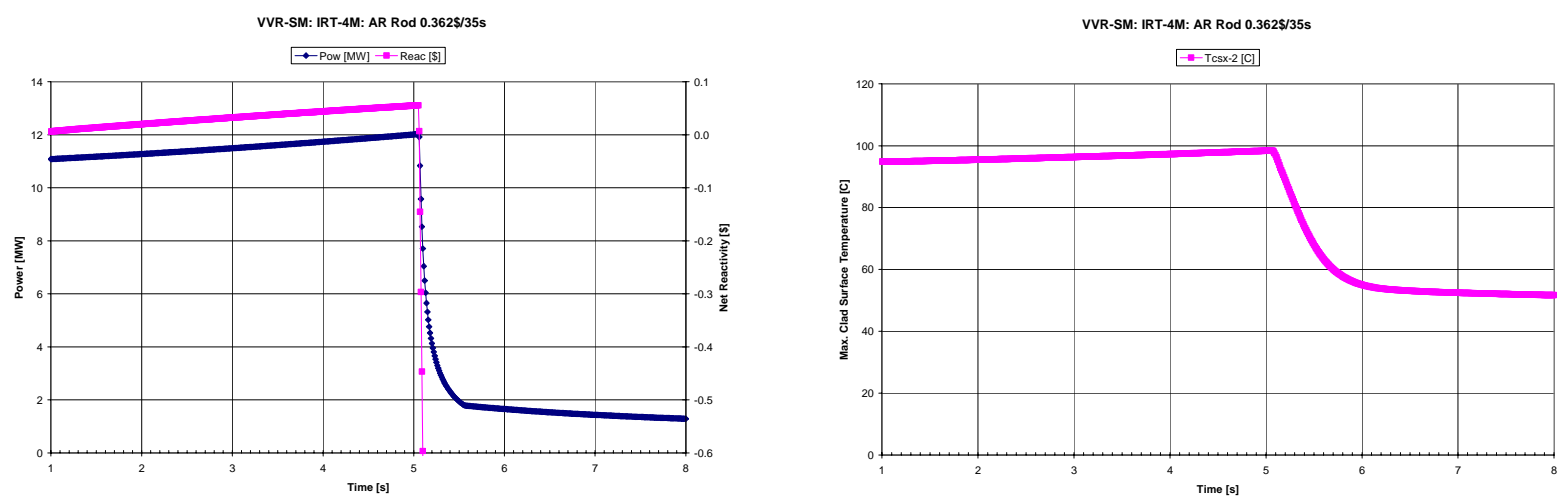

Figure 3.10.5 and 3.10.6 LEU Core PARET Results for Automatic Power Rod Withdrawal 


\subsection{Loss of Primary Coolant Pumps}

\subsubsection{Boundary Conditions}

This case is discussed in Section 4.2.3.1 of the 2003 SAR. The initiator is loss of offsite electrical power. The loss of power causes an immediate reactor scram (which will be a $0.1 \mathrm{~s}$ delay in PARET). The primary coolant pumps (3 are normally operating) decrease to zero flow over 4 s. A small battery-operated pump (BOP, to be installed in fall 2007) provides continuous flow of $100 \mathrm{~m}^{3} / \mathrm{h}$ in the primary circuit. (A diesel-generator would start within $15 \mathrm{~s}$, which would allow quick restoration of power to critical systems but this is ignored in the current analysis.) In PARET input terms, the relative coolant flow decreases from 1 to 100/1250 over $4 \mathrm{~s}$; the decrease is shown in Table 3.11.1

Table 3.11.1 Pump Coastdown During Loss of Offsite Power

\begin{tabular}{|l|l|l|l|l|l|l|l|l|l|}
\hline Time [s] & 0 & 0.5 & 1 & 1.5 & 2 & 2.5 & 3 & 3.5 & 4 \\
\hline Flow [-] & 1 & 0.68 & 0.51 & 0.41 & 0.32 & 0.25 & 0.19 & 0.12 & 0.08 \\
\hline
\end{tabular}

The operability of the BOP is an important feature in the analysis of this transient. This aspect of the reactor facility design has been changed several times. An earlier configuration had one of the main coolant pumps on battery at all times. A later configuration had removed the battery. The current facility has a $20 \mathrm{~m}^{3} / \mathrm{h}$ BOP scavenged from elsewhere in the facility. The future design will have a small (but not insignificant) flow BOP; if INP fails to install the $100 \mathrm{~m}^{3} / \mathrm{h}$ BOP then the loss of offsite power situation will need to be analyzed using different assumptions. Without some sort of reliable pump to provide some coolant flow, there would likely be coolant boiling in portions of the core during some portion of this transient.

\subsubsection{Results}

The calculated results for the full HEU core are shown in Figures 3.11.1 and 3.11.2. The decrease in coolant flow rate at constant (actually, slightly decreasing) power leads to an initial increase in temperature, peaking at $100.9^{\circ} \mathrm{C}$; this value is less than $1^{\circ} \mathrm{C}$ higher than its steadystate value. After a delay of $0.1 \mathrm{~s}$; the safety rods start moving into the core. After about $1.3 \mathrm{~s}$, the flow decrease outpaces the power decrease, resulting in a minimum in temperature, $61.8^{\circ} \mathrm{C}$. The coolant flow reaches its minimum value $4 \mathrm{~s}$ into the transient. After about $7.3 \mathrm{~s}$, the cladding surface temperature has a second peak of $90.6^{\circ} \mathrm{C}$; this value is much less than its steady-state value. All peak temperatures are well below the limit at which fuel damage might occur.

The calculated results for the first mixed HEU-LEU core are shown in Figures 3.11.3 and 3.11.4. The decrease in coolant flow rate at constant (actually, slightly decreasing) power leads to an initial increase in temperature, peaking at $106.2^{\circ} \mathrm{C}$ in IRT-3M fuel and $94.0^{\circ} \mathrm{C}$ in IRT-4M fuel; these values are less than $1^{\circ} \mathrm{C}$ higher than their steady-state values. After a delay of $0.1 \mathrm{~s}$; the safety rods start moving into the core. After about $1.4 \mathrm{~s}$, the flow decrease outpaces the power decrease, resulting in a minimum in temperature, $63.5^{\circ} \mathrm{C}$ in IRT-3M fuel and $60.1^{\circ} \mathrm{C}$ in IRT-4M fuel. The coolant flow reaches its minimum value $4 \mathrm{~s}$ into the transient. After about $7.9 \mathrm{~s}$, the cladding surface temperature has a second peak of $94.2^{\circ} \mathrm{C}$ in IRT-3M fuel and $85.7^{\circ} \mathrm{C}$ in IRT-4M 
fuel; these values are much less than their steady-state values. All peak temperatures are well below the limit at which fuel damage might occur.

The calculated results for the full LEU core are shown in Figures 3.11.5 and 3.11.6. The decrease in coolant flow rate at constant (actually, slightly decreasing) power leads to an initial increase in temperature, peaking at $95.4^{\circ} \mathrm{C}$; this value is less than $1{ }^{\circ} \mathrm{C}$ higher than its steady-state value. After a delay of $0.1 \mathrm{~s}$; the safety rods start moving into the core. After about $1.5 \mathrm{~s}$, the flow decrease outpaces the power decrease, resulting in a minimum in temperature, $60.7^{\circ} \mathrm{C}$. The coolant flow reaches its minimum value $4 \mathrm{~s}$ into the transient. After about $7.9 \mathrm{~s}$, the cladding surface temperature has a second peak of $86.5^{\circ} \mathrm{C}$; this value is much less than its steady-state value. All peak temperatures are well below the limit at which fuel damage might occur. 
VVR-SM: IRT-3M: LOPS 3 Pump to 1 BOP in $4 \mathrm{~s}$

$\rightarrow-P_{0 w}[\mathrm{MW}]-\mathrm{m}-\mathrm{Reac}[\mathrm{s}]$

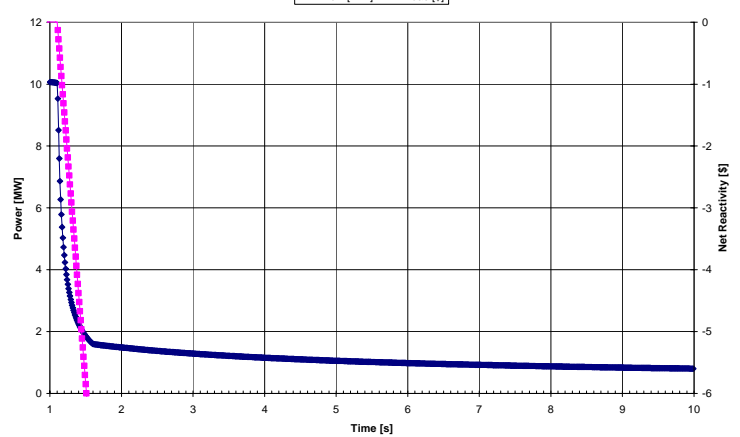

VVR-SM: IRT-3M: LOPS 3 Pump to 1 BOP in $4 \mathrm{~s}$

- Tcsx-2[C]

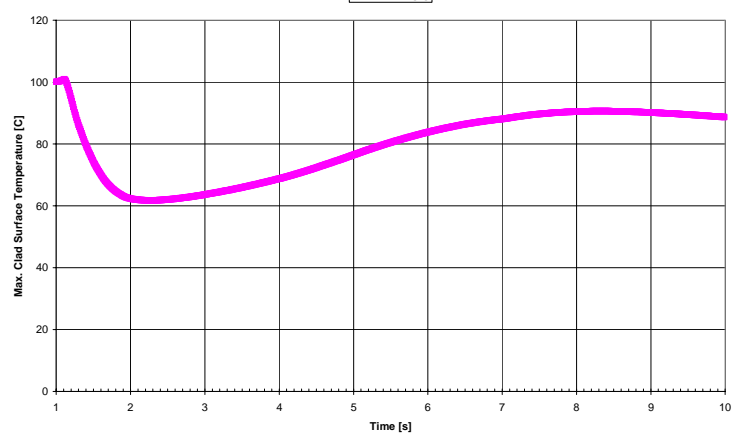

Figure 3.11.1 and 3.11.2 HEU Core PARET Results for Loss of Offsite Power
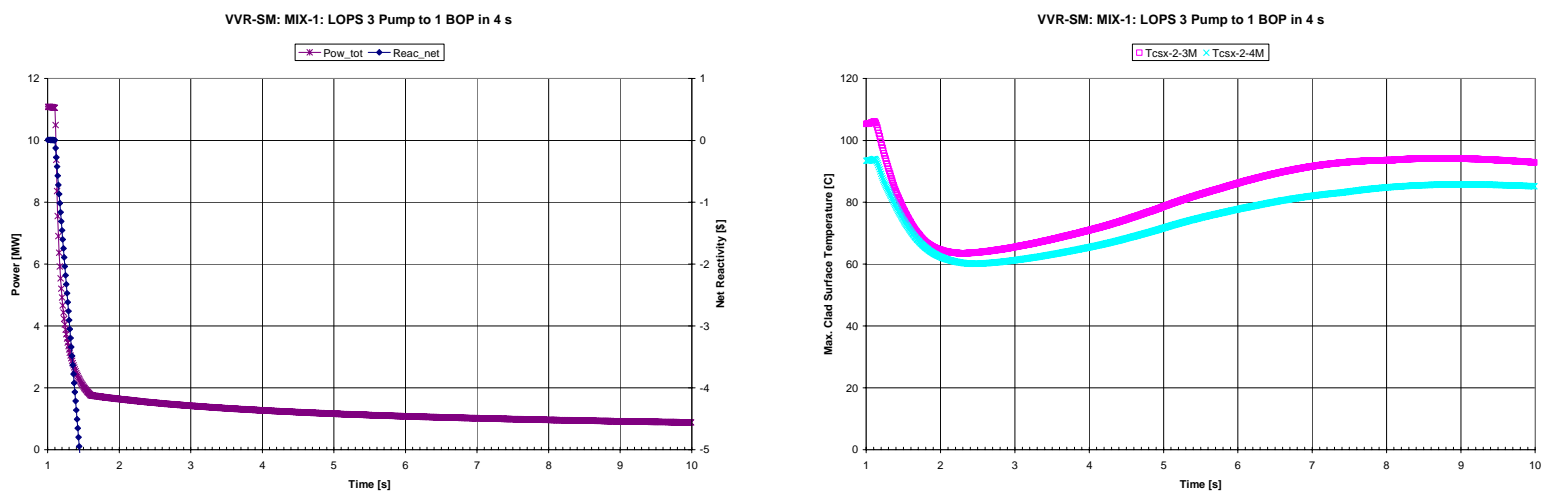

Figure 3.11.3 and 3.11.4 Mix1 Core PARET Results for Loss of Offsite Power

VVR-SM: IRT-4M: LOPS 3 Pump to 1 BOP in $4 \mathrm{~s}$

$\rightarrow-$ Pow [MW] - Reac [\$]

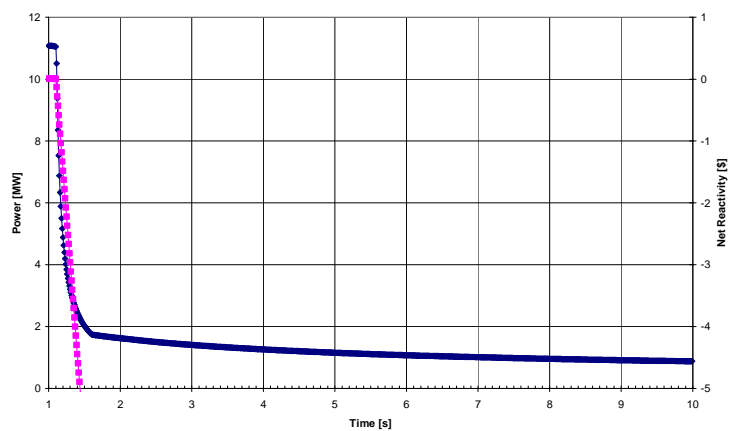

VVR-SM: IRT-4M: LOPS 3 Pump to 1 BOP in $4 \mathrm{~s}$

- Tcsx-2[C]

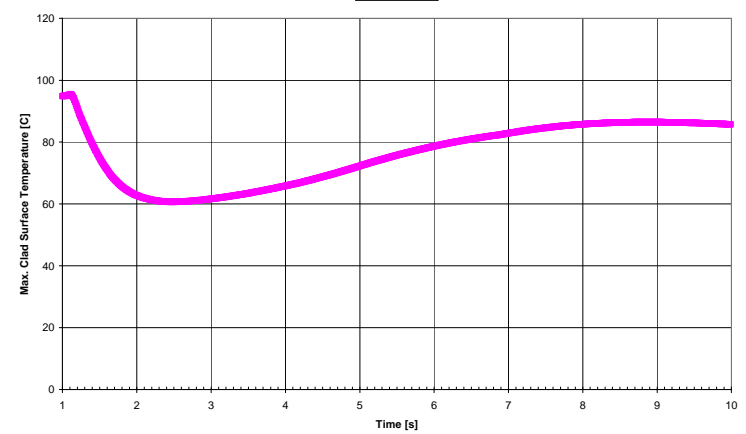

Figure 3.11.5 and 3.11.6 LEU Core PARET Results for Loss of Offsite Power 


\subsection{Loss of One Primary Coolant Pump}

\subsubsection{Boundary Conditions}

This case is discussed in Section 4.2.3.5 of the 2003 SAR. The initiator is closing of shutoff valve to one pump. One primary coolant pump (3 are normally operating) decreases to zero flow over $4 \mathrm{~s}$. In PARET input terms, the relative coolant flow decreases from 1 to $2 / 3$ over $4 \mathrm{~s}$; the decrease is shown in Table 3.12.1. Scram will occur when total primary relative flow is below 0.8 ; this occurs $1.2 \mathrm{~s}$ after start of flow decrease.

Table 3.12.1 Pump Coastdown During Loss of One Pump

\begin{tabular}{|l|l|l|l|l|l|l|l|l|l|}
\hline Time [s] & 0 & 0.5 & 1 & 1.5 & 2 & 2.5 & 3 & 3.5 & 4 \\
\hline Flow [-] & 1 & 0.89 & 0.82 & 0.77 & 0.74 & 0.71 & 0.70 & 0.68 & 0.67 \\
\hline
\end{tabular}

\subsubsection{Results}

The calculated results for the full HEU core are shown in Figures 3.12.1 and 3.12.2. The decrease in coolant flow rate gives an increase in temperature which is a negative reactivity feedback which leads to lower power. Scram occurs $0.1 \mathrm{~s}$ after flow decreases below 0.8 . The peak clad temperature of $107.7^{\circ} \mathrm{C}$ occurs at this time; this value is less than $8^{\circ} \mathrm{C}$ higher than its steady-state value. The peak temperature is well below the limit at which fuel damage might occur.

The calculated results for the first mixed HEU-LEU core are shown in Figures 3.12.3 and 3.12.4. The decrease in coolant flow rate gives an increase in temperature which is a negative reactivity feedback which leads to lower power. Scram occurs $0.1 \mathrm{~s}$ after flow decreases below 0.8 . The peak clad temperatures occur at this time: $113.7^{\circ} \mathrm{C}$ in IRT-3M fuel and $99.4^{\circ} \mathrm{C}$ in IRT-4M fuel; these values are less than $9^{\circ} \mathrm{C}$ higher than their steady-state values. The peak temperatures are well below the limit at which fuel damage might occur.

The calculated results for the full LEU core are shown in Figures 3.12.5 and 3.12.6. The decrease in coolant flow rate gives an increase in temperature which is a negative reactivity feedback which leads to lower power. Scram occurs $0.1 \mathrm{~s}$ after flow decreases below 0.8 . The peak clad temperature of $101.5^{\circ} \mathrm{C}$ occurs at this time; this value is less than $7^{\circ} \mathrm{C}$ higher than its steady-state value. The peak temperature is well below the limit at which fuel damage might occur. 

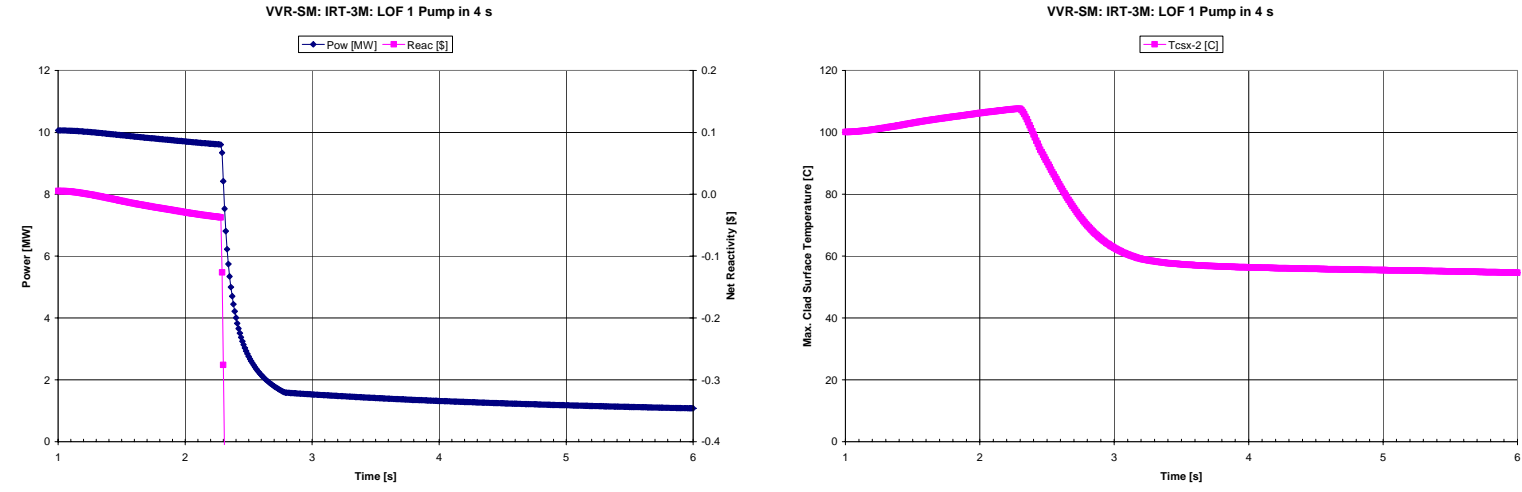

Figure 3.12.1 and 3.12.2 HEU Core PARET Results for Loss of One Primary Pump
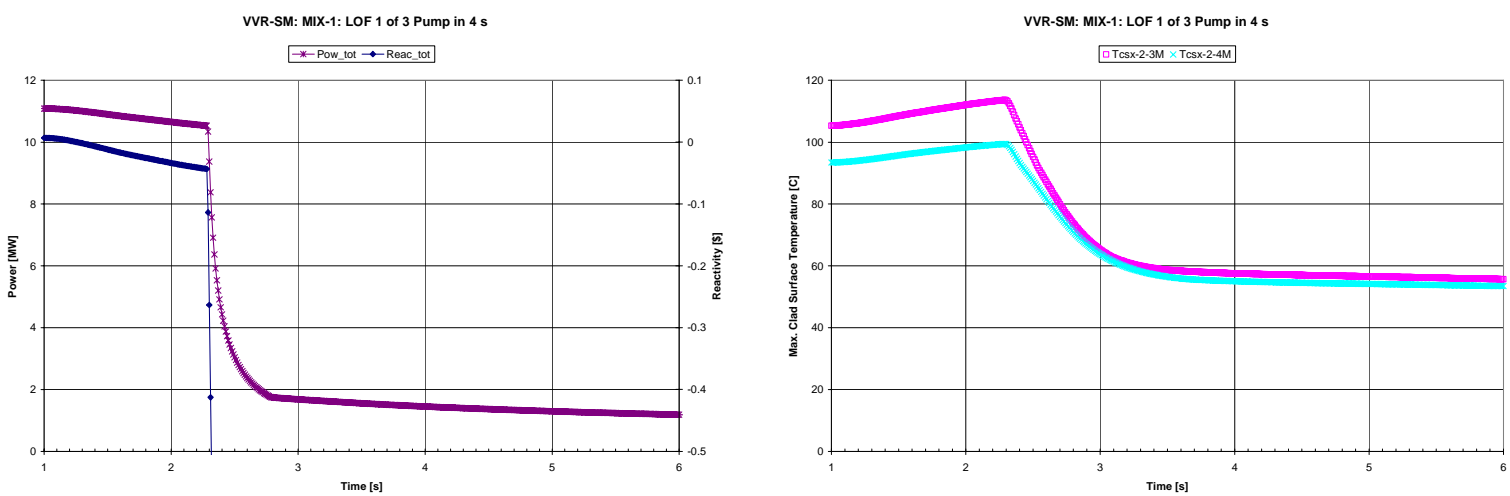

Figure 3.12.3 and 3.12.4 Mix1 Core PARET Results for Loss of One Primary Pump
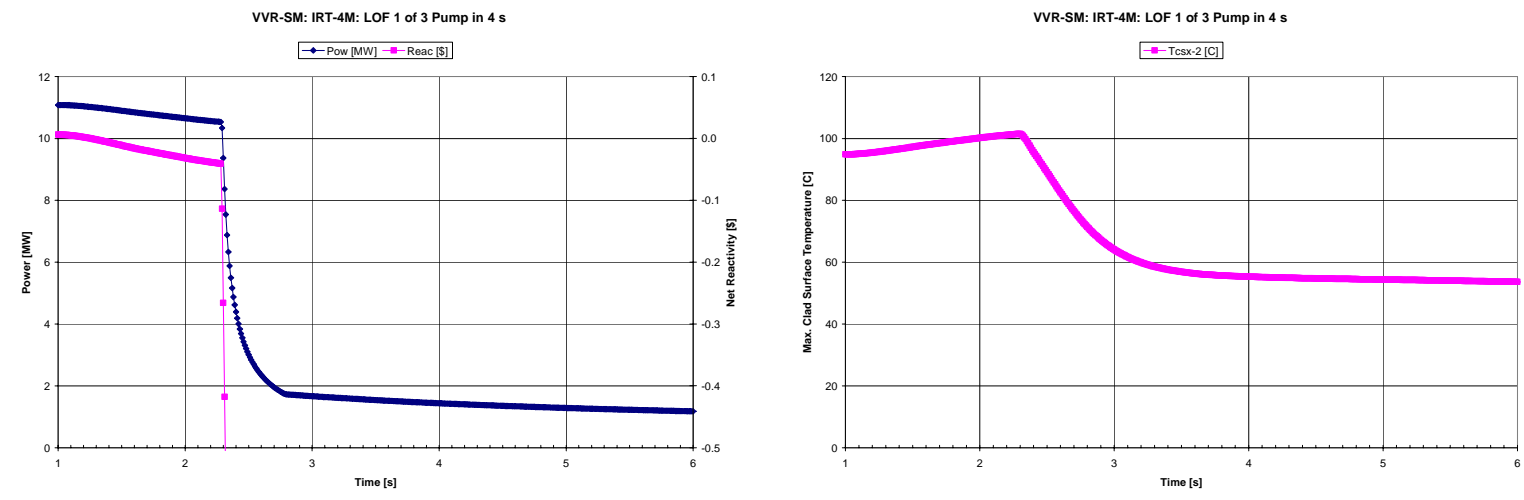

Figure 3.12.5 and 3.12.6 LEU Core PARET Results for Loss of One Primary Pump 


\subsubsection{Modified Boundary Conditions}

After performing the above calculations and while preparing this report, a closer reading of Ref. 1 reveals that the initiator for this transient is supposed to be instantaneous valve closure, which would result in flow decrease in time much shorter than the $4 \mathrm{~s}$ used here. Since power is approximately constant before scram, it is the time of scram relative the rate of flow decrease which determines how much temperatures increase. A faster flow decrease would result in an earlier scram time (still based on $80 \%$ flow) but a faster temperature increase than shown in Sec. 3.12.2.

An additional loss of 1 pump calculation has been performed for the full LEU core assuming a flow decrease time of $0.4 \mathrm{~s}$ instead of $4 \mathrm{~s}$. The flow crosses the $80 \%$ trip set point $0.12 \mathrm{~s}$ after start of the flow decrease. The maximum cladding surface temperature in the hot channel is shown in Figure 3.12.7. The peak is $100.1^{\circ} \mathrm{C}$ at $0.24 \mathrm{~s}$ after start of flow decrease, which is slightly lower than the $101.5^{\circ} \mathrm{C}$ peak in the $4 \mathrm{~s}$ flow decrease case. There is no need to run additional PARET cases to demonstrate the safety aspects of this modified case for the other core configurations.

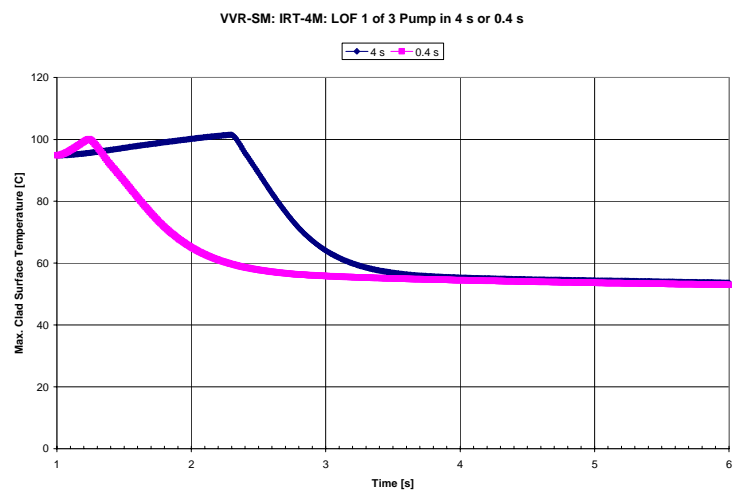

Figure 3.12.7 LEU Core PARET Results for Loss of One Primary Pump over $4 \mathrm{~s}$ and $0.4 \mathrm{~s}$ 


\subsection{Double-Ended Rupture of Primary Coolant Pipe}

\subsubsection{Boundary Conditions}

This case is discussed in Section 4.2.3.2 of the 2003 SAR. The initiator is complete breakage of the primary coolant outlet pipe. The breakage location is not specified; if double-ended then the worst place to break the pipe is just below the point where this pipe connects to the bottom of the reactor vessel. The mechanism leading to pipe breakage is not specified. There are a series of responses as this accident progresses.

Reactor scram will be initiated due to one or more of the following safety system settings being crossed: primary pressure decrease by $10 \%$, primary coolant flow decrease by $20 \%$, core pressure drop decrease by $20 \%$, or central tank water level decrease by $0.3 \mathrm{~m}$.

When water level in the reactor central tank is lower than $2.7 \mathrm{~m}$ (which corresponds to $1 \mathrm{~m}$ above the core), valves 71 and 61 will be opened automatically and water from the distilled water storage tanks (DWST) will enter into the reactor tank through the shower device of core emergency spraying system. The volume of each DWST is $10 \mathrm{~m}^{3}$ and there are 4 tanks for a total of $40 \mathrm{~m}^{3}$. The tanks are mounted in the reactor building above the reactor vessel elevation. Water flows from the tanks to the shower device by gravity with a flow rate of $15 \mathrm{~m}^{3} / \mathrm{h}$. There are several ways to supply additional water to the DWSTs.

Water flowing out of reactor tank is collected in the leakage-collection channel located in the floor of primary-loop pump station. When the water level in leakage-collection channel reaches $0.7 \mathrm{~m}$, one of two emergency spraying pumps (ESP) will be turned on to return water into the central tank through separate shower device of core emergency spraying system with flow rate $20 \mathrm{~m}^{3} / \mathrm{h}$. After turning on pump to return water into reactor tank and developing corresponding pressure valves 71 and 61 will be closed automatically which precludes flow of water from DWSTs.

The goal of either of these two supplies of emergency spray system water is to provide sufficient water on surface of fuel elements to remove the decay-level of power generation and prevent the fuel from being damaged (e.g., stay below melting temperature). This cooling process may change part of the liquid water to water vapor (i.e., steam).

In case the water supplied to emergency spraying system from leakage-collection channel increases above temperature of $80^{\circ} \mathrm{C}$, valves 71 and 61 will open automatically and the water for core spraying will be supplied simultaneously from the DWSTs and the leakage-collection channel. As water temperature decreases below $80^{\circ} \mathrm{C}$, valves 61 and 71 will close automatically and the water will be supplied to the emergency spraying system by ESPs only from leakagecollection channel. If DWST reserves are depleted, the water to the core emergency spraying system will be supplied from the service water system or from the second loop. There is a possibility to supply service water also from fire-protection supply pipe or from fire engine (which is on site). 
Other interactions between the various systems are as follows. If $1^{\text {st }}$ ESP turns off then the $2^{\text {nd }}$ ESP will start automatically continuing to supply emergency spray from leakage-collection channel; there are corresponding indicators on the operator console. If $2^{\text {nd }}$ ESP turns off then valves 61 and 71 will open automatically to supply emergency spray from DWSTs; there are corresponding indicators on the operator console. The operators can also engage or disengage these systems manually. The refill of DWSTs from service water or fire engine (drawing water from basin of cooling tower) require manual operator actions.

The PARET code is not able to compute transient progression of the loss-of-coolant accident (LOCA). Two aspects of the LOCA can be analyzed on an approximate basis using other techniques: (1) estimate the time to empty the reactor vessel and (2) estimate the minimum flow rate of water (through the shower device) required to remove heat from the core after draining.

\subsubsection{Vessel Emptying Time}

A Bernoulli-type approach shows that the velocity $V_{3}$ of water exiting a hole of area $S_{3}$ in the bottom of a large diameter tank of water is

$$
\mathrm{V}_{3}=\left(2 * \mathrm{~g} * \mathrm{H}_{1}\right)^{0.5}
$$

where $\mathrm{g}$ is the acceleration due to gravity $\left(9.8 \mathrm{~m} / \mathrm{s}^{2}\right)$ and $\mathrm{H}_{1}$ is the height of water above the hole. The nominal height of water in the VVR-SM reactor vessel is about $7 \mathrm{~m}$; the corresponding exit velocity is $11.7 \mathrm{~m} / \mathrm{s}$. The exit hole is the $0.35 \mathrm{~m}$ diameter primary coolant pipe having a flow area $\mathrm{S}_{3}$ of $0.0962 \mathrm{~m}^{2}$; coolant is therefore leaving the reactor vessel at an initial rate of $1.13 \mathrm{~m}^{3} / \mathrm{s}$ (or $4060 \mathrm{~m}^{3} / \mathrm{h}$ which is about 3.2 times the normal primary coolant flow rate of $1250 \mathrm{~m}^{3} / \mathrm{h}$ ). The water loss rate would decrease in time as the water level decreases; this decrease is neglected in this analysis; using the highest water loss rate is a conservative approach in terms of safety analysis since it gives shorter times for vessel emptying.

The portion of the central tank which is above the core is $1.1 \mathrm{~m}$ in diameter and has a height of $4.7 \mathrm{~m}$. When the water level drops $0.3 \mathrm{~m}$, a trip signal will be generated on low water level; this requires a water loss of $0.3 \mathrm{~m}^{3}$; this will occur in $0.25 \mathrm{~s}$ if the loss rate is $1.13 \mathrm{~m}^{3} / \mathrm{s}$. When the water level drops to $1 \mathrm{~m}$ above core, the spray system is activated; this requires a water loss of $3.5 \mathrm{~m}^{3}$; this will occur in $3.1 \mathrm{~s}$ if the loss rate is $1.13 \mathrm{~m}^{3} / \mathrm{s}$. Core uncovery starts when water level has decreased $4.7 \mathrm{~m}$; this will occur in $4.0 \mathrm{~s}$ if the loss rate is $1.13 \mathrm{~m}^{3} / \mathrm{s}$. The reactor vessel has a diameter of $0.652 \mathrm{~m}$ and a height of approximately $1 \mathrm{~m}$; when water has drained from this additional volume, the fuel is completely uncovered; this will occur in an additional $0.2 \mathrm{~s}$ if the loss rate is $1.13 \mathrm{~m}^{3} / \mathrm{s}$.

With fuel uncovery occurring so quickly, systems must act automatically as they are designed to do in order to provide emergency cooling to the core when required. Note that the initial water loss rate of about $4100 \mathrm{~m}^{3} / \mathrm{h}$ is 200 to 275 times larger than the 20 and $15 \mathrm{~m}^{3} / \mathrm{h}$ rates stated for emergency spray flow. Therefore, a double-ended break of the primary coolant pipe will lead to core uncovery - the emergency sprays do not provide refill of the vessel, merely a cooling mechanism. 


\subsubsection{Shutdown Core Cooling}

After loss of normal coolant from the core a shower cooling of FA is provided by a film of water which is flowing down on the surface of the fuel elements. When this film is present the temperature of fuel elements differs slightly from the temperature of boiling water. When there is insufficient flow of water down on fuel elements the water evaporates before reaching the bottom of the FA; thus the lower part of fuel elements will be cooled only by steam (i.e., water vapor) and can heat up to higher temperature.

The minimum flow of water required for a given energy release is defined by equality of energy generation in FA and heat absorbed by the flow of falling water in the FA. The heating of water is from its temperature at inlet to FA up to temperature of saturation, and then additional energy is absorbed causing evaporation of water to form steam. The case of full vaporization corresponds to the minimum water supply. The energy balance may be expressed as

$$
\mathrm{G}_{\min }=\mathrm{Q} /\left\{\mathrm{N} *\left[\mathrm{C}_{\mathrm{p}} *\left(\mathrm{~T}_{\mathrm{sat}}-\mathrm{T}_{\mathrm{in}}\right)+\mathrm{h}_{\mathrm{fg}}\right]\right\},
$$

where $\mathrm{G}_{\min }$ is the minimum mass flow rate $[\mathrm{kg} / \mathrm{s}]$ of water required to cool one $\mathrm{FA}, \mathrm{Q}$ is the core power [W], N is the number of FAs, $\mathrm{C}_{\mathrm{p}}$ is the specific heat capacity $[4.2 \mathrm{~kJ} / \mathrm{kg}-\mathrm{C}]$ of liquid water, $\mathrm{T}_{\text {sat }}$ and $\mathrm{T}_{\mathrm{in}}$ are the saturation $\left[105^{\circ} \mathrm{C}\right]$ and inlet $\left[45^{\circ} \mathrm{C}\right]$ temperature of water, respectively, and $\mathrm{h}_{\mathrm{fg}}$ is the heat of vaporization $[2.256 \mathrm{MJ} / \mathrm{kg}]$ of water.

The rapidly decreasing water level will generate a trip $0.25 \mathrm{~s}$ after the pipe break; therefore, the reactor will be at decay power when the spray cooling starts a few seconds later. The relative core power after long-term operation [Ref. 14] is $6.2 \%$ after $1 \mathrm{~s}, 3.3 \%$ after $100 \mathrm{~s}$, and $1 \%$ after 2.2 hours. For illustration, the required coolant flow will be based on the power at $1 \mathrm{~s}$; from Eq. 3.13.2 one can see that the coolant flow scales linearly with core power, so that less coolant flow is required at later times. The specific numbers from here onward depend on the specific core.

Unlike other sections of this report, the analysis for the first mixed core will be presented first as the method is explained. This will be followed by a single paragraph each for the full HEU and full LEU cores presenting the changed values.

The first mixed HEU-LEU core has a nominal power of $11 \mathrm{MW}$; the decay power at $1 \mathrm{~s}$ is $0.682 \mathrm{MW}$. Divide the total power by the number of FA, which is $20(=\mathrm{N})$, to get average power of $0.0341 \mathrm{MW}$ per FA.

One must be able to cool the hottest channel of FA not just the average FA; therefore, increase the power for 1 FA by 2 factors:

1. Peak/Average for FA to FA variation; this is 1.33 in first mixed core.

2. Peak/Average for tube to tube variation within peak FA; this is 1.23 in first mixed core. Multiply these two factors: $1.33 * 1.23=1.64$.

Apply the combined peaking factor to average power gives the power which needs to be removed from $1 \mathrm{FA}$ with peaking is $0.0559 \mathrm{MW}$ at $1 \mathrm{~s}$ in order to prevent fuel heating. Use this value for $\mathrm{Q} / \mathrm{N}$ in Eq. 3.13.2. 
Note that the heat of vaporization dominates the denomination of Eq. 3.13.2 because we have assume full vaporization of the water. For this core, the flow rate required to cool $1 \mathrm{FA}$ is $0.022 \mathrm{~kg} / \mathrm{s}$ or $0.084 \mathrm{~m}^{3} / \mathrm{h}$ (using liquid water density of $960 \mathrm{~kg} / \mathrm{m}^{3}$ ).

Look at the spray flow, which is stated to be $15 \mathrm{~m}^{3} / \mathrm{h}$ from DWST and $20 \mathrm{~m}^{3} / \mathrm{h}$ from ESP. A certain portion of the spray water is assume to go somewhere other than the reactor vessel (due to divergence of spray from nozzle); this is assumed to be $20 \%$; this leaves $80 \%$ or $12 \mathrm{~m}^{3} / \mathrm{h}$ (if from DWST) and $16 \mathrm{~m}^{3} / \mathrm{h}$ (if from ESP) spray flow into interior of reactor vessel.

Assume that within the reactor vessel the distribution of spray water is uniform; thus each FA gets an amount of flow based on its total (not flow) cross sectional area (square with $71.5 \mathrm{~mm}$ on a side, or $0.005112 \mathrm{~m}^{2}$ ) relative to the total cross sectional area in the reactor vessel (circle with $0.652 \mathrm{~m}$ diameter, or $0.334 \mathrm{~m}^{2}$ area), which is an area factor of 0.0153 . Multiply by 12 or $16 \mathrm{~m}^{3} / \mathrm{h}$ flow to reactor vessel gives 0.184 (if from DWST) or $0.245 \mathrm{~m}^{3} / \mathrm{h}$ (if from ESP) to 1 FA. This exceeds the required flow of $0.084 \mathrm{~m}^{3} / \mathrm{h}$ by a factor of 2.2 or 2.9 .

The above results are for the first mixed core. Corresponding values for the full IRT-3M core are as follows. The core power at $1 \mathrm{~s}$ is $6.2 \%$ of $10 \mathrm{MW}$, which is $0.620 \mathrm{MW}$. Since there are $18 \mathrm{FA}$, the average power per FA is $0.034 \mathrm{MW}$ at $1 \mathrm{~s}$ (or about the same value as for the first mixed core). The peaking factors are 1.42 for FA to FA and 1.20 for tube to tube within peak FA; the product of the two peaking factors is 1.70 . Therefore the power to be removed from 1 FA with peaking is $0.0578 \mathrm{MW}(=\mathrm{Q} / \mathrm{N})$. The minimum water flow needed for cooling $1 \mathrm{FA}$ (using Eq. 3.13.2) is $0.023 \mathrm{~kg} / \mathrm{s}$ or $0.086 \mathrm{~m}^{3} / \mathrm{h}$ (again about the same as for the first mixed core). The supplied flow per FA of 0.184 (if from DWST) or $0.245 \mathrm{~m}^{3} / \mathrm{h}$ (if from ESP) as shown above are not a function of the various core designs being considered. Therefore the supplied flow exceeds the required flow by a factor of 2.1 or 2.8 in the full IRT-3M core.

Corresponding values for the full IRT-4M core are as follows. The core power at $1 \mathrm{~s}$ is $6.2 \%$ of $11 \mathrm{MW}$, which is $0.682 \mathrm{MW}$. Since there are $20 \mathrm{FA}$, the average power per FA is $0.034 \mathrm{MW}$ at $1 \mathrm{~s}$ (or about the same value as for the full IRT-3M and first mixed core). The peaking factors are 1.32 for FA to FA and 1.19 for tube to tube within peak FA; the product of the two peaking factors is 1.57. Therefore the power to be removed from $1 \mathrm{FA}$ with peaking is $0.0534 \mathrm{MW}$. The minimum water flow needed for cooling $1 \mathrm{FA}$ (using Eq. 3.13.2) is $0.021 \mathrm{~kg} / \mathrm{s}$ or $0.080 \mathrm{~m}^{3} / \mathrm{h}$ (again about the same as for the first mixed core). The supplied flow per FA of 0.184 (if from DWST) or $0.245 \mathrm{~m}^{3} / \mathrm{h}$ (if from ESP) as shown above are not a function of the various core designs being considered. Therefore the supplied flow exceeds the required flow by a factor of 2.3 or 3.1 in the full IRT-4M core.

Based on the foregoing lumped-parameter estimate, the $15-20 \mathrm{~m}^{3} / \mathrm{h}$ water flow from the emergency spray systems is sufficient to remove decay heat from the fuel.

\subsubsection{Cautions}

The preceding analysis is only a estimate. There are a number of assumptions and limitations. These are enumerated below.

a. Uniformity of spray is an assumption. 
b. There is no examination of the actual heat transfer process between the fuel and the water. For example, what is the heat transfer coefficient and what is the resulting fuel surface temperature?

c. If the water does not fully vaporize, then a higher coolant flow rate will be required to remove the same amount of heat.

d. Vaporizing water (even some of it) produces steam which wants to flow upward due to buoyancy and will inhibit the downward flow of liquid water between the fuel tubes. If steam up flow is sufficiently fast it can totally prevent down flow of liquid, a situation know as "flooding" or "counter current flow limitation". Supplying additional spray water does not necessarily eliminate this phenomenon.

e. In a transient analysis, the fuel could be allowed to heat somewhat during the early part of the LOCA (as long as the fuel does not exceed its structural integrity limit) and then show decreasing temperature as decay power decreases and coolant flow is maintained.

f. Fortunately, less water is needed as time gets longer since decay power continues to decrease.

A more detailed analysis could be useful. 


\subsection{Secondary System Failures}

\subsubsection{Boundary Conditions}

This case is discussed in Section 4.2.3.7 of the 2003 SAR; however, no transient analysis is presented. Any significant failure in the secondary system will lead to increase of temperature in the primary system. There are scrams based on core inlet temperature greater than $57^{\circ} \mathrm{C}$ and for $20 \%$ increase in core temperature rise; warnings are given before these values are reached. Modeling the transient behavior of transients initiated from the secondary loop would require a rather elaborate model of the entire primary loop plus portions of the secondary loop; such an effort is not justified by the severity of the transients. Instead, an assessment of conditions can be provided by performing additional steady-state calculation(s) using the PLTEMP code and specifying higher inlet temperature(s).

\subsubsection{Results}

The results are shown in Table 3.14.1. The nominal steady-state results at $45^{\circ} \mathrm{C}$ inlet temperature have been brought forward from Table 2.5.1. Corresponding values are also shown for a $5^{\circ} \mathrm{C}$ higher inlet temperature and for the trip value of $57^{\circ} \mathrm{C}$. For all cores, the increase in maximum cladding temperature is somewhat less than the increase in inlet temperature. For several cores, the inlet temperature increase causes the fuel to cross either the ONB or temperature limit specified in the catalog; the values for these cases are shown in italics in Table 3.14.1. For a $50^{\circ} \mathrm{C}$ inlet temperature, the first mixed core would need to stay below $10.75 \mathrm{MW}$ in order to satisfy the $100^{\circ} \mathrm{C}$ temperature limit for the IRT-3M FA. For a $57^{\circ} \mathrm{C}$ inlet temperature, the power would need to be reduced in all cores: to $9.2 \mathrm{MW}$ to satisfy the temperature limit for the full HEU core, to $9.5 \mathrm{MW}$ to satisfy the temperature limit for IRT-3M (and thus also for IRT-4M) in the first mixed core, and to $9.75 \mathrm{MW}$ to satisfy the $98^{\circ} \mathrm{C}$ temperature limit for IRT-4M fuel in the full LEU core.

Table 3.14.1 Effect of Inlet Temperature on Steady State

\begin{tabular}{|c|c|c|c|c|}
\hline & \multicolumn{2}{|c|}{ IRT-3M } & \multicolumn{2}{|c|}{ IRT-4M } \\
\hline & ONBR (F-G) & $\begin{array}{c}\text { Clad Surface } \\
\text { Temperature }\left[{ }^{\circ} \mathrm{C}\right]\end{array}$ & ONBR (B-R) & $\begin{array}{c}\text { Clad Surface } \\
\text { Temperature }\left[{ }^{\circ} \mathrm{C}\right]\end{array}$ \\
\hline \multicolumn{5}{|c|}{$\mathrm{T}_{\mathrm{in}}=45^{\circ} \mathrm{C}$} \\
\hline Full HEU & 1.56 & 93.7 & & \\
\hline $1 \mathrm{st}$ mixed & 1.48 & 97.3 & 1.48 & 90.1 \\
\hline Full LEU & & & 1.39 & 92.9 \\
\hline \multicolumn{5}{|c|}{$\mathrm{T}_{\mathrm{in}}=50^{\circ} \mathrm{C}$} \\
\hline Full HEU & 1.49 & 97.6 & & \\
\hline 1st mixed & 1.42 & 100.9 & 1.40 & 94.1 \\
\hline Full LEU & & & 1.31 & 96.9 \\
\hline \multicolumn{5}{|c|}{$\mathrm{T}_{\mathrm{in}}=57^{\circ} \mathrm{C}$} \\
\hline Full HEU & 1.38 & 103.4 & & \\
\hline 1st mixed & 1.32 & 106.3 & 1.28 & 99.8 \\
\hline Full LEU & & & 1.20 & 102.7 \\
\hline
\end{tabular}




\subsection{FA Drop into Core During Refueling}

\subsubsection{Boundary Conditions}

This case is discussed in Section 4.2.4.1 of the 2003 SAR. Fuel handling operations are normally done in such a way that adding a FA to the core does not result in criticality. A situation might arise due to an error in calculations where the reactor is not as sub-critical as was thought and the addition of a FA does cause criticality. The operating procedures require a $2 \%$ subcriticality (equivalent to $2.63 \$$ ) with shim rods inserted. Therefore, the net reactivity addition from dropping a FA would be the FA worth minus $2 \%$; the specific net reactivity values are $1.82 \$$ for the full HEU core, $0.66 \$$ for the first mixed HEU-LEU core, and $0.76 \$$ for the full LEU core. The net reactivity concept is used since the PARET calculation must begin at just critical. The PARET calculation must also start at non-zero power; $1 \mathrm{~W}$ is used for this case. The reactivity addition is taken to be sudden $(0.05 \mathrm{~s})$. The power transient will be terminated by period being less than $10 \mathrm{~s}$, causing the safety rods to enter the core after a $0.1 \mathrm{~s}$ delay (as is true for the other reactivity transients). There is no period-trip logic within PARET; trip for these cases is obtained by adjusting the over-power trip so that trip occurs when the period is less than $10 \mathrm{~s}$; for the cases to be shown the period is less than $10 \mathrm{~s}$ within $0.01 \mathrm{~s}$ of the start of the FA drop reactivity insertion.

\subsubsection{Results}

Temperature plots are omitted for this transient; since the initial power is low and never gets high for any significant time, the core materials are within $1{ }^{\circ} \mathrm{C}$ of the inlet temperature for the entire transient in all cores. Temperatures remain way below the value at which fuel damage might occur.

The calculated results for the full HEU core are shown in Figure 3.15.1. The step reactivity insertion shows as a ramp over $0.05 \mathrm{~s}$ up to a constant value due to the expanded time scale of the figure. This results in an increase in power; the period is less than $10 \mathrm{~s}$ (actually, $0.008 \mathrm{~s}$ ) immediately, which starts the scram logic. After a delay of $0.1 \mathrm{~s}$; the safety rods start moving into the core. The peak power is $0.39 \mathrm{MW}$; after $0.6 \mathrm{~s}$ the power is less than $1 \mathrm{~kW}$. The peak power is much larger in the HEU core than in the two LEU cores to be shown next due to the significant difference in the net reactivity associated with the dropped FA.

The calculated results for the first mixed HEU-LEU core are shown in Figure 3.15.2. The step reactivity insertion shows as a ramp over $0.05 \mathrm{~s}$ up to a constant value due to the expanded time scale of the figure. This results in an increase in power; the period is less than $10 \mathrm{~s}$ (actually $0.05 \mathrm{~s}$ ) immediately, which starts the scram logic. After a delay of $0.1 \mathrm{~s}$; the safety rods start moving into the core. The peak power is $2.9 \mathrm{~W}$ (not MW).

The calculated results for the full LEU core are shown in Figures 3.15.3. The step reactivity insertion shows as a ramp over $0.05 \mathrm{~s}$ up to a constant value due to the expanded time scale of the figure. This results in an increase in power; the period is less than $10 \mathrm{~s}$ (actually $0.05 \mathrm{~s}$ ) 
immediately, which starts the scram logic. After a delay of $0.1 \mathrm{~s}$; the safety rods start moving into the core. The peak power is $3.8 \mathrm{~W}$ (not MW).
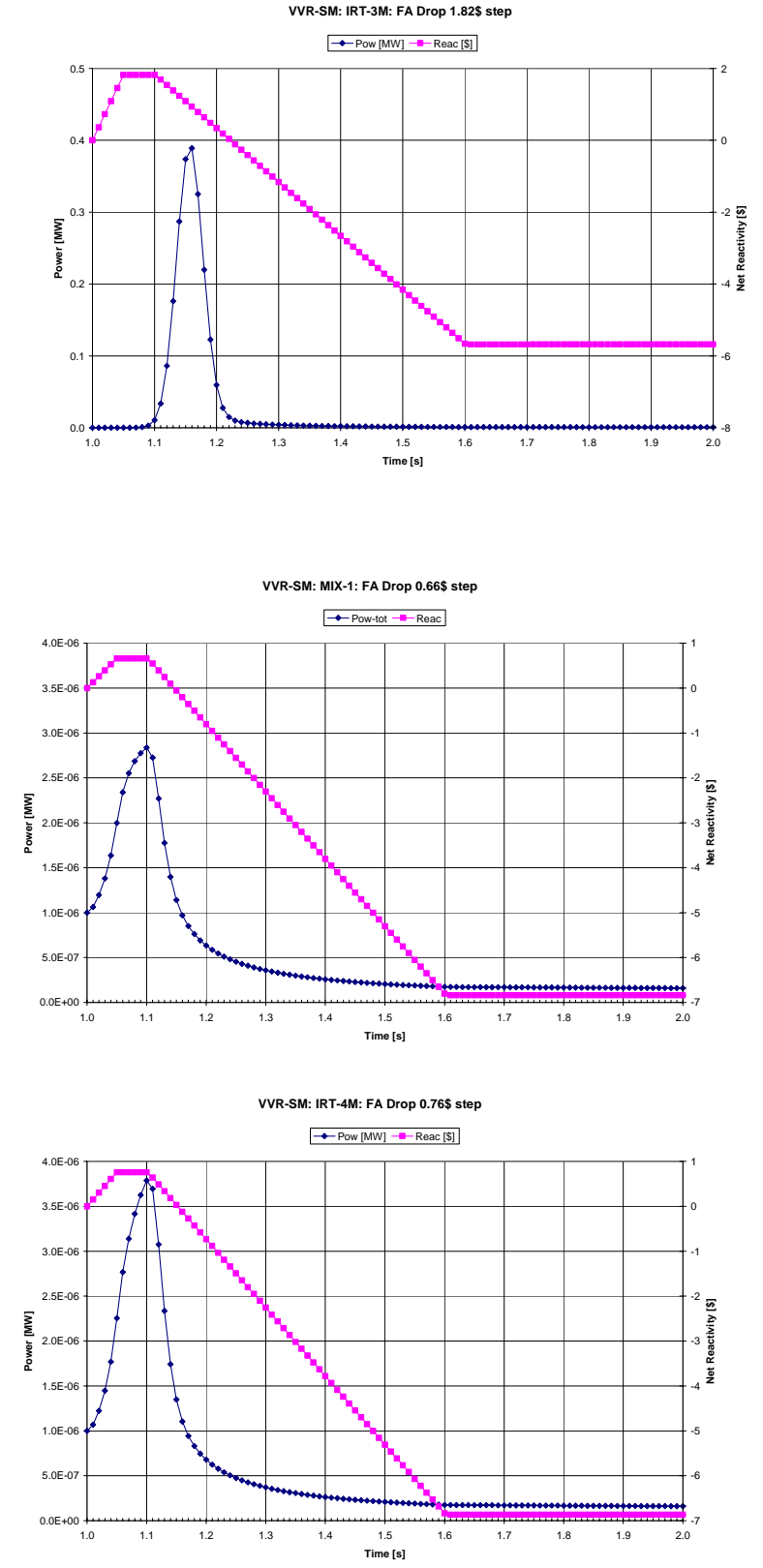

Figure 3.15.1 HEU Core PARET Results for Fuel Assembly Drop during Refueling

Figure 3.15.2 Mix1 Core PARET Results for Fuel Assembly Drop during Refueling

Figure 3.15.3 LEU Core PARET Results for Fuel Assembly Drop during Refueling 


\section{Conclusions}

Calculations have been performed for the requested transients using full HEU, first mixed HEULEU, and full LEU cores in the VVR-SM nuclear reactor at INP. The emergency protection "scram" system is assumed to be operable for all transients. Because of this, all power transients in all cores are terminated by either high power, low period, low coolant flow rate, or low pool water level scrams within a few seconds of initiation, at which time there are only small increases in temperature above normal operating values. In particular, the clad temperature in all cases calculated using PARET remains much lower than the temperature at which clad damage might occur. There are two cases which deserve special attention. The first special case is total blockage of coolant flow to one fuel assembly; we do not have a computer code to calculate this situation; therefore, fuel assembly melting was assumed in order to establish an inventory of radionuclides to use in the dispersion calculation. The second special case is catastrophic failure of the primary coolant piping at exit from reactor vessel which results in loss of coolant which uncovers the reactor core; we do not have a complete computer model for this situation; a lumped-parameter analysis indicates that sufficient flow rate of water is provided by spray system to cool the fuel; additional work is required to show conclusively that the water is provided in the right place(s) and that it actually can remove the generated heat.

The results shown in this report are in substantial agreement with those [Ref. 15] computed independently by INP staff.

\section{References}

1. "Detailed Conversion Analysis Plan and Transient Description", Institute of Nuclear Physics, Ulugbek, Uzbekistan, Deliverable 1 of ANL Contract 6F-01024 (September 26, 2006).

2. J. F. Briesmeister et al., "MCNP - A General Monte Carlo N-Particle Transport Code, Version 4C", LA-13709-M, Los Alamos National Laboratory, Los Alamos, New Mexico (April 2000).

3. N. A. Hanan, Umar S. Salikhbaev, Sapar Bayetlesov, and A. A. Dosimbaev, "WWR-SM Conversion to LEU IRT-4M Oxide Fuel", presented at 2006 International RERTR Meeting (Cape Town, South Africa), http://www.rertr.anl.gov/RERTR28/, Argonne National Laboratory, Argonne, Illinois, (October 29 - November 2, 2006).

4. N. A. Hanan, A. P. Olson, R. B. Pond, and J. E. Matos, "A Monte Carlo Burnup Code Linking MCNP and REBUS", Proceedings of the $21^{\text {st }}$ International Meeting on Reduced Enrichment for Research and Test Reactors, Sao Paulo, Brazil (October 18-23, 1998).

5. A. P. Olson and Kalimullah, "A Users Guide to the PLTEMP/ANL Code", Nuclear Engineering Division, Argonne National Laboratory (May 2006).

6. "Engineering Analysis for Safety Operations of Reactor VVR-SM NPhI AS UR", Report I/431-2, Nuclear Physics Institute of Academy of Sciences, Ulugbek, Uzbekistan (March 2003).

7. Pavel Egorenkov, personal communication (August 23, 2004). 
8. W. L. Woodruff, R. S. Smith,and A. P. Olson, "A Users Guide for the ANL Version of the PARET Code, PARET/ANL (Version 6.1, 2007 Rev.)", ANL/RERTR/TM-16, Argonne National Laboratory, Argonne, Illinois (March 2007); W. L. Woodruff, "A User's Guide for the ANL Version of the PARET Code", National Energy Software Center, Argonne, Illinois (1984); and C. F. Obenchain, "PARET - A Program for the Analysis of Reactor Transients", IDO-17282, AEC Research and Development Report, Phillips Petroleum Company, Idaho Falls, Idaho (January 1969).

9. "RELAP5/MOD3 Code Manual”, NUREG/CR-5535 (or INEL-95/0174), Idaho National Engineering Laboratory, Idaho Falls, Idaho (June 1995).

10. P. L. Garner and N. A. Hanan, "Investigation of Approximations in Thermal-Hydraulic Modeling of Core Conversions", submitted for presentation at presented at 2007 International RERTR Meeting (Prague, Czech Republic), http://www.rertr.anl.gov/RERTR29/, Argonne National Laboratory, Argonne, Illinois, (September $23-28,2007)$.

11. A. G. Croff, "ORIGEN2 - A Revised and Updated Version of the Oak Ridge Isotope Generation and Depletion Code," ORNL-5621, Oak Ridge National Laboratory, Oak Ridge, Tennessee (July 1980).

12. "Assumptions Used for Evaluating the Potential Radiological Consequences of a Loss of Coolant for Boiling Water Reactors," Regulatory Guide 1.3, Revision 2, U. S. Nuclear Regulatory Commission, Washington, DC (June 1974).

13. W. W. Woodruff and R. J. Cornella, "DOSER - A Code for Radiological Consequence Analysis," Internal Memorandum, Argonne National Laboratory, Argonne, Illinois (February 20, 1984).

14. "American National Standard for Decay Heat Power in Light Water Reactors", ANSI/ANS-5.1-2005, American Nuclear Society, La Grange Park, Illinois (2005).

15. "Draft Report with the Results of the Transient/Accident Analysis for the First Mixed HEU-LEU Core", Institute of Nuclear Physics, Ulugbek, Uzbekistan, Deliverable 3 of ANL Contract 6F-01024 (August 7, 2007).

Computer files associated with PARET analyses for this work are stored on node sol15 under directory $\sim b 27484 / U Z B E K I S T A N$ under subdirectories and file names like IRT3M/GARNER_FINAL/VVRSM_MEU_XX_24*,

IRT3M4M1_CY0/GARNER_FINAL/VVRSM_MIX1_xx_yy_24*, and IRT4M_CYC8/GARNER_FINAL/VVRSM_LEU_XX_24*, where $x x$ is transient identifier and $y y$ is both $3 M$ and $4 M$, with file name suffixes inp for input, out for print output, PLOTT.txt and SUMMARY for ASCII- and binary-type plot output, respectively, and xls for collection of results into Excel workbooks for plotting purposes. The geometry, power, loss-of-flow, loss-of-coolant, and some other information are in files VVRSM_info_coreid.xls, outpwrmod.txt, and power.doc in separate directories for each core.

END OF LAST PAGE 
Argonne

Nuclear Engineering Division

Argonne National Laboratory

9700 South Cass Avenue, Bldg. 208

Argonne, IL 60439-4842

www.anl.gov

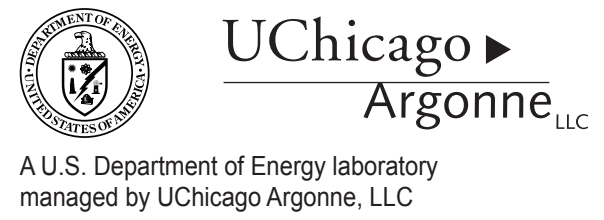


Argonne

Nuclear Engineering Division

Argonne National Laboratory

9700 South Cass Avenue, Bldg. 208

Argonne, IL 60439-4842

www.anl.gov

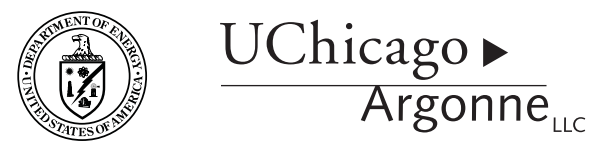

A U.S. Department of Energy laboratory

managed by UChicago Argonne, LLC 